\title{
DIGITALCOMMONS
}

@WAYNESTATE-

Wayne State University

Wayne State University Dissertations

$1-1-2017$

\section{Arab American Adolescents' Bullying Experiences And Effects On Their Perceived Stress And Health}

\author{
Maha Albdour \\ Wayne State University,
}

Follow this and additional works at: http://digitalcommons.wayne.edu/oa_dissertations

Part of the Nursing Commons, and the Public Health Commons

\section{Recommended Citation}

Albdour, Maha, "Arab American Adolescents' Bullying Experiences And Effects On Their Perceived Stress And Health" (2017). Wayne State University Dissertations. 1677.

http://digitalcommons.wayne.edu/oa_dissertations/1677

This Open Access Dissertation is brought to you for free and open access by DigitalCommons@WayneState. It has been accepted for inclusion in Wayne State University Dissertations by an authorized administrator of DigitalCommons@WayneState. 


\title{
ARAB AMERICAN ADOLESCENTS' BULLYING EXPERIENCES AND EFFECTS ON THEIR PERCEIVED STRESS AND HEALTH
}

by

\author{
MAHA MOHAMMAD ALBDOUR \\ DISSERTATION \\ Submitted to the Graduate School \\ of Wayne State University, \\ Detroit, Michigan \\ in partial fulfillment of the requirements \\ for the degree of \\ DOCTOR OF PHILOSOPHY
}

2017

MAJOR: NURSING

Approved By:

Advisor

Date 
(C) COPYRIGHT BY

\section{MAHA MOHAMMAD ALBDOUR}

2017

All Rights Reserved 


\section{DEDICATION}

This dissertation is dedicated to my mother (Shamah) whose affection, love, encouragement and prayers made me able to get such success and honor. To my deceased father Mohammad (May Allah give mercy upon him), whose moral investment shaded my entire life. I also dedicate this work to my brothers, Zayed and Zaid, for believing in me more than I believed in myself, knowing I have made you proud is one of my greatest accomplishments. To all my brothers and sisters and their families for their loving support and constant encouragement.

I also would like to dedicate this work to my friend and companion in this journey, my loving husband Hazem, thank you for living this adventure with me, I will always be grateful for everything you did to make this dream come true. To my children, Saif and Sanad, you have provided the love, strength, and humor that I dearly needed.

A very special thanks to my committee chair, Dr. Feleta Wilson and committee members, Dr. Linda Lewin, Dr. Hossein Yarandi, and Dr. Jun Hong for the invaluable expertise and feedback you provided to me. I am forever grateful for your time and support. I am blessed to have had this opportunity and will always be grateful for my family, friends, and those who educated me in this process. 


\section{ACKNOWLEDGMWNTS}

I would like to express the deepest appreciation to my committee chair, Dr. Feleta Wilson, who has been a wonderful supportive advisor for my master as well as my PhD. Without her guidance and persistent help this dissertation would not have been possible.

I would also like to thank Dr. Hossein Yarandi for his guidance for the statistical methods and research analysis of this dissertation. Dr. Yarandi made statistics applicable and easy to understand throughout my PhD program. His mentoring and advice along this journey is highly appreciated.

My deepest appreciation to Dr. Linda Lewin, who provided me with the valued and enormous comments and recommendations related to adolescents' development and psychological health. Dr. Lewin's insight and support helped me to better understand and interpret the results of my dissertation.

Heartfelt thanks goes to Dr. Jun Hong, who had a significant and positive impact upon me during this journey. Dr. Hong is an outstanding scholar and mentor who brought a different perspective on my dissertation. I am grateful for his advice, encouragement, and opportunity he has provided along this journey.

I am most appreciative of the Arab Community Center for Economic and Social Services (ACCESS)/Adolescents health program for their support. A special 
thanks and appreciation to Mr. Jehad Najda and Ms. Kshama Vaghela for their help, efforts, and support in data collection for my dissertation.

I would like to thank the Islamic Center of Detroit (ICD) including the International Islamic Academy (IIA) for supporting data collection in their sites. Their help and efforts made data collection possible in a considerable short time.

This dissertation was supported by the student award program grant from the Blue Cross and Blue Shield of Michigan Foundation (BCBS), as well as Wayne State University Graduate School and College of Nursing. Many thanks for their financial support that made this dissertation possible.

Many Thanks for all adolescents who open their hearts and share their experiences with me. 


\section{TABLE OF CONTENTS}

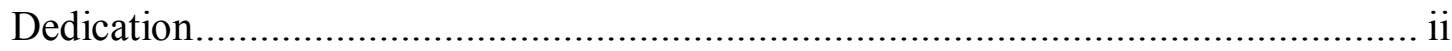

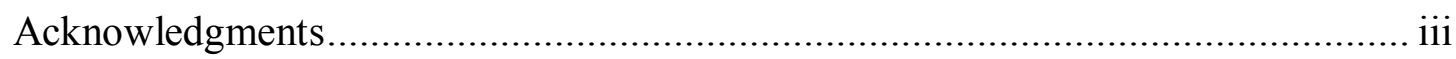

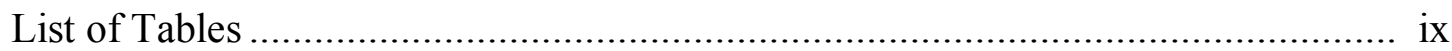

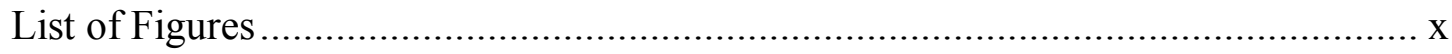

Chapter 1 "Background, Identification of Variables, and Significance" ................... 1

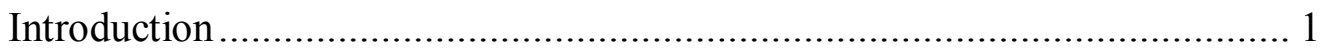

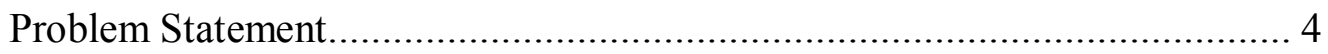

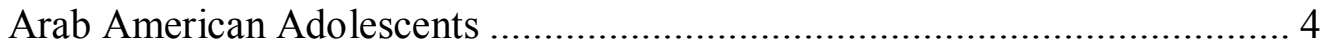

Bullying among Arab American Adolescents.............................................. 5

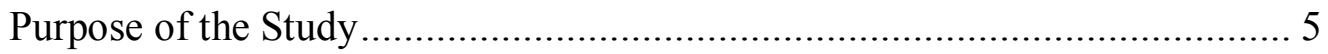

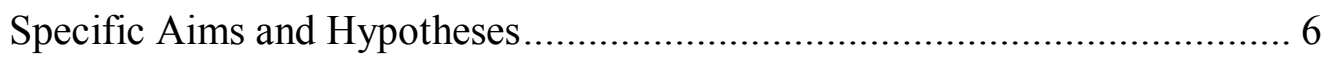

Significance to Nursing ....................................................................... 7

Chapter 2 "Literature Review and Theoretical Framework .................................... 9

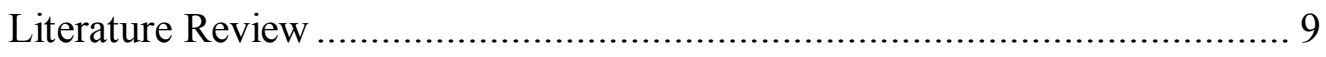

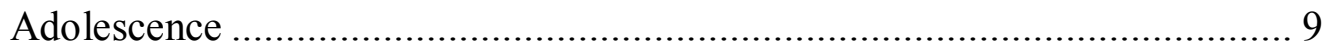

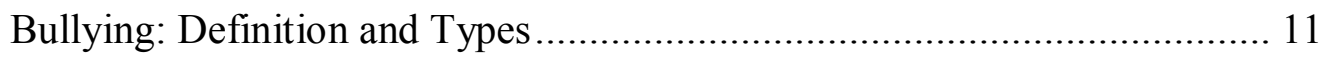

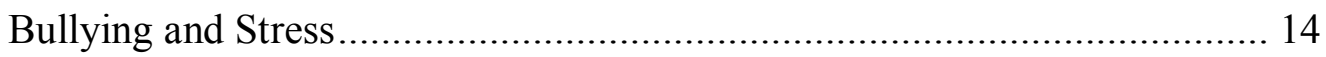

Bullying Stress, Perceived Stress, and Adolescents' Health ......................... 15

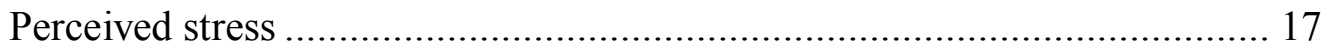

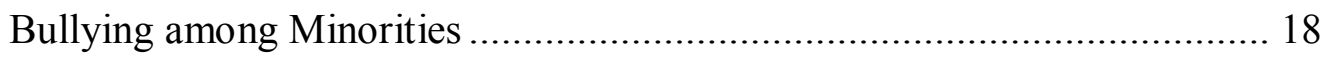

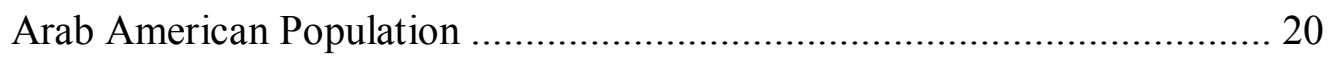

Arab American Adolescents: The Invisible Population ............................... 22 
Theoretical Framework............................................................... 25

The Neuman System Model............................................................... 25

Neuman System Model Applied to the Bullying Experience ..................... 26

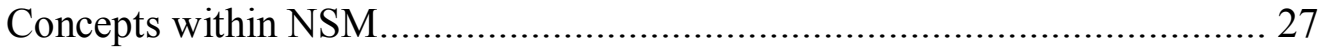

Client or Client Systems .............................................................. 27

Five Interacting Variables ......................................................... 28

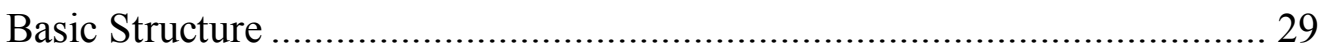

Flexible Line of Defense ................................................................ 30

Normal Line of Defense ................................................................. 30

Lines of Resistance .................................................................. 30

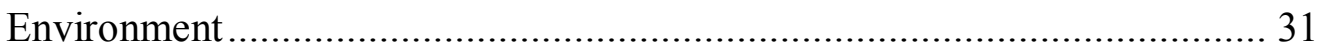

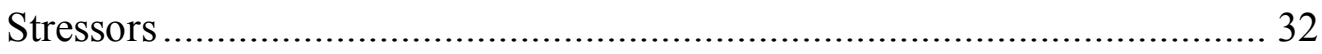

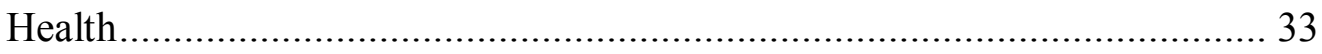

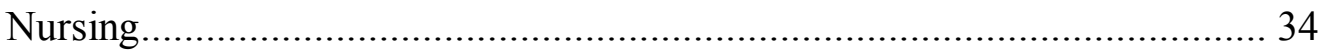

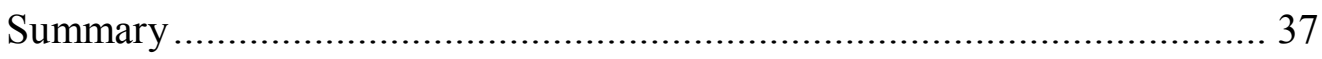

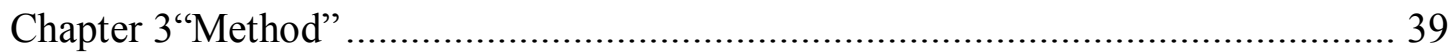

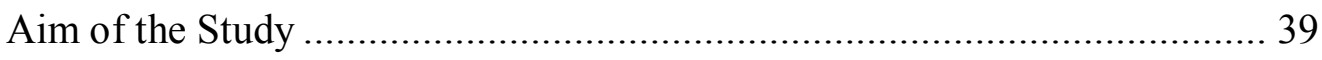

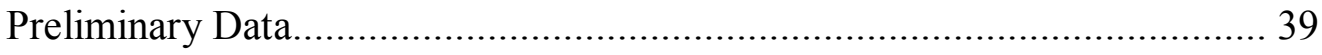

Current Study Design ............................................................... 41

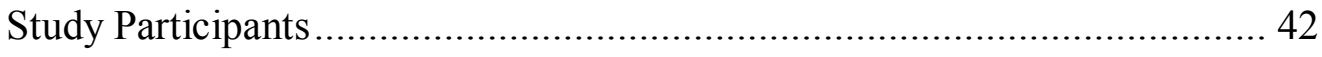

Population ............................................................................. 42

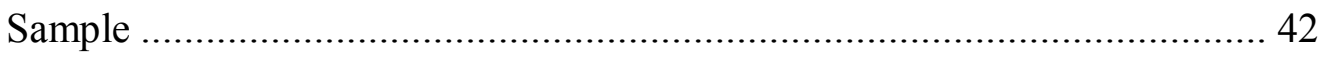

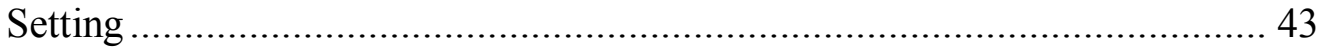




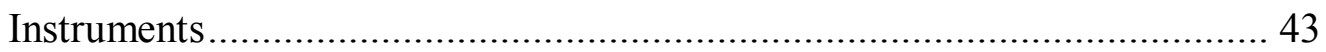

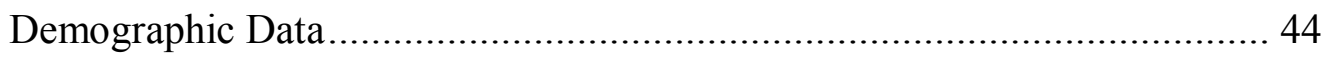

Adolescent Peer Relations Instrument (APRI) .......................................... 44

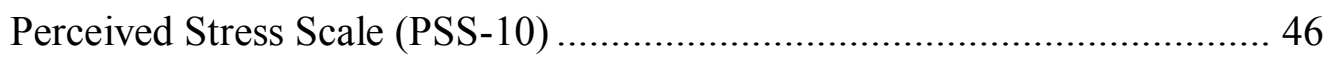

Children's Somatization Inventory (CSI-24) ............................................. 48

Kessler Psychological Distress Scale (K10) ............................................... 49

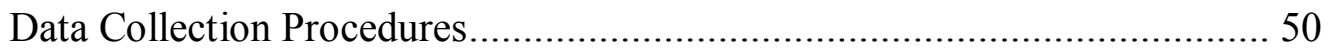

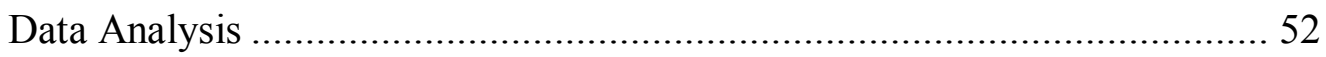

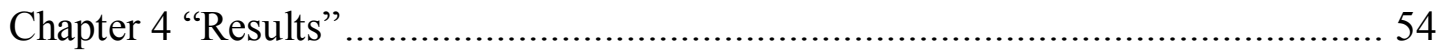

Descriptive Statistics of the sample ............................................................. 54

Descriptive Statistics for Bullying Involvement .......................................... 56

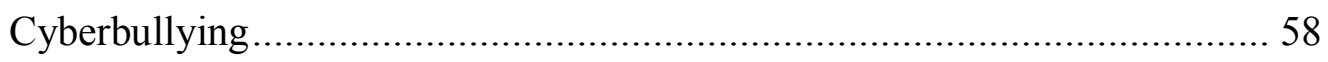

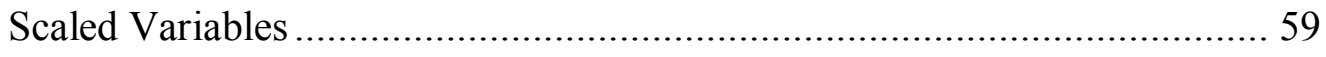

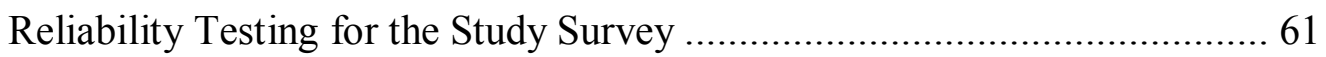

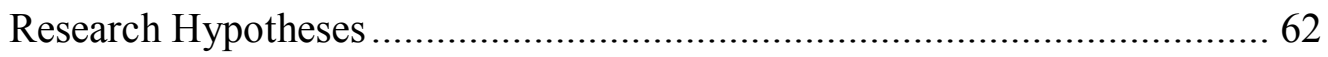

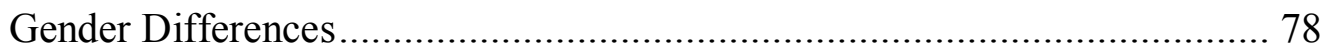

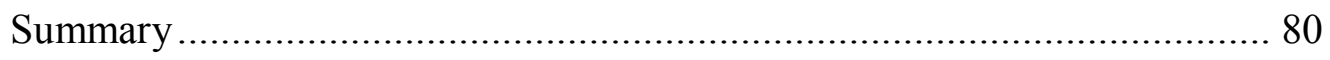

Chapter 5 "Discussion, Implications, and Recommendations.................................... 81

Bullying among Arab American Adolescents............................................. 81

Recommendations for Future Research ..................................................... 94

Implications for Practice and Policy .......................................................... 95

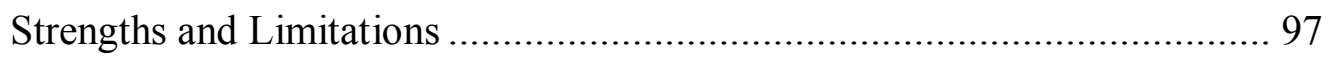

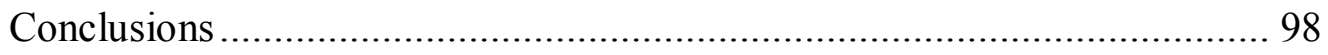




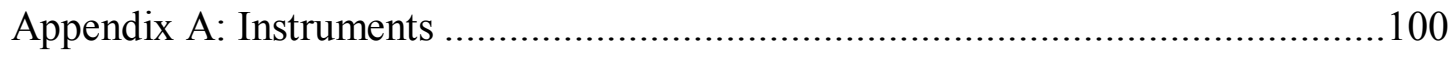

Appendix B: Human Investigation Committee Approval ....................................112

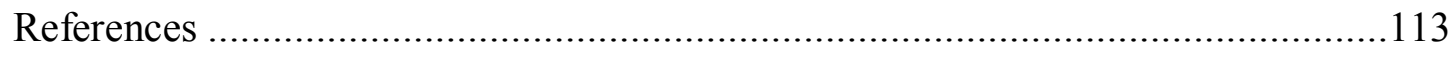

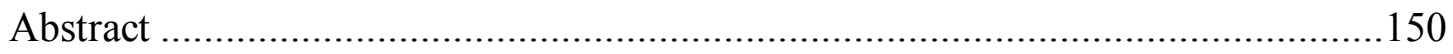

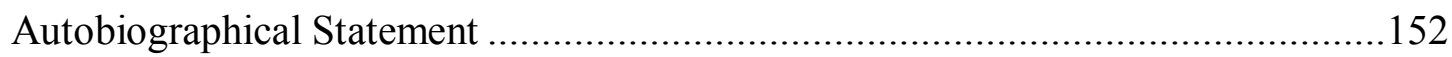




\section{LIST OF TABLES}

Table 1: Developments in The Conceptualization of School-Based Bullying........... 11

Table2: Study Variables and Measurements Used ........................................ 44

Table 3: Frequencies and Percentages of Demographic Variables......................... 54

Table 4: Continuous Demographic Variables, Age and Grade .............................. 55

Table 5: Descriptive Statistics of Bullying Involvement ................................. 56

Table 6: Descriptive Statistics for Cyberbullying …........................................ 58

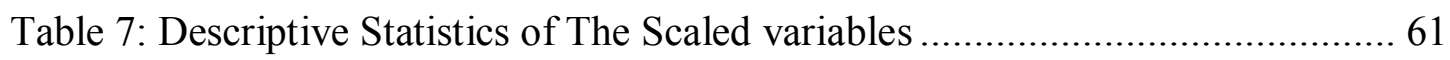

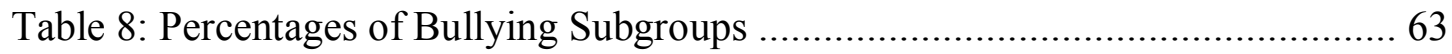

Table 9: Pearson's Correlation for APRI-Bully Total Score, Verbal Bully, Social Bully, Physical Bully and Perceived Stress................................................. 64

Table 10: Pearson's Correlation for APRI-Victim Total Score, Verbal Victim, Social Victim, Physical Victim and Perceived Stress ................................................ 65

Table 11: Pearson's Correlation of Cyberbullying and Perceived Stress ................. 65

Table 12: Pearson's Correlation for APRI-Bully Total Score, Verbal bully, Social Bully, Physical Bully and Physical Health (CSI-Total Score) ............................ 67

Table 13: Pearson's Correlation for APRI-Victim Total Score, Verbal Victim, Social Victim, Physical Victim and Physical Health (CSI-Total Score) ........................... 68

Table 14: Pearson's Correlation for APRI-Bully Total Score, Verbal Bully, Social Bully, Physical Bully and Psychological Health (K10-Total Score).

Table 15: Pearson's Correlation for APRI-Victim Total Score, Verbal Victim, Social Victim, Physical Victim and Psychological Health (K10-Total Score)................... 70

Table 16: Pearson's Correlation for Cyberbullying, Physical Health and Physiological Health............................................................................................... 71

Table 17: Gender Differences in Bullying Experiences..................................... 78

Table 18: Physical Complaints and Psychological Distress among Males and Females 79 


\section{LIST OF FIGURES}

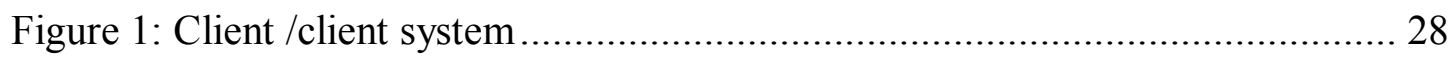

Figure 2: Environment/environmental stressors .......................................... 33

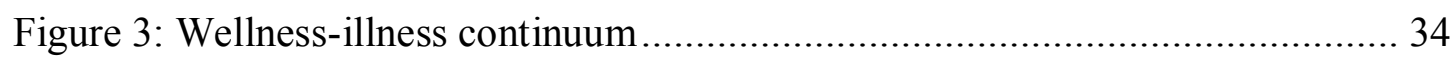

Figure 4: Middle-range theory of bullying, perceived stress from bullying, and adolescents' wellness/health (pictorial presentation of the substruction model) .............. 37

Figure 5: Study Concepts and Hypothesized Relationships................................. 38

Figure 6: Variables and relationships examined through mediation analysis ........... 72

Figure 7: Mediation Model - Being a Victim and Physical Complaints as mediated by Perceived Stress...................................................................................... 76

Figure 8: Mediation Model - Being a Victim and Psychological Distress as mediated by Perceived Stress. 


\section{CHAPTER 1 “BACKGROUND, IDENTIFICATION OF VARIABLES, AND SIGNIFICANCE"}

\section{Introduction}

Bullying is a major public health problem affecting a significant number of adolescents in the United States (U.S.) and other countries around the world. Olweus (1993a, 1996) was the first to differentiate bullying from other types of violence in 1993 as "any repeated attack or intimidation with the intention to cause fear, distress, or harm, and it includes a real or perceived imbalance of power between the bully and the victim". The prevalence of bullying is high among adolescents in the United States. A national survey revealed that $29.9 \%$ of the surveyed sample reported moderate or frequent involvement in bullying. Among that sample, $13.0 \%$ were bullies, $10.6 \%$ were victims, and $6.3 \%$ were bully/victims (Nansel et al., 2001; Wang, Nansel \& Iannotti, 2011). According to the Centers for Disease Control and Prevention (CDC) in 2015 youth risk behavior surveillance statistics, one in five students is bullied on school property, and approximately one in six students are cyberbullied.

Recently, studies found that adolescents who are vulnerable or marginalized, such as African American, Latino, Hispanic adolescents, and other minorities might be at high risk for bullying victimization and perpetration (Albdour \& Krouse, 2014; Goldweber, Waasdorp, \& Bradshaw, 2013; Luk, Wang, \& Simons-Morton, 2012; Schuster et al., 2012; Wang, Iannotti, \& Nasel, 2009). In addition, immigrant adolescents, particularly first-generation immigrants, reported experiencing more bullying than non-immigrants (Mouttapa, Valente, Gallaher, Rohrbach \& Unger, 2004, Peguero, 2009; Qin, Way, \& Rana, 2008). However, Arab American adolescents have not been included in studies examining bullying. In fact, Arab American children and their families appear to be the least visible population in the U.S. (Haboush, 2007; Pavlovskaya \& Bier, 2012). Arab American adolescents might have higher risks of being victimized than other 
minority populations due to discrimination, immigration, religious beliefs, and negative portrayal of Arabs and Muslims in the media (Awad, 2010; El-Sayed \& Galea, 2009; Wray-Lake, Syvertsen \& Flanagan, 2008). My study is intended to fill the gap by examining Arab American adolescents' experiences in bullying.

Bullying is strongly associated with stress which can consequently lead to negative health outcomes. The majority of the researchers of published studies suggest that bullying-related stress has resulted from being a victim, a perpetrator, or both (Grant, Compas, Thurm, McMahon \& Gipson, 2004; Kurokawa, 2010; McGuckin, Lewis \& Cummins, 2010; Konishi \& Hymel, 2009). In particular, victims of bullying are at an increased risk of mental health problems (e.g., depression and anxiety) and psychosomatic ailments (e.g., headaches and poor school adjustment; Smokowski \& Kopasz, 2005). According to Velderman, Dorst, Wiefferink, Detmar, and Paulussen (2008), victims of bullying scored markedly lower on all dimensions of quality of life (QOL) than non-victims, and they reported being less happy and cheerful, feeling sad and depressed more often, having low self-esteem, and being less optimistic about their school. In addition, Delfabbro et al. (2006) found that victims showed higher levels of social alienation and isolation, poorer psychological functioning, and lower self-esteem and self-image. On the other hand, bullies are proven to be at an increased risk for substance abuse, academic problems, and violence later in adolescence and adulthood (Hong, Davis, Sterzing, Yoon, Choi \& Smith, 2014; Glew, Fan, Katon, Rivara \& Kernic, 2005; Smokowski \& Kopasz, 2005). Bullying perpetration is also found to be associated with physical ailments such as nervousness, irritability or bad temper, difficulty falling asleep, and dizziness (Gobina, Zaborskis, Pudule, Kalnins, \& Villerusa, 2008). Also, bullies reported higher levels of externalizing problems, such as delinquent or rule-breaking behavior and aggressive behaviors (Menesini, Modena, \& Tani, 2009). Compared to the students who are either 
a bully or victim, those who are bully/victims (i.e., adolescents who are victims of bullying and simultaneously bully other students) suffer the most serious consequences and are at a heightened risk for both mental health and behavioral problems (Smokowski \& Kopasz, 2005). Bully/victims appear to be most adversely impacted by their bullying experience, reporting higher levels of both externalizing and internalizing symptoms when compared to bullies and victims groups (Menesini et al., 2009). These individuals rated their health as fair or poor, experienced weekly health complaints, and had lower life satisfaction (Gobina et al., 2008). Moreover, victims of bullying often suffer from chronic absenteeism, reduced academic performance, increased apprehension, loneliness, feelings of abandonment, and suicidal ideation (Glew et al., 2005; Smokowski \& Kopasz, 2005).

The negative consequences of bullying-related stress may continue throughout adolescence and into adulthood, adversely affecting victims later in life. Farrington and Ttofi (2011) found that bullying at age fourteen predicted violence-related offense, self-harm, drug use in adulthood, and an unsuccessful life by age 48 . Being a victim of bullying is also found to be associated with feelings of entrapment, hopelessness, depression, and suicidal behavior in later life (Allison, Roeger \& Reinfeld-Kirkman, 2009; Meltzer, Vostanis, Ford, Bebbington, \& Dennis, 2011). Adolescents who bully were found to display externalizing problems and hyperactivity in adulthood, and bullying behavior was associated with antisocial development and personality defects during adulthood (Smokowski \& Kopasz, 2005).

Perceived stress refers to the individual's perception of a situation or the appraisal of the situation as stressful (Folkman, Lazarus, Dunkel-Schetter, DeLongis \& Gruen, 1986; Lazarus \& Folkman, 1984). Adolescents who perceived more stress from their daily stressors (e.g., negative parental or peer relationships) are found to experience undesirable physical and psychological 
health problems related to their social life (Björling, 2009; Zhang, Yan, Zhao \& Yuan, 2015). On the other hand, the relationship between bullying, adolescents' perceived stress, and the effect on their health has not been fully investigated, to my knowledge (Combs, 2012). My study intended to fill the gap and describe the effect of Arab American adolescents' bullying experiences on their perceived stress and health. In addition, my study examined whether the relationship between adolescents' bullying involvement and adolescents' health is mediated by their perceived stress.

\section{Problem Statement}

\section{Arab American Adolescents}

There is a significant misunderstanding and conflict regarding how Arab Americans are defined. Historically, Arab Americans, Middle Eastern immigrants, and Muslims were conflated in public presentation, and the misunderstanding of the three terms continues to the present (Naber, 2000; Suleiman, 1999). Arab Americans are immigrants from the 22 Arabic-speaking countries of southwestern Asia and North Africa who have been settling in the United States since the 1880s. The waves of immigrants include both Muslims and Christians (Arab American Institute Foundation (AAI; 2014). Middle Eastern immigrants settling in the United States are those coming from countries surrounding the Eastern Mediterranean and can be Arab or non-Arab (Salari, 2002). The non-Arabic Middle Eastern immigrants speak languages other than Arabic, and this is how they are distinguished from Arab Americans. Found in every corner of the globe, Muslims constitute one-sixth of the entire world's population. While all Muslims follow the religion of Islam, only $20 \%$ of Muslims are Arabs (Nydell, 2012; Salari, 2002; Suleiman, 1999). The approximately six million Muslims in the United States are a diverse group in terms of race, country-of-origin, language, and culture. Just over one-third (37\%) of American Muslims are of Arab ancestry or from Arabic speaking countries (Pew Research Center, 2007; Salari, 2002). The 
terms "Arab Americans" and "American immigrants of Arabic decent" are used interchangeably (AAI, 2014). In the present study, the concept of Arab American adolescents refers to adolescents of Arabic descent who were born in Arabic countries and then immigrated to the U.S., as well as those born and raised in the U.S.

\section{Bullying among Arab American Adolescents}

Bullying represents a significant problem in U.S. schools. The National School Safety Center recognized bullying the most enduring and underrated problem in U.S. school districts (Beale, 2001). Arab American adolescents received the least amount of attention compared to other ethnic minorities in terms of bullying experiences and related stress research. The attacks of September 11, 2001, have aggravated discrimination and aggression directed at Arab American adolescents at schools (Zaal, 2012). For example, Awad (2010) found that Arab Americans experience discrimination because of their race/ethnicity and religious beliefs. Muslim students and Arab Americans reported more assaults and violence after the 9/11 terrorist attacks (Abdelkarim, 2003). For instance, there was an increase in physical and verbal bullying directed at Arab American children (Abdelkarim, 2003; U.S. Commission on Civil Rights, 2011). However, to date, there is lack of published studies in which researchers examined the bullying experiences of Arab American adolescents and the negative effects on their health resulting from stress related to the bullying experience (Albdour, Lewin, Kavanaugh, Hong, Wilson, 2016).

\section{Purpose of the Study}

The purpose of this study was to examine experiences in bullying among Arab American adolescents and the effect of bullying on their perceived stress and physical and psychological health. More specifically, the study examined whether the relationship between adolescents' bullying involvement and health is mediated by adolescents' perceived stress. 


\section{Specific Aims and Hypotheses}

This study was guided by a recently completed qualitative pilot study entitled, "Arab American Adolescents' Perceived Stress and Bullying Experience: A Qualitative Study" (Albdour, Lewin, Kavanaugh, Hong, Wilson, 2016). The pilot study findings revealed that Arab American adolescents who experienced bullying perceived high stress levels related to bullying. Further, they experienced multiple negative feelings when being bullied, such as feeling sad, overwhelmed, and nervous. The study was aimed to examine the relationships among adolescents' bullying involvement and their health and stress on a larger scale. The specific aims were to:

1. Identify the prevalence of bullying among a sample of Arab American adolescents in the U.S. as well as the types of bullying involvement (bullies, victims, or bully/victims).

$\mathrm{H}_{1}$ : This sample of Arab American adolescents is expected to have a higher prevalence of bullying compared to national samples of general youth population in the U.S.

$\mathrm{H}_{2}$ : Arab American adolescents in this sample are more likely to be involved as victims than bullies.

2. Identify the relationship between bullying involvement and perceived stress among a sample of Arab American adolescents.

$\mathrm{H}_{3}$ : Bullying involvement will be positively associated with levels of perceived stress.

$\mathrm{H}_{4}$ : Adolescents who are victims are more likely to perceive higher stress levels compared to bullies.

3. Examine the effect of bullying on physical and psychological health of Arab American adolescents.

$\mathrm{H}_{5:}$ More bullying involvement will have a positive relationship with adolescents' physical complaints and psychological distress. 
4. Identify whether perceived stress from bullying mediates the relationship between bullying experiences and adolescents' health.

$\mathrm{H}_{6:}$ Perceived stress mediates the relationship between adolescents' bullying involvement and their physical and psychological health.

\section{Significance to Nursing}

The American Nurses Association (ANA) defines nursing as "the protection, promotion, and optimization of health and abilities, prevention of illness and injury, alleviation of suffering through the diagnosis and treatment of human response, and advocacy in the care of individuals, families, communities, and populations" (ANA, 2016). Nursing is concerned with reducing environmental stress and optimizing an individual's reaction to and coping with stress in order to maintain his or her health and abilities (Lyon, 2000). Stress prevention, reduction, and coping are central to nursing theories and practice as it is connected with individuals, families, and community health (Rice, 2000). Bullying experiences have been found to be associated with increased levels of stress among adolescents. As primary health care providers, school nurses can work with other professionals to reduce bullying among students, strengthen their stress resistance and coping mechanisms, as well as to promote their overall health. From a nursing perspective, bullying is a stressor with catastrophic effects on an adolescent's physical, psychological, and developmental health. Stress stemming from bullying can reinforce the development of somatic and psychological health problems (Fekkes, Pijpers, Fredriks, Vogels \& Verloove-Vanhorick, 2006) because it can activate stress responses and influence levels of cortisol in adolescents' bodies (Carney, Hazler, Oh, Hibel, \& Granger, 2010; Vaillancourt, et al., 2011). For example, youth who experience bullying may be at an increased risk for anxiety, depressive symptoms, and memory deficits during adolescence and later in life (Carney, et al., 2010; Fekkes, et al., 2006; Rudolph, Troop-Gordon, 
\& Granger 2011; Vaillancourt, et al., 2011). In addition, it is evident in the literature that bullying is strongly associated with greater risks of posttraumatic stress disorder (PTSD; Idsoe, Dyregrov \& Idsoe, 2012; Mynard, Joseph \& Alexander, 2000). Bullying is also found to be associated with several physical health problems among adolescents, including headaches, poor appetite, breathing problems, and nausea. In addition, bullying is associated with psychological health problems, including depression, anxiety, and low self-esteem (Smokowski \& Kopasz, 2005; Wolke, Woods, Bloomfield \& Karstadt, 2001). This study will help school nurses to understand how bullying can affect adolescents' physical and psychological health and the role of perceived stress in this relationship. Perceived stress is defined as the individual's appraisal of a situation as stressful, Cohen and colleagues suggested that perceived stress explain how a stressor might affect an individual's health (Cohen, Kamarck \& Mermelstein, 1983). To date, the relationship between bullying and adolescents' perceived stress has not been fully investigated (Combs, 2012). This study may help nurses to understand how adolescents' perceived stress explain bullying and health link, which may facilitate the development of prevention and intervention strategies targeting how adolescents perceive bullying and improve their coping skills. Furthermore, this study will specifically examine this relationship within the Arab American adolescent population which will fill a major research gap. 


\section{CHAPTER 2 "LITERATURE REVIEW AND THEORETICAL FRAMEWORK" Literature Review}

\section{Adolescence}

Adolescence is a time period during which individuals grow up and move from childhood into the maturity of adulthood. Steinberg (2011) defined adolescence as the period of transitions, biological, psychological, social, and economic in which individuals become interested in sex and become biologically capable of having children. Biological transition basically involves changes in a young person's physical appearance and the ability to conceive children (e.g., breast development for females and growth of hair in the genital area for both sexes). The physical change affects adolescents' psychological development (e.g., changes in body image) and social relationships (e.g., increased need for privacy and interest in intimate relationships) and is characterized by brain and neural development (Steinberg, 2011; Steinberg \& Morris, 2001). Cognitive transition involves the gradual development of abstract thinking and the ability to propose hypotheses. Cognitive transition affects how adolescents think about their surrounding world and relationships. As logical thinking improves, the day-to-day decision-making process is affected, as well as adolescents' relationships with friends and family (Steinberg). Social transition involves changes in adolescents' social status and gaining more rights, privileges, and responsibilities (e.g., ability to drive, marry, and vote). As adolescents engage in more social activity, their self-image and decisions regarding surrounding relationships also develop (Steinberg, 2011; Steinberg \& Morris, 2001).

Adolescence is composed of a series of stages: early adolescence (age 10-13), middle adolescence (age 14-17), and late adolescence (age 18-21; Barrett, 1996). Steinberg (2011) indicated that adolescence can be very challenging and identified five psychosocial issues that are 
especially important during this period: 1) Identity (understanding who they are as individuals; 2) Autonomy (establishing a healthy sense of independence); 3) Intimacy (forming close and caring relationships with others); 4) Sexuality (expressing sexual feelings and enjoying physical contact with others); and 5) Achievement (being successful and competent members of society). Most common psychosocial problems during adolescence have been found to be associated with deviant adolescent development in one or more of these five areas, including drug and alcohol use, delinquency and other externalizing problems (e.g., conduct disorder) depression and other internalizing problems (e.g., anxiety; Ellis et al., 2012).

Peers are a central part of adolescent social life and are considered to be very important for adolescents' physical and psychological health, as well as their successful development and socialization (Holler \& Hurrelmann, 1990). The social life of adolescents takes a central role in their daily activities and thoughts, and adolescents have a tendency to spend less time with their families and more time with their peers (Somerville, 2013). Peer relations significantly influence adolescents' identity, autonomy, and decision-making (Steinberg, 2011). Adolescents are also very sensitive about how they are evaluated by their peers. How their peers perceive and think about them is very important and valued (Somerville). Negative peer relationships may adversely affect adolescents' health and development. For example, aggression and victimization among peers are associated with internalizing (e.g. loneliness and depression) and externalizing problems (e.g., antisocial behavior and delinquency; Steinberg \& Morris, 2001). On the other hand, positive peer relations and high social status may function as protective factors that can mitigate psychological problems (e.g., depression and anxiety; La Greca \& Harrison, 2005). 


\section{Bullying: Definition and Types}

Bullying among children and adolescents was first defined and examined through systematic research during the 1970s. This research suggested that bullying is an old phenomenon, as old as schools and education. However, it was not until few decades ago that this phenomenon gained the attention and raised awareness of researchers in different countries (Olweus, 1978, 1993a, 1993b). The earliest bullying studies and research efforts were largely taking place in Scandinavia. In the 1980s and early 1990s, bullying among school-aged children attracted the attention of other countries, including Japan, Great Britain, the Netherlands, Australia, Canada, and the United States (Olweus, 1993a, 1993b, 1996). Today, bullying is considered to be a major public health problem all over the world (Harel-Fisch, et al., 2011).

Dan Olweus, a Norwegian researcher, was the first to provide a definition for bullying and differentiate bullying from other aggressive behaviors. In his 1993 study, Olweus (1993) defined bullying as any repeated attack or intimidation with the intent to cause fear, distress, or harm and including a real or perceived imbalance of power between the bully and the victim. Olweus intended to differentiate bullying from other aggressive behaviors known at that time, including mobbing (Olweus, 1993a, 1993b, 1996). The definition of bullying has evolved through the years to include characteristics that are more specific. Hemphill, Heerde, and Gomo (2014) summarized the historical evolution of the bullying concept since was first recognized as a phenomenon (see Table 1).

Table 1

Developments in the Conceptualization of School-Based Bullying.

\begin{tabular}{lll}
\hline Year & Researcher & Definition/Development \\
\hline 1897 & Burk & $\begin{array}{l}\text { First major academic publication on bullying among young } \\
\text { people. }\end{array}$
\end{tabular}


$1975 \quad$ Pikas Mobbing, as distinct from bullying, is a negative activity, employed by two or more people, against one person or a welldefined group. The perpetrators must interact with one another (they reinforce each other), and there must be no negative intentions other than the persecution of the victim. In other words, "mobbing tends to be a goal in itself."

$1978 \quad$ Olweus "Bullying . . . has a broader meaning compared to mobbing, and it is different from mobbing, especially in the number of assaulters. Mobbing happens to someone who is somewhat different from the major group and it could be considered as part of human nature in rejecting someone different from the majority. Although for victims of bullying, external characteristics could be a part of the reasons for being bullied, there could be many other reasons as well."

$1993 \quad$ Olweus "A person is being bullied when he or she is exposed, repeatedly over time, to negative actions on the part of one or more other students."

1993 Farrington "Bullying is repeated oppression of a less powerful person, physical or psychological, by a more powerful person."

1994 Smith \& Bullying is "the systematic abuse of power." Sharp

1996 Pepler et al. Bullying is a relationship problem "because it is a form of aggression that unfolds in the context of a relationship in which one child asserts interpersonal power through aggression."

2012 Langos

Cyberbullying involves the use of ICTs (information and communication technologies) to carry out a series of acts as in the case of direct cyberbullying, or an act as in the case of indirect cyberbullying, intended to harm another (the victim) who cannot easily defend him or herself.

2013

Rigby

Bullying is "a desire to hurt + hurtful action + a power imbalance + (typically) repetition + an unjust use of power + evident enjoyment by the aggressor and a sense of being oppressed on the part of the victim."

Note: Adopted from Hemphill, S.A., Heerde, J.A., \& Gomo, R. (2014). A conceptual definition of school based bullying for the Australian research and academic community. Canberra, Australia: Australian Research Alliance for Children and Youth.

The Centers for Disease Control and Prevention (CDC) recently updated their definition of bullying to distinguish bullying from other types of youth violence. Bullying is defined as 
any unwanted aggressive behavior(s) by another youth or group of youths who are not siblings or current dating partners that involves an observed or perceived power imbalance and is repeated multiple times or is highly likely to be repeated (CDC, 2012, 2014). All proposed definitions confirm that bullying can include aggression that is physical (hitting, tripping), verbal (name calling, teasing), or relational/social (spreading rumors, excluding from group; CDC; Smokowski \& Kopasz, 2005). Both physical and verbal bullying are considered direct forms or types of bullying, whereas relational bullying is considered an indirect form of bullying (Wang et al., 2009). Cyberbullying is defined as aggression that occurs through electronic communication technologies, including mobile phones and the Internet (Mesch, 2009). Cyberbullying may occur through e-mail, chat rooms, instant messaging, website posts, text messaging, or videos or pictures posted on websites or sent through cell phones (CDC, 2014; Low \& Espelage, 2013; Smokowski \& Kopasz).

Research on school bullying worldwide revealed that bullying is a significant public health problem in many countries. An international report from the Health Behavior in School-aged Children (HBSC) 2005/2006 research revealed that bullying is a significant problem among adolescents in 41 countries and regions across Europe and North America (Craig et al., 2009). The latest report in 2008 shows that bullying and victimization are global public health problems affecting substantial numbers of adolescents, ages 11 to 15 . The report revealed that $26 \%$ of the participating adolescents reported involvement in bullying at that time in those 41 countries. The results show that bullying involvement is global, surpassing cultural and geographic boundaries (Craig et al., 2009).

Although school bullying has been studied since the 1970s in Western countries, it has not been adequately investigated in Middle Eastern countries. Israel, Palestine, Egypt, and Turkey 
were the only countries that conducted research on adolescent bullying during the last two decades. In Turkey, approximately $40 \%$ of high school students reported bullying involvement (Alikasifoglu et al., 2004). In Israel and Palestine, approximately (18\%-57\%) of adolescents reported involvement, and the bullying prevalence rate in Egyptian schools is also high, with $59.7 \%$ of participating students reporting experiencing at least one form of bullying (Hussein, 2012). A more recent review conducted by Kazarian and Ammar (2013) revealed that $20.9 \%$ of middle-school adolescents reporting bullying in the United Arab Emirates, 31.9\% in Morocco, $33.6 \%$ in Lebanon, $39.1 \%$ in Oman, and $44.2 \%$ in Jordan. The individual studies, as well as the review of current research, support one conclusion: Adolescents living in Middle Eastern countries also experience a high rate of bullying, even higher than adolescents in Western countries.

\section{Bullying and Stress}

Adolescents who report bullying involvement experience high levels of stress that negatively affect their health and well-being. Bullying-related stress affects adolescents' physical health (Rigby, 1998; Srabstien \& Piazza, 2012) as well as their psychological and social health (Hawker \& Boulton, 2000). Stress related to bullying may affect adolescents' health years later. Newman, Holden and Delville (2005) examined college students who experienced bullying during high school. Their study found that both males and females reported higher stress symptoms (e.g., sadness, weight loss, trouble breathing) if they were bullied during high school. The long-term effect of stress related to bullying may also have physical manifestations, including high blood pressure and increased heart rate in adulthood (Hamilton, Newman, Delville \& Delville, 2008).

The relationship between peer victimization and poor health is explained by differences in neuroendocrine functioning. Bullying experiences may alter the function of the hypothalamicpituitary-adrenal axis (HPA), which might lead to fluctuations in the cortisol levels and result in 
poorer physical and psychological health (Knack, Jensen-Campbell \& Baum, 2011). Vaillancourt and colleagues (2008) found that bullying victimization was associated with altered cortisol levels, and this relation is mediated by gender. They found that male victims had higher cortisol levels, whereas female victims had lower cortisol levels. Epigenetic researchers have suggested that bullying may trigger an effect on adolescents' genetics that is reflected in their hypothalamicpituitary-adrenal axis function and subsequently affects their health. For example, Ouellet-Morin and colleagues (2013) examined bullied ten-year-old children and compared them to their nonbullied twin. The authors found that the experience of bullying early in life can modify adolescents' DNA methylation at specific gene sites and results in lower cortisol levels, which may affect their health and functioning.

\section{Bullying Stress, Perceived Stress, and Adolescents' Health}

Bullying experiences and related stress has a substantial negative effect on adolescent health. It was found that bullying experiences in any form (physical, verbal, relational and cyber) are associated with worse physical and psychological health (Smokowski \& Kopasz, 2005; Kowalski \& Limber, 2013). The negative effect of bullying is significant, regardless of the type of involvement as bullies, victims, or both (bully/victims; Smokowski \& Kopasz). In regard to physical health, bullying involvement is associated with adolescents' manifestation of physical symptoms, including headaches (Gini, Pozzoli, Lenzi \& Vieno, 2014), poor appetite, sleep disturbances, abdominal pain, dizziness and fatigue, sore throat, cold, and cough (Due et al., 2005; Rigby, 1998; Sansone \& Sansone, 2008; Wolke et al., 2001). Similarly, psychological symptoms include social difficulties, internalizing symptoms, eating disorders (i.e., anorexia or bulimia nervosa; Sansone \& Sansone, 2008), bad temper, feeling nervous, feeling low, feeling left out, loneliness and helplessness (Due et al., 2005). Symptoms of relatively poor physical and 
psychological health are often associated with being stressed (Rigby, 1998, 2000). It has been suggested that adolescent victims and bully/victims are mostly affected physically and psychologically (Sansone \& Sansone; Smokowski \& Kopasz, 2005; Turner, Exum, Brame \& Holt, 2013; Wolke et al.). In addition, cyberbullying victims and bully/victims might experience greater level of negative health outcomes (Kowalski \& Limber, 2013; Waasdorp \& Bradshaw, 2015)

Bullying involvement is strongly associated with adolescent suicide attempts and completions (Hertz, Donato, \& Wright, 2013; Litwiller \& Brausch, 2013). This relationship remains significant during adolescence and later in adulthood (Klomek, Sourander \& Gould, 2010). All three forms of bullying involvement (bullies, victims, and bully/victims) are significantly associated with suicidal thoughts and behaviors (Hong, Kral, \& Sterzing, 2015; Klomek et al., 2013). However, the degree of association might be inconsistent across research. For example, others have found that adolescents who bully others reported significantly more severe suicidal ideation and have more risk factors for suicide (King, Horwitz, Berona \& Jiang, 2013). On the other hand, Hinduja and Patchin (2010) found that victims of bullying have a higher risk for suicide. The current literature confirms that cyberbullying has a more catastrophic effect, and it is more strongly related to suicidal ideation relative to traditional bullying (Gini \& Espelage, 2014).

Bullying is found to be associated with immediate and delayed signs and symptoms of depression and anxiety (Bond, Carlin, Thomas, Rubin \& Patton, 2001; Stapinski, Araya, Heron, Montgomery \& Stallard, 2015). For anxiety, bullying involvement was strongly related to high levels of comorbid anxiety, as well as social phobia and agoraphobia (Gladstone, Parker \& Malhi, 2006). Bullying involvement was also found to be a strong predictor of higher levels of generalstate anxiety, especially under stress during adolescence and adulthood (Gladstone et al., 2006). 
Depression was strongly associated with four forms of bullying (physical, verbal, relational, and cyberbullying) (Wang, Nansel \& Iannotti, 2011; Turner et al., 2013). It is evident that victims and bully/victims experienced significantly higher levels of depression symptoms compared to bullies, especially in cases of cyberbullying (Wang et al., 2011; West \& Salmon, 2000). The relationship between depression and bullying remains significant among adolescent males and females (Turner et al.).

\section{Perceived Stress}

An individual's perception of a situation as stressful is an important factor that influences the individual's reaction and his or her ability to cope with stress (Folkman et al., 1986; Lazarus \& Folkman, 1984). The effect that stress has on a person depends more on whether that person feels threatened, vulnerable, and is able to cope with the stressor than on the stressful event itself (Folkman et al., 1986; Lazarus \& Folkman, 1984). In other words, the effect of bullying is greatly determined by adolescents' perception of bullying as a stressor and threat. Lazarus and colleagues (1982) suggested that stress is not limited to major life events (e.g., death or divorce); it also includes daily hassles (e.g., repeated or chronic strains of everyday life; DeLongis, Coyne, Dakof, Folkman, \& Lazarus, 1982). A daily hassle for adolescents can be their negative peer relations and bullying involvement.

Adolescents' cognitive appraisals of past experiences such as bullying are found to influence what they determine to be stressful (Compas, Connor-Smith, Saltzman, Thomsen \& Wadsworth, 2001). Adolescent perceptions, interpretation, and reactions to stressful situations are strongly associated with internalizing and externalizing symptoms (Compas et al., 2001). Among adolescents, perceptions of high stress levels significantly influenced developing depression, anxiety, and low self-esteem (Yarcheski \& Mahon, 2000). Perceptions of high stress levels are 
also significantly related to anger control problems, emotional distress, and negative selfperception (Hampel \& Petermann, 2006). Perceived stress related to bullying also influences symptoms of psychopathology, such as depression, anxiety and aggression (Sontag \& Graber, 2010). However, adolescents do not perceive bullying involvement in similar ways. Therefore, adolescents who experienced bullying as bullies, victims or bully/victims may or may not experience symptoms of depression or anxiety (Combs, 2012). Examining perceived stress related to bullying is important and may provide valuable information about the association between bullying and adolescents' health outcomes. For example, Alfven, Östberg, and Hjern (2008) examined the relationship between a stressor (school bullying), perceived stress, and stressinduced pain in Swedish children aged 10-18 years. Adolescents who experienced bullying perceived more stress and experienced more pain (e.g., headache and abdominal pain). In the current literature, only a few studies examined the role of adolescents' perceived stress in the relationship between bullying and health. Furthermore, no studies to date examined this relationship among a marginalized group of adolescents, such as Arab Americans.

\section{Bullying among Minorities}

Racial and ethnic minority adolescents, such as African Americans and Latinos are vulnerable and marginalized which puts them at higher risk for bullying victimization and perpetration relative to White adolescents (Albdour \& Krouse, 2014; Goldweber et al., 2013; Luk et al., 2012; Schuster et al., 2012; Wang et al., 2009). In addition, Asian youth have been found to have the highest risk of victimization compared to any other ethnic group (Mouttapa et al., 2004). Biracial and multiracial adolescents are also more likely to be victimized than are single-race adolescents (Stein, Dukes, \& Warren, 2007). However, an earlier study conducted by Seals and Young (2003) found that race/ethnicity was not a significant predictor of bullying involvement 
among adolescents, which was inconsistent with subsequent studies. Although research evidence supports the finding that bullying involvement is higher among minority adolescents than among White students, the nature of involvement as bully, victim, or bully/victim was not consistent across studies. For example, Schuster and colleagues (2012) found that fifth-grade African American and Latino adolescents reported higher rates of peer victimization and discrimination than did Whites students. On the other hand, White students were found to be at a significantly higher risk of victimization compared to African American and Hispanic/Latino students (Hanish \& Guerra, 2000; Spriggs, Iannotti, Nansel, and Haynie, 2007). In addition, several studies found that African American, Native American, and Hispanic adolescents are more involved in bullying as bullies but not victims (Carlyle \& Steinman, 2007; Fitzpatrick, Dulin, \& Piko, 2007; Shetgiri, Lin, Avila \& Flores, 2012; Wang et al. 2009). The inconsistent findings in the current literature can be explained by the finding that the association between adolescents' race/ethnicity and bullying involvement can be influenced by several factors, such as socioeconomic status, exposure to community violence, and racism (Bradshaw, Waasdorp, Goldweber \& Johnson, 2013; Goldweber et al., 2013). For example, African American adolescents who live in low socioeconomic environments and are constantly exposed to community violence are more likely to exhibit aggressive attitudes and behaviors compared to their peers who live in a low-risk and minimum-violence environment (Fitzpatrick, 1997; Fitzpatrick et al., 2007). Environmental setting (urban/nonurban) might influence minority adolescents' involvement in bullying, as well. For instance, urban, African American adolescents are more involved in bullying, especially as bullies, compared to African American adolescents in other settings (Bradshaw et al., 2013). Another significant factor may be school-grade level. McKenney, Pepler, Craig and Connolly (2006) found that ethnic minority youth in elementary school reported being bullied because of 
their ethnicity. Conversely, the study also found no differences in victimization based on the ethnicity of youth in high school (McKenney, et al., 2006).

In terms of immigration status, adolescents born in the U.S. were more involved in bullying as bullies compared to foreign-born adolescents (Shetgiri et al., 2012).

Several studies found that for Hispanic/Latino and Asian youth, immigrant status and language/cultural barriers are significant predictors for peer victimization at school (Mouttapa et al., 2004, Peguero, 2009; Qin et al., 2008). Bullying involvement among immigrant adolescents are also influenced by generation status (first-, second-, or third-plus generation) (Peguero, 2009; Pottie, Dahal, Georgiades, Premji \& Hassan, G. (2014). First-generation immigrant youth are often subjected to negative treatment, such as discrimination, ridicule, and harassment from other students, teachers, and school administrators (Olsen, 1988, 2000). For example, Qin and colleagues (2008) found that first-generation Chinese American immigrant students are more likely to report bullying victimization than other generations. An adolescent immigrant's bullying experience might also be affected by their adaptation to the new environment and culture (Hong \& Espelage, 2012; Peguero, 2009). In summary, the association between race/ethnicity and bullying is complex, influenced by multiple characteristics of the individual student, school, and community levels (Hong \& Espelage, 2012) and might be aggravated by acculturation stress (Bauman \& Summers, 2009).

\section{Arab American Population}

The U.S. Census Bureau estimated the Arab American population in 2000 to be 1.2 million. However, other academic and community research organizations have provided higher estimates. For example, the Arab American Institute Foundation (AAI, 2014) estimates that at least 3.5 million Americans were of Arabic descent in 2014. Arab American immigrants came to the U.S. 
during the 1880 s and continued to immigrate in waves up to the present, coming from 22 Arabic speaking countries (i.e., Algeria, Bahrain, Comoros, Djibouti, Egypt, Iraq, Jordan, Kuwait, Lebanon, Libya, Mauritania, Morocco, Oman, the Palestine Liberation Organization, Qatar, Saudi Arabia, Somalia, Sudan, Syria, Tunisia, the United Arab Emirates, and Yemen; AAIF, 2014; Nydell, 2012). It is a common belief that Arabs are all Muslims; however, according to Nydell (2012), 95\% of Arabs are Muslims, 5\% are Christians, and an even smaller percentage are Jews. Muslims constitute a huge global population that follows the Islamic faith, speaks different languages, and can be Arabs or non-Arabs. In fact, only $20 \%$ of the Muslims are Arabs (Nydell, 2012).

Arab Americans live all over the U. S. However, one- third reside in California, New York, and Michigan. Ninety-four percent reside in metropolitan areas, most notably Detroit, Los Angeles, New York, Chicago, Washington, D.C., and Northeastern New Jersey (AAI, 2014; U.S. Census Bureau, 2003). Contrary to a Western culture that encourages individualism and independence, Arab culture encourages the collective good of the family (Haboush, 2007; Nydell, 2012). Family, respect, honor and loyalty are central to Arabic culture, regardless of the religion practiced. Adolescents are encouraged to maintain family honor and to find solutions within the family instead of developing their own individual problem solving skills (Haboush, 2007; NassarMcMillan, Ajrouch \& Hakim-Larson, 2013). Males are the head of the house, and they have powerful roles in the decision-making process (Nydell, 2012). Expressing emotions is often strongly discouraged, especially among males (Haboush, 2007; Nassar-McMillan et al., 2013). Arab American adolescents may struggle to maintain their own culture while being immersed in Western culture (Haboush, 2007; Nassar-McMillan et al., 2013). 
After the attacks of 9/11, Arab Americans moved into the public and media hot spot, especially after the U.S. involvement in Iraq. Arab Americans were subjected to discrimination, prejudice, and physical/verbal assaults (Abdelkarim, 2003; Singh, 2002). Moreover, current literature shows that hate crimes against Arabs and Muslims increased dramatically in the months following 9/11, including beatings, shootings, and verbal threats (Disha, Cavendish \& King, 2011; Singh, 2002). Padela and Heisler (2010) surveyed Arab American adults and found that after 9/11, Arab Americans perceived an increase in abuse and discrimination and reported significant psychological distress, lower levels of happiness, and declining health. The 9/11 attacks also had a huge effect on Arab American adolescents. Arab American adolescents faced negative peer relations after 9/11 and experienced stress, including bullying and discrimination (NassarMcMillan et al., 2013). The attacks contributed to confusion in Arab American adolescents' identity formation (Arab identity versus American identity) as they felt marginalized and unwelcomed (Nassar-McMillan et al.). Despite the current evidence of stress facing Arab American adolescents, no studies to date focused on their bullying involvement and stress related to this experience.

\section{Arab American Adolescents: The Invisible Population}

Arab American adolescents are one of the minority populations living in the U.S. that have not been included in research examining bullying. In fact, Arab American adults and their children appear to be the least visible population in the U.S. (Haboush, 2007). Although Arab American adolescents face major bullying risk factors, such as immigration, acculturation, and discrimination, there is a paucity of studies examining the bullying experiences of this population (El-Sayed \& Galea, 2009). Although Arab American adolescents' experience in discrimination and acculturative stress have been found to negatively affect their psychological health (Ahmed, 
Kia-Keating \& Tsai, 2011), the effect of these factors combined with bullying has not, to date, been investigated.

Acculturation generally refers to how sustained, intergroup contact changes the behaviors and psychological processes among members of interacting groups and typically applies to all participating ethnic group members from various age groups (Berry, 2001). Arab and Muslim American adolescents fluctuate between integrating into Western/U.S. norms versus those of Islam (Sheikh, 2009). It was evident in the literature that Arab families that experienced war before immigration-for example, the Gulf War, the Iraq-Iran war, the U.S. invasion of Iraq, and the Lebanon civil war-may experience more complex acculturation in the U.S. and may need tailored, psychological health services (Nasser-McMillan \& Hakim-Larson, 2003).

Discrimination is a major factor affecting Arab American health and quality of life, particularly after $9 / 11$. The events of $9 / 11$ have further contributed to negative mainstream perceptions of Arab culture (Wray-Lake et al., 2008). After the 9/11, Arab American immigrants reported experiencing social exclusion and they were perceived by the mainstream as a threat to American security (Awad, 2010). Religion was the strongest predictor of perceived discrimination among the Arab American population. In fact, Arab American Muslims experienced more discrimination than Arab American Christians (Awad, 2010). After 9/11, schools reported an increase in physical and verbal bullying directed at Arab American children (Abdelkarim, 2003; U.S. Commission on Civil Rights, 2011). Peek (2003) interviewed 99 Muslim college students, including Arab Americans immediately following 9/11. Muslim students reported feeling isolated from the mainstream society after $9 / 11$ due to four primary reasons: (a) feeling blamed for the attacks; (b) being excluded from mourning, bonding, and helping behaviors; (c) having to manage increased concerns for individual safety; and (d) witnessing acts of discrimination and violence 
perpetrated against Muslims in the U.S. In addition, Muedini (2009) interviewed twenty Arab American and Muslim college students studying in the U.S. Several of the Muslim students interviewed in the study shared stories describing acts of discrimination perpetrated against them because of their Muslim faith following 9/11. Also, they reported feeling less safe than before 9/11. Students also felt that the 9/11 attacks affected their identity: They reported being proud to be Americans; however, they did not believe that they were viewed as Americans (Muedini, 2009). After 9/11, Muslim students believed that misperceptions and negative stereotypes about Islam and Muslim values were prevalent in schools, and they felt they were affected by them (Ahmad \& Szpara, 2003). The increased assaults and aggression against Muslim adolescents at schools across the country were aggravated by the negative media image of Muslims after 9/11 (Abdelkarim, 2003). As $95 \%$ of Arab Americans are Muslims, it is essential to examine discrimination and bullying among Arab American adolescents.

Despite the fact that there is a serious dearth of research on Arab American and Muslim adolescents at the school level, the U.S. Commission on Civil Rights (2011) presented and discussed individual cases of bullying against Muslim adolescents in order to raise awareness of religion-based bullying at schools. In their 2011 report, they included one incident during the 20092010 school year in which a middle-school student in Staten Island, New York was taunted, teased, and ultimately attacked by his classmates because he was a Muslim. This boy spoke to the media, telling the New York Post, "They punched me... They spit in my face... They tripped me on the floor...They kicked me with their feet and punched me... And as they were kicking and laughing, they kept saying, 'you terrorist, you Muslim"” (U.S. Commission on Civil Rights, 2011). In another incident, students allegedly attacked a thirteen-year-old Muslim girl, beating her and yanking off her head scarf. According to the Daily News, "They just attacked me... They called me 
'terrorist'... They called me 'Muslim'. I am afraid they might come back and beat me again" (U.S. Commission on Civil Rights, 2011). In light of these trends, more research efforts are needed to examine the prevalence of religion-based bullying among Arab and Muslim adolescents and the factors associated with this phenomenon.

\section{Theoretical Framework}

The theoretical framework entails the examination of bullying experiences and the effect on Arab American health flows from the conceptual assumption that bullying is stressful. Adolescent perceptions of this stress may influence the negative effect of bullying on their physical and psychological health. The Neuman System Model (1990; 1995; Neuman \& Fawcett, 2002) was used to examine Arab American bullying involvement and related stress effects on their physical and psychological health.

\section{The Neuman System Model}

The Neuman System Model (NSM) focuses on the wellness of the client system in relation to environmental stress. The client or client system is defined as the individual, group/aggregate, and community in the NSM (1985). According to Neuman, the client system is in a continuous interaction with the environment; the open and reciprocal interaction with the environment may result in environmental stressors (e.g., intrapersonal, interpersonal, and extra-personal stressors). The degree of impact with an identified stressor can determine if the client system maintains optimal system stability or suffers from system instability (health vs. illness).

The NSM was applied and used in research in individual, family, and community level. At the individual level, NSM guided the research to identify stressors affecting different client populations, including caregivers, cancer survivors, patients in intensive care units, care receivers, and parents whose children were undergoing day surgery (Skalski, DiGerolamo \& Gigliotti, 2006). 
The NSM Model was also adapted to identify stressors within the family, as well as to develop family focused nursing interventions (Reed, 1993). In addition, NSM was adapted to identify community stressors and to develop community-focused nursing practices (Newman, 2005).

In terms of targeted populations, NSM was used across different age groups. In the elderly population, NSM was utilized to guide nursing interventions for older adults within the community, as well as mental health facilities (Moore \& Munro, 1990, Newman, 2005). In the adult population, NSM was used to examine the needs of cancer patients and their caregivers (Blank, Clark, Longman \& Atwood, 1989; Loescher, Clark, Atwood, Leigh \& Lamb, 1989). Finally, in the adolescent population, NSM was used to develop a middle-range theory that guides the assessment of adolescents' risk of inhalant use (Cazzell, 2008). In 2012, Spurr, Bally, Ogenchuk and Walker conducted a study to examine adolescents' wellness. In this study, the authors utilized NSM to explore adolescent wellness through the perceptions of adolescents themselves and explained the relationship between wellness and development. The authors found that the majority of the youth in the study suggested that psychological (89\%), social (85\%), and physical (80\%) development contributed most significantly to their wellness. Slightly more than half of the youth felt that spirituality (53\%) contributed to their sense of wellness. These research

findings indicated that using NSM was a convenient way to identify what should be a high priority in adolescent wellness.

\section{Neuman System Model Applied to the Bullying Experience}

Previous research studies identified stress as a major factor in understanding adolescents' wellness (Sleet \& Dane, 1985). In the last ten years, NSM was used to examine stress related to adolescent wellness. In particular, perceived stress was found to be inversely related to adolescents' wellness (Yarcheski, Mahon, Yarcheski \& Hanks, 2010). The Neuman System Model 
concepts of stress, environment, health, and prevention could be used to guide and provide evidence for school nurses and other health professionals who promote wellness as a way to reduce stress in adolescents.

In terms of bullying, the utility of NSM in examining this phenomena is limited and almost non-existent, despite the fact that NSM is well founded framework to guide research and practices among adolescents' wellness. It was only recently applied to examine bullying among adolescents. Particularly, NSM was used to examine cyberbullying among adolescents in urban and suburban environments in relation to their psychological and physical health (Carter, 2011). Findings of the present study provided evidence that NSM can be applied as a theoretical framework when studying adolescents' bullying involvement and its effects on their health. The Neuman System Model can guide nurses and other healthcare professionals to better understand the negative health outcomes of bullying and to establish primary, secondary, and tertiary interventions for bullying.

\section{Concepts within NSM}

\section{Client or Client Systems}

The terms "client" and "client systems" are used in the NSM instead of "patient" or "person" to indicate respect and mutual collaboration between caregivers and the care receiver (Neuman, 2002). According to Neuman (1995), a client is viewed as an open system in constant dynamic interaction with the environment. This constant interaction consists of making adjustments as needed to attain, maintain, and retain stability for an optimal level of health (Neuman \& Fawcett, 2002). The client/client system can be defined as an individual (a human being; Neuman \& Fawcett 2002). Furthermore, client/client system can be considered a family, community, or social issues which represent a certain type of group (Neuman \& Fawcett, 2002). As displayed in figure 1, utilizing NSM, adolescents can be viewed as open systems in a continuous 
interaction with the surrounding environment (e.g., school).

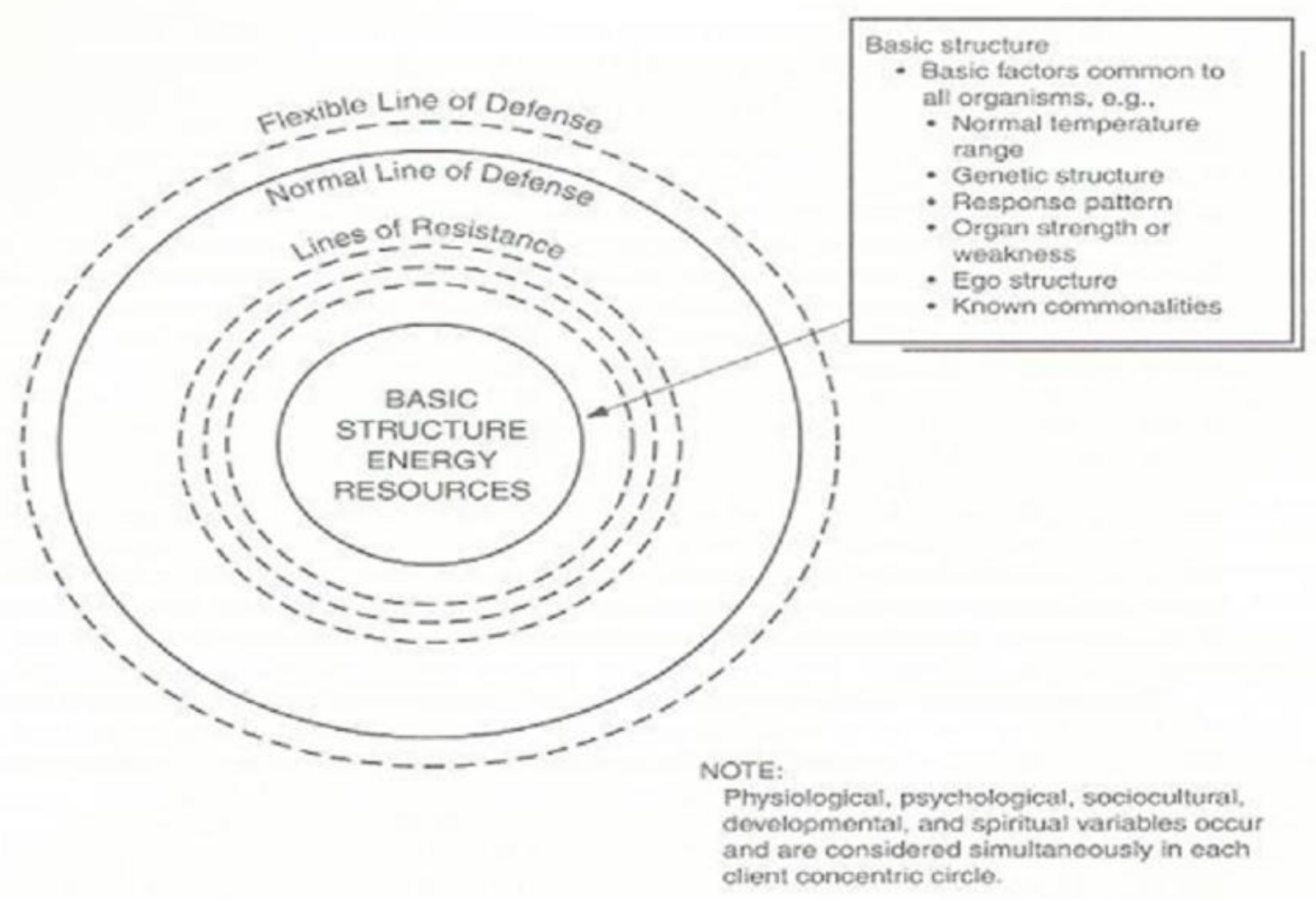

Figure 1. Client /client system adopted from Neuman, B., \& Fawcett, J. (2002). The Neuman System Model. (4th ed.). Upper Saddle River, NJ: Prentice Hall.

\section{Five Interacting Variables}

As indicated by Neuman (1995), the client system is composed of the following five interacting variables: physiological, psychological, sociocultural, developmental, and spiritual (Neuman, 1995; Neuman \& Fawcett, 2002). The physiological variable represents the bodily structure (e.g. genetic structure) and internal function (e.g. normal body temperature). The psychological variable refers to mental processes (e.g. ego structure, response patterns) and interactive environmental effects, both internally and externally. The sociocultural variable represents the combined effects of social and cultural conditions and influences. The development variable represents processes and activities associated with age-related growth and maturity. The 
spiritual variable refers to spiritual beliefs and influences. The five interacting variables function together in harmony to protect the client system from internal and external environmental stressors, and they are considered simultaneously in each of the client's concentric circles, which will be explained below (Neuman, 1995; Neuman \& Fawcett, 2002). The five variables exist within adolescents (client/client system) and manifest as the core competencies adolescents demonstrate in the face of an environmental stressor, such as bullying. Adolescents' physical (e.g., genetics),

psychological (e.g., cognition), developmental (e.g., age when bullying experienced), social variable (e.g., social support), cultural variable (e.g. male dominance) and spiritual (e.g., faith) variables are all important factors in determining the adolescents' reaction to bullying as an environmental stressor. Figure 1 illustrates client/client system as defined by Neuman (1995).

\section{Basic Structure}

Defined by Neuman (1995) as the central core of the client/client system, the basic structure consists of basic survival factors common to the species, such as innate or genetic features, as well as strength and weaknesses of the system parts (Neuman, 1995; Neuman \& Fawcett, 2002). Neuman (1995) used the innate mechanisms for maintenance of normal temperature, genetic response patterns, and strengths and weaknesses of body organs as examples of basic structure. The goal of the basic structure is to preserve the integrity of the client system (Neuman \& Fawcett 2002). In relation to bullying, the basic structure may represent the adolescent's physical resilience to bullying (biological makeup or genetics). The basic structure is protected by concentric circles, including the flexible line of defense, the normal line of defense, and the lines of resistance. The concentric circles function essentially as protective mechanisms for the basic structure in order to preserve the integrity of the client system (Neuman, 1995; Neuman \& Fawcett, 2002). Each circle (line) individually contains five system variables 
(physiological, psychological, sociocultural, developmental, and spiritual) and protects the components of the system. Input, output, and feedback across circles (lines) provide corrective action to change, enhance, and stabilize the system in order to achieve the optimal level of wellness.

\section{Flexible Line of Defense}

The outer boundary of the client/client system is defined as the flexible line of defense (Neuman, 1995; Neuman \& Fawcett, 2002). In Figure 1, the flexible line of defense is depicted as the outer, broken circle surrounding the normal line of defense, lines of resistance, and the basic structure. The flexible line of defense acts as a protective system for the client's stability and inhibits stressor (e.g., bullying) invasion to the client system (e.g. bullying), keeping the system free from stressor reactions (e.g., anxiety related to bullying) or symptomatology (e.g., somatic symptoms related to bullying and high cortisol levels).

\section{Normal Line of Defense}

The normal line of defense represents what the client has become or evolved into overtime. This is the usual wellness level, depicted in Figure 1 as the solid boundary line that encircles the lines of resistance in the client system. The normal line of defense changes over time in response to environmental stressors (e.g., bullying) that may affect the system wellness. This line is affected by previous system behaviors and stressors (e.g., past bullying experiences) in addition to other factors, such as system variables, coping patterns, lifestyle factors, developmental and spiritual influences, and cultural considerations. The function of this line is to protect and preserve the client/client system stability and integrity (Neuman \& Fawcett, 2002).

\section{Lines of Resistance}


The lines of resistance are presented by three broken lines that surround the basic structure and energy resources (see Figure 1). This series of concentric, broken circles surrounds and protects the basic structure (Neuman \& Fawcett, 2002). Lines of resistance are activated following an invasion of the normal line of defense by environmental stressors (e.g., bullying) and contain certain factors that support the client's basic structure and normal defense line, protecting the system's integrity. Lines of resistance reverse the reaction to stressors, allowing the system to reconstitute (e.g., cope with bullying). Ineffectiveness of the lines of resistance, however, can lead to energy depletion and death (e.g., suicide resulting from bullying; Neuman \& Fawcett, 2002). Reconstitution represents the return and maintenance of system stability following treatment for stressor reactions. This process starts after the initial invasion of the stressor and is determined by the energy increase related to the degree of reaction (Neuman \& Fawcett, 2002). Reconstitution includes successful mobilization of client resources to prevent further stressor reactions (e.g., group therapy for bullied adolescents).

\section{Environment}

Environment is defined by Neuman (1995) as all of the internal and external factors or influences surrounding the client/client system. Neuman (1995) identified three relevant environments in the client/client system (e.g., adolescent). The internal environment is intrapersonal in nature, consisting of all forces/interactive influences that are internal to, or contained solely within the boundaries of the client system (e.g., cognitive and social information processing). The external environment is defined as all forces or interactive influences that are external to, or existing outside of the defined client system (e.g., school and home). The created environment is a concept developed by Neuman (1995) to represent the environment developed unconsciously by the client. The client develop this environment to acts as an immediate or long- 
range safe reservoir for existence or the maintenance of system integrity expressed consciously, unconsciously, or both simultaneously (e.g., use of denial or imagination).

\section{Stressors}

Neuman (1995) defined stressors as tension-producing stimuli with the potential of causing system instability. Stressors occur within the internal and external environmental boundaries. Bullying represents an environmental stressor that affects adolescents and causes system instability (e.g., anxiety and depression). According to Neuman (1995), stressors are positive or negative based on the client's perception. In other words, stressors are neutral, but the outcome of a reaction to a stressor may be beneficial or harmful (Neuman, 1995; Neuman \& Fawcett, 2002). Therefore, reactions to stressors are key factors in determining the effect of these stressors. Stress reaction is a process influenced by several factors, including time, nature and intensity of the stressor, coping behaviors, patterns of similar situations, and the amount of energy and resources available (Neuman \& Fawcett, 2002). One of the important factors influencing the client's reaction to stress is the client's perception of the stressors as threatening or overwhelming (e.g., perception of bullying as overwhelming). Neuman (1995) adapted the views of Lazarus and Folkman (1984) regarding perceived stress and stress appraisal. How the situation is appraised as threatening is a key factor influencing the reaction to a stressor such as bullying (Lazarus \& Folkman, 1984; Neuman \& Fawcett 2002). Neuman (1995) classified stressors into three types, intrapersonal, interpersonal, and extra-personal. Intrapersonal stressors are internal environmental forces, which occur within the boundary of client systems (e.g., deviant social information processing). Interpersonal stressors are external environmental forces, which occur outside the boundary of client systems (e.g., bullying). Extra-personal stressors are external environmental interaction forces, which occur outside the boundary of client systems at the distal range (e.g., 
discrimination). Figure 2 illustrates environment and environmental stressors based on Neuman's (1995) theory.

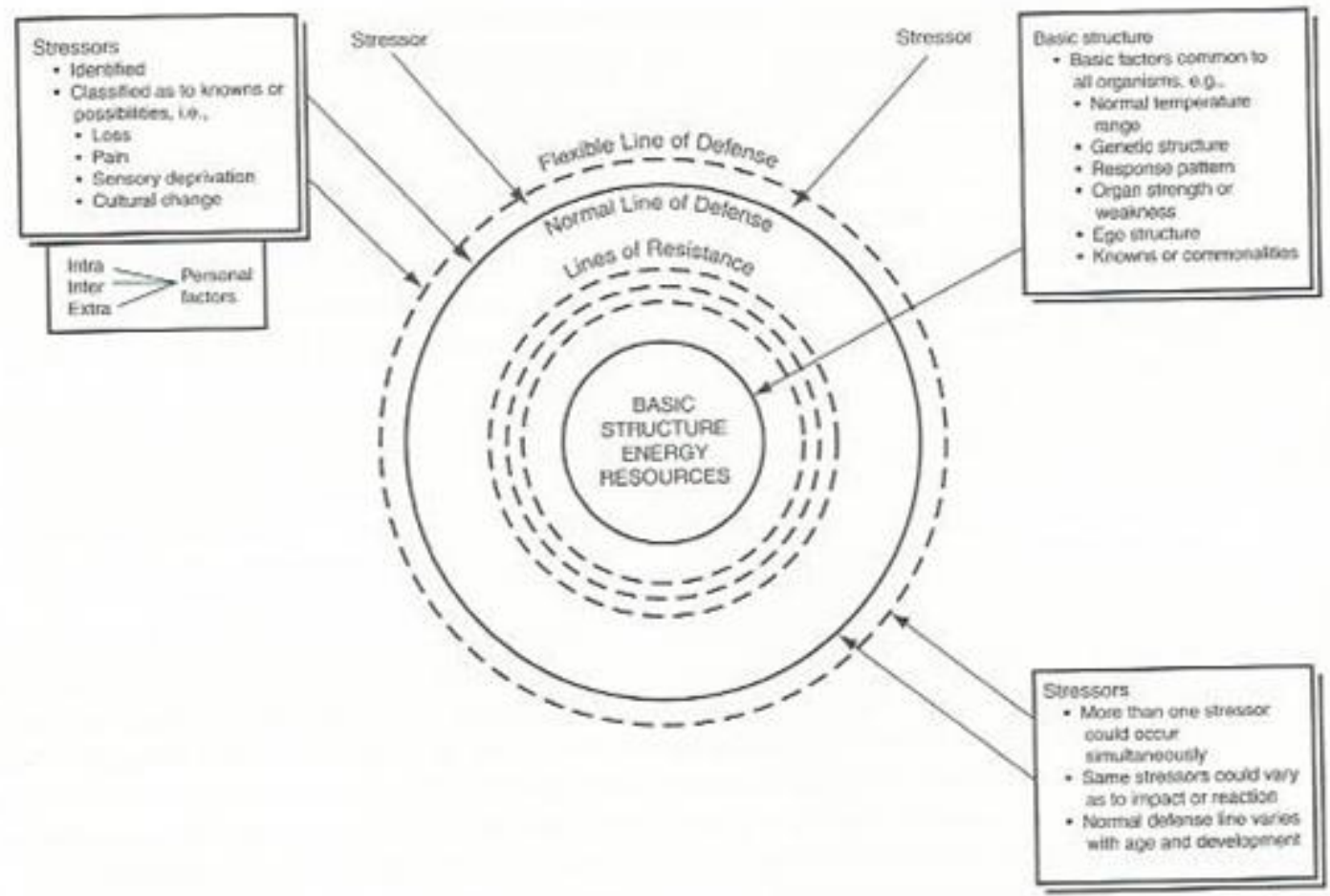

Figure 2. Environment/environmental stressors adopted from Neuman, B., \& Fawcett, J. (2002). The Neuman System Model. (4th ed.). Upper Saddle River, NJ: Prentice Hall

\section{Health}

Health is defined within the context of NSM as the optimal wellness and system stability. It also represents the living energy available to preserve and enhance system integrity (Neuman, 1990). Health and wellness are used interchangeably within NSM, and both mean that the subparts of the system are in harmony with the whole (e.g., healthy adolescent). Illness is defined as instability in the system as unmet needs and is at the opposite end from wellness in the 
wellness/illness continuum (e.g., depression associated with bullying). Figure 3 illustrates health/illness continuum.

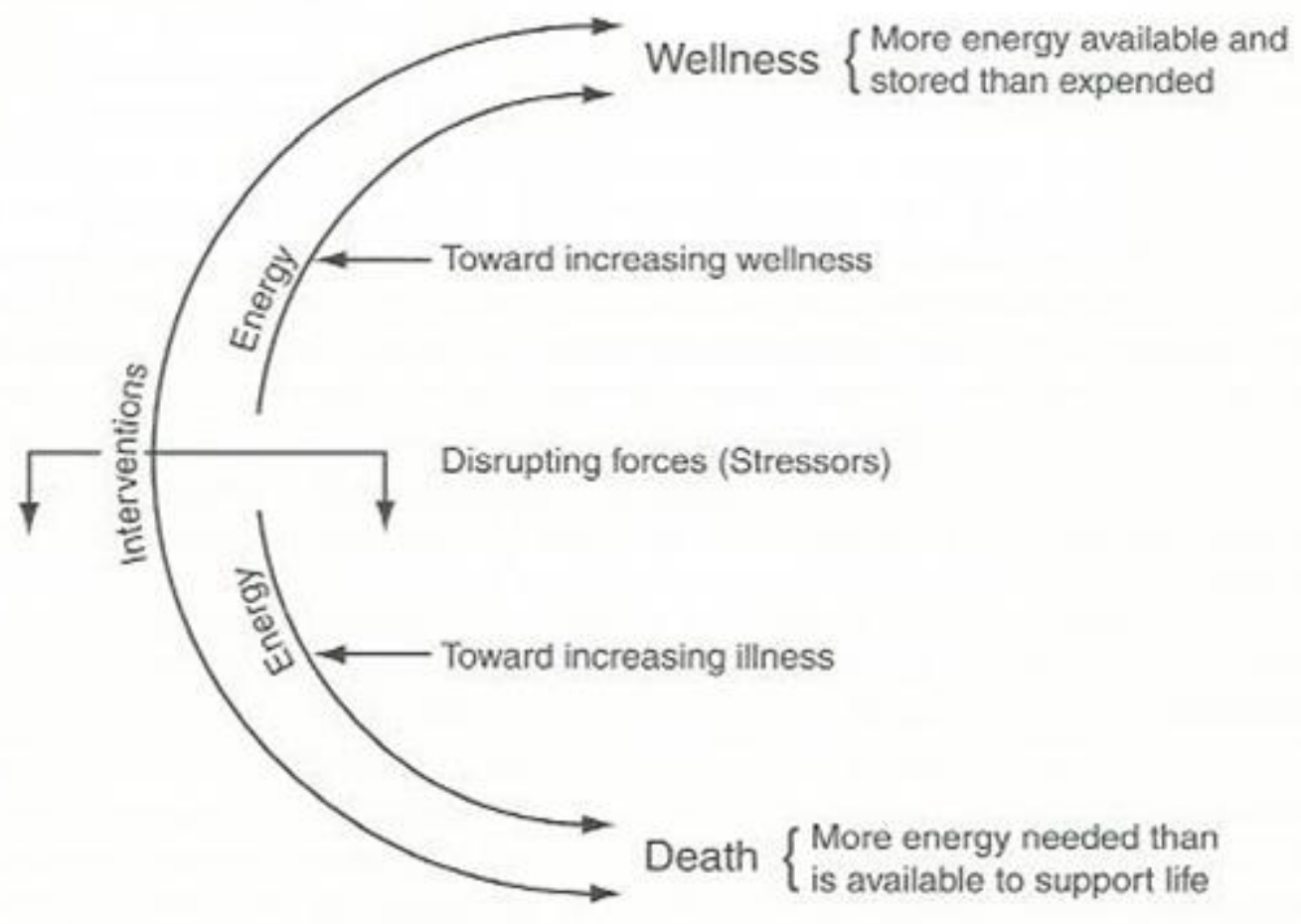

Figure 3. Wellness-illness continuum adopted from Neuman, B., \& Fawcett, J. (2002). The Neuman System Model. (4th ed.). Upper Saddle River, NJ: Prentice Hall

\section{Nursing}

Neuman (1995) defined nursing as a unique profession, concerned with all the variables affecting an individual's response to stressors (Neuman \& Fawcett, 2002; e.g., adolescents' responses to bullying). Nursing's major aim is keeping the client system stable through accuracy in assessing the effects and potential effects of environmental stressors (e.g., bullying) and assisting client adjustments required for an optimal wellness level (coping with bullying). According to Neuman (1995), nursing interventions include primary, secondary, and tertiary preventions. In primary prevention, the nurse acts as the entry point into the health care system to 
reduce the possibility of the stressor the person encounters. The goal of nursing at this level is to protect the client system and promote wellness by strengthening the flexible line of defense, which includes stress prevention and reduction of risk factors (e.g., bullying prevention education programs). Secondary prevention is needed when primary prevention is not provided or fails. Reaction to stressors occurred and symptoms presented, and the goal is to provide treatment and protect the basic structure by strengthening the internal lines of resistance and attaining optimal client system stability or wellness (e.g., intervention for bully victims). For tertiary prevention, nursing is geared to protect the client system reconstitution or return to wellness following treatment (e.g., coping). The goal is to maintain optimal wellness levels by supporting existing strengths and conserving client system energy as well as successful mobilization of client resources to prevent further stress reactions. Tertiary prevention as intervention includes the client system's adjustment to stressors and integrates all of the necessary resources toward optimal wellness (e.g., support groups for victims of bullying).

The application of NSM to examine adolescents' bullying involvement is very limited in the literature. However, one previous study has demonstrated that NSM was applied as theoretical framework examining adolescents' cyberbullying experiences in suburban and urban environments (Carter, 2011). The NSM can provide guidance for developing and implementing primary, secondary, and tertiary bullying interventions at the individual level, as well as family and community levels. Utilizing NSM to improve nursing care for adolescents as this model suggests perceived stress as a potential mediator on the association between adolescents' stress and wellness (Yarcheski et al., 2010). A proposed middle-range theory of bullying, perceived stress from bullying, and adolescent wellness are presented in Figure 4. The NSM have been helpful in understanding adolescents' wellness (Spurr et al., 2012) and adolescents' risky 
behaviors, including smoking and inhalant use (Cazzell, 2008; Hanson \& Laffrey, 1999). The dynamic nature of the NSM, as well as the understandable language of the model concepts, make it valuable guide for nursing education, research, and practice (Neuman \& Reed, 2007) in addition to making it convenient for disentangling complex phenomena such as bullying. Utilizing NSM in understanding the stress-wellness relationship among adolescents can increase knowledge about adolescents' health and wellness, which can inform nursing practice. There is a significant lack of theory-driven research in the area of stress effects on adolescents' wellness (Grant et al., 2003). Utilizing NSM can fill the gap in the literature and enrich the current literature by providing knowledge about adolescents' stress, perceived stress, and the wellness/health relationship in general, and bullying, perceived stress from bullying, and adolescents' wellness/health in particular. 


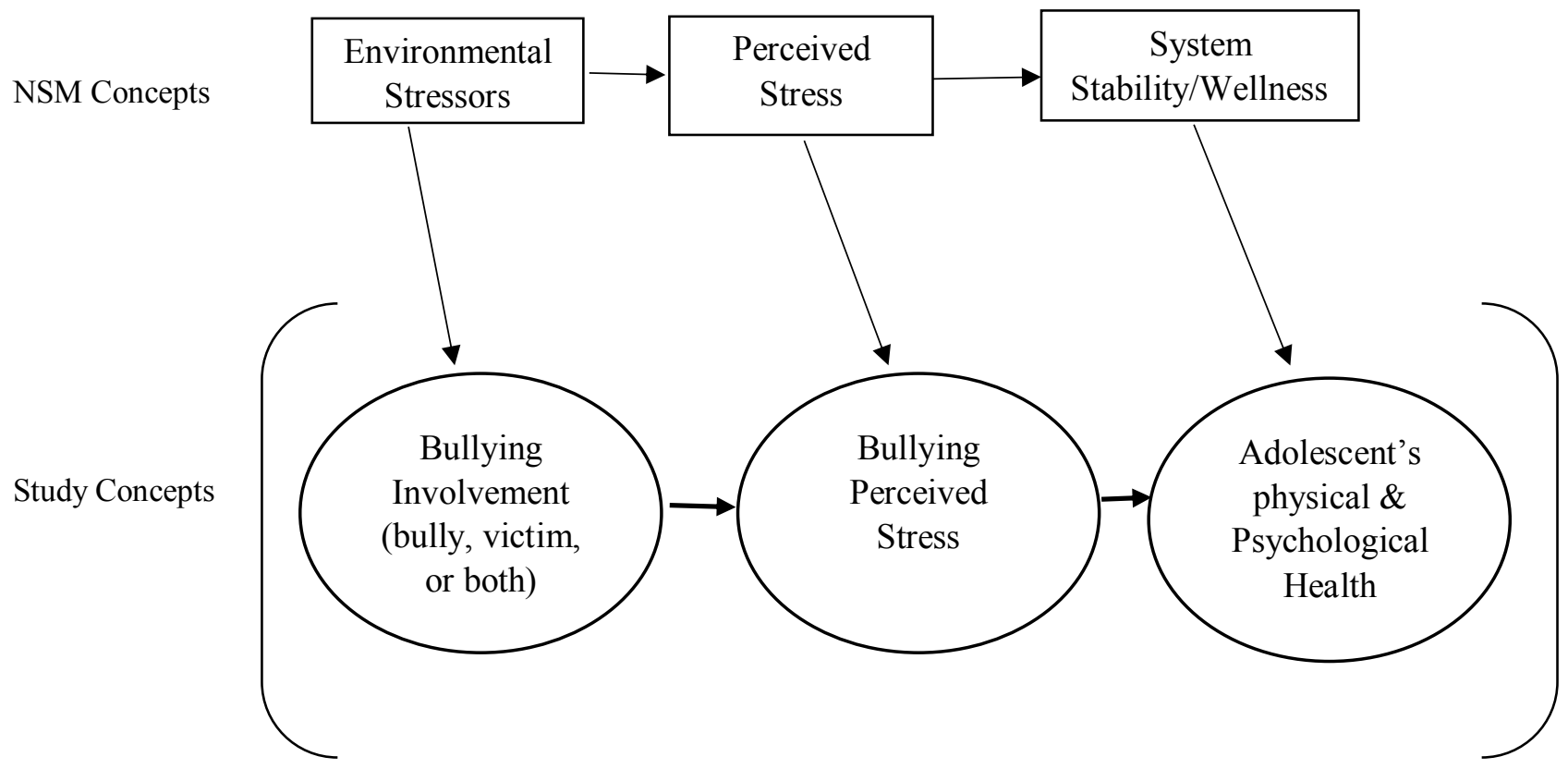

Figure 4. Middle-range theory of bullying, perceived stress from bullying, and adolescents' wellness/health (pictorial presentation of the substruction model)

\section{Summary}

In summary, the review of the literature reveals that bullying involvement among adolescents, either as bullies, victims, or both, are related to negative health outcomes. Numerous studies emphasized the fact that adolescents' bullying experiences have increased their stress levels. However, the mediating role of perceived stress in the link between bullying and health has not adequately examined to date. The prevalence and types of bullying have been investigated among general population of adolescents, as well as racial and ethnic minorities in the U.S., including African Americans, Latinos, and Asians. Regrettably, Arab American adolescents' experiences in bullying have not particularly investigated, although they are at an elevated risk of social exclusion, harassment, and violence. Therefore, this study was proposed to examine the bullying involvement among Arab American adolescents and its effects on their perceived stress and health. The role of perceived stress as a mediator in the associations between bullying and 
health among Arab American adolescents was also examined. Figure 5 illustrates the main conceptual framework that will be examined in this study as well as the relationships among these concepts.

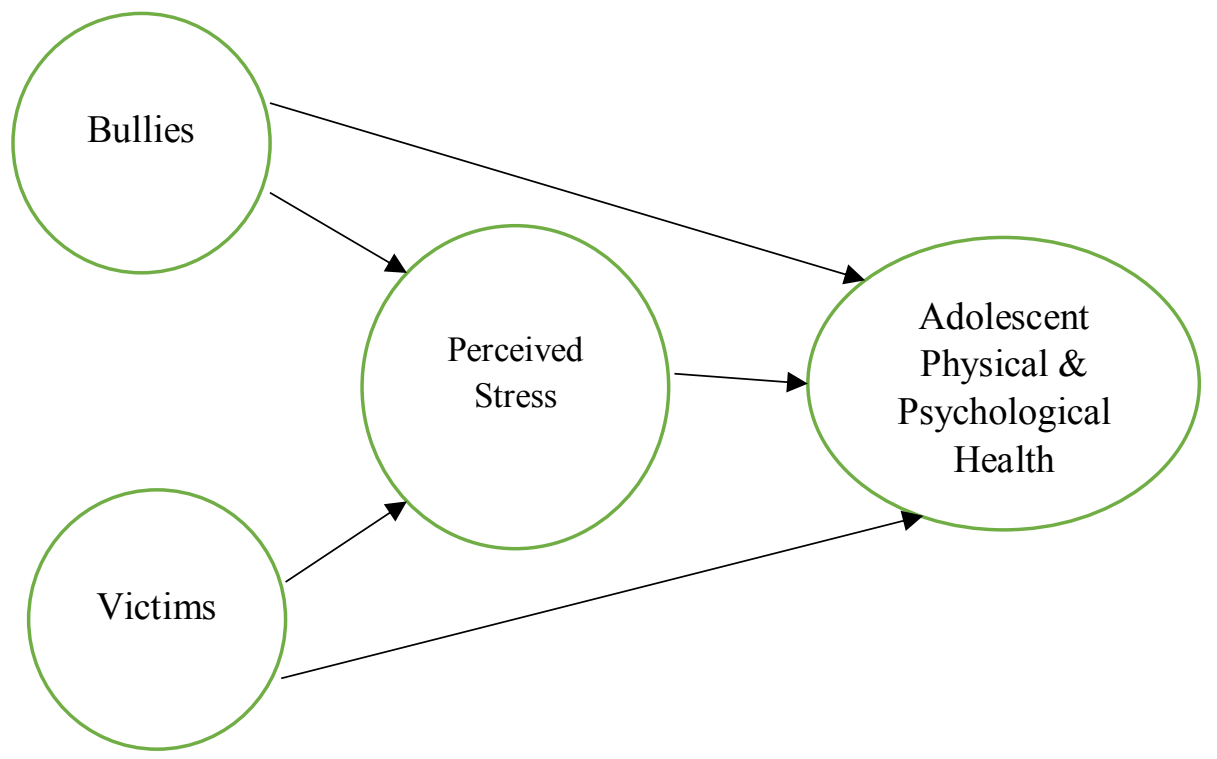

Figure 5. Study Concepts and Hypothesized Relationships 


\section{CHAPTER 3 "METHOD"}

Methods and research designs used for the present study are presented in this chapter. Topics in this chapter include: restatement of the problem, research design, setting for the study, participants, instruments, data collection, and data analysis.

\section{Aim of the Study}

The purpose of this study was to examine the bullying involvement of Arab American adolescents and the effect of bullying on their perceived stress and physical and psychological health. The study examined whether the relationship between adolescents' bullying involvement and health is mediated by their perceived stress. Specific aims of the study were as follows: 1) Identify the prevalence of bullying among a sample of Arab American adolescents in the U.S. and the subtypes of bullying involvement (as bullies, victims, or bully/victims); 2) Identify the relationship between bullying involvement and perceived stress among a sample of Arab American adolescents; 3) Examine the effects of bullying involvement on the physical and psychological health of a sample of Arab American adolescents; 4) Identify if perceived stress from bullying mediates the relationship between bullying involvement experiences and health.

\section{Preliminary Data}

A pilot study was conducted in a Midwestern suburban area using descriptive exploratory qualitative research design (Albdour et al., 2016). The pilot study was intended to examine Arab American adolescents' bullying involvement and related stress. A qualitative research design was chosen because there were no previous studies examining Arab American adolescents' bullying involvement, and little is known about these phenomena. In addition, qualitative research design was chosen to better understand the context of Arab American Bullying experience as well as related stress. Ten Arab American adolescents were recruited through a community center youth 
clinic located in Michigan. The community center serves Arab immigrant population and assist them is adapting to life in the U.S. The center youth clinic provides health care as well as psychological and social services for Arab American adolescents. Adolescents in the clinic recruited for the study were 14-16 years old and identified themselves as victims of bullying. Recruited adolescents answered yes when they were asked if someone bullied them at school. The participant adolescents lived with their biological parents (at least one parent was the biological mother or father). Because the developed interview guide was in English, adolescents recruited were required to understand and write English language efficiently.

Using semi-structured interviews, eligible participants were interviewed for 45 to 60 minutes. Adolescents were asked about 1) their bullying experiences, including specific information about the bullying incident(s), such as when, where, why, and how it occurred; 2) their perceived stress when bullied, more specifically, how they felt when they were bullied, how unpredictable, uncontrollable, and overloaded adolescents felt their lives were during the bullying incident; 3) how long they felt that way; and 4) what helped them cope with their feelings. The interviews were transcribed verbatim onto computer files and were double checked for accuracy. Using conventional content analysis, major codes and sub-codes were developed. Interviews were coded by two research members independently, and coded transcripts were compared. The final version was entered into the NVivo computer program. All coded data were reviewed within and across cases through the construction of matrices to allow for category identification and description. Themes emerged from the identified categories, and the links between categories were used to understand the experience of bullying and related perceived stress that is unique to Arab American adolescents. 
Results. In addition to being bullied because of health problems or social disadvantages, Arab American adolescents reported feeling they were bullied because of their ethnic/racial background and religious affiliation. Adolescents who were bullied described being nervous and experiencing high level of stress. Adolescents reported a wide range of negative feelings when bullied. Mostly sadness, anger, overwhelmed, hurt, and feeling upset. Adolescents did not know what to do when bullying happened, and they felt that schools and teachers were not great sources of support. Arab American adolescents reported experiencing bullying because of their ethnicity/race and religious beliefs in addition to other reasons commonly experienced by their non-Arab American adolescents peers. It is imperative that public health nurses and other health professionals develop tailored and culturally relevant prevention and intervention programs to reduce bullying and related stress among Arab American adolescents.

\section{Current Study Design}

A non-experimental, cross-sectional correlational research design was used in this study. Participants were asked to complete survey instruments that measure demographics, bullying experience, perceived stress, physical health, and psychological health. The correlational research design allowed examination of the relationships among the variables to determine how Arab American adolescents' involvement in bullying as bullies or victims affects their perceived stress, physical health, and psychological health. The study design made it possible to identify whether

perceived stress from bullying mediates the relationship between the bullying experience and adolescent health. Quantitative research method was chosen because surveys and questionnaires in particular are found to be the best method of examining the prevalence of bullying (Crothers \& Levinson, 2004). Surveys and questionnaires are also effective in identifying the association between bullying and physical and psychological problems (Gini \& Pozzoli, 2009; Reijntjes et al., 
2011; Reijntjes, Kamphuis, Prinzie, \& Telch, 2010). Figure 5 illustrates the study variables and hypothesized relationships in the current study.

\section{Study Participants}

\section{Population.}

The population of interest was Arab American adolescents living in the U.S. A purposive convenience sample sampling was used in this study. The study population included adolescents utilizing a community center and attending prayers and events at the mosques located in the Midwest.

\section{Sample}

The sample for this study included Arab American adolescents ages 12 to 16 who were attending middle and high school in Midwest state. The appropriate sample size was determined using the G-Power 3.1.0 analysis, which is a program that calculates the require sample size (Faul, Erdfelder, Buchner \& Lang, 2009). For a moderate effect size of 0.15, alpha level of .05, and 8 predictor variables, a sample size of 110 was determined to reach a power of .80. A sample size greater than 110 was recruited to enhance the analysis power. In this study, a convenience sample of 150 Arab American adolescents were recruited. A convenience sample was used because the study was community- based, and parental permission was required prior to participation. The participants met the following inclusion criteria that were established for the study:

- 12 to 16 years of age

- Self-identified as Arab American

- Living with one or two biological parents

- Speaking and understanding English language

Adolescents were excluded based on the following criteria: 
- Non-Arab Americans

- Living in foster care or have guardians other than parents

- Cannot understand or read English

\section{Study Setting}

A community-based approach was used to collect data for this study. The settings for the study included a mosque that contains a summer school, in addition to a community center located at southeastern Michigan. The staff of both settings identified and recruited participants during prayers and youth activities. Having served the Arab American community for more than four decades, ACCESS has developed several programs to serve adolescents' physical, psychological, and social health. With the help of the community center staff, participants were recruited at these sites during a back-to-school health fair and school-supply event. In addition, the study utilized the mosque and summer school at southeastern Michigan, which serve the Arab American population and provide a variety of youth programs (e.g., youth power). The summer school provides weekly programs, including Arabic language classes, Islamic history and Qur'an classes, art classes, gym time, and weekly field trips. Members of the ACCESS and ICD staff helped to recruit the study participants at prayer times, religious occasions, and youth events at both settings.

\section{Instruments}

The study variables were examined using reliable and valid measurement tools, study variables and measurement tools (see Table 2). 
Table 2

Study Variables and Measurements Used

\begin{tabular}{ll}
\hline \multicolumn{1}{c}{ Variables } & \multicolumn{1}{c}{ Measurements } \\
\hline Bullying Involvement (bully or victim) & Adolescent Peer Relations Instrument (APRI). \\
Bullying Perceived Stress & Perceived Stress Scale (PSS-10) \\
Adolescent's Physical Health & Children Somatization Inventory (CSI-24) \\
Adolescent's Psychological Health & Kessler Psychological Distress Scale (K10) \\
\hline
\end{tabular}

\section{Demographic Data}

Each participant completed the demographic data form developed by the researcher which included information about the participant's age, gender, religion, grade and school level, country of origin, duration in the U.S., and whether the participant was receiving any medications (see Appendix A).

Adolescent Peer Relations Instrument (APRI). The APRI was originally developed by Parada (2000) to examine bullying among secondary-school adolescents in Australia. The scale consists of 36 items that can be divided into two sections with 18 items each. The first section is designated to measure bullying perpetration, whereas the second section is designated to measure bullying victimization (Parada, 2000, 2006). The APRI measures the three types of bullying (physical, verbal, and social) in the two categories (bullies and victims). The instrument captures the multidimensional nature of bullying and was found to be valid among primary school adolescents (Finger, Yeung, Craven, Parada \& Newey, 2008; Marsh et al., 2011).

Scoring. The first section (bullying perpetration) includes 18 items that were divided into three subscales: verbal bullying (items $1,3,5,7,10$, and 14), social bullying (items 4, 8, 11, 13, 17, and 18), and physical bullying (items 2, 6, 9, 12, 15, and 16). The second section (bullying victimization) includes 18 items that were divided into three subscales: verbal victimization (items $1,4,7,11,13$, and 18), social victimization (items 3, 6, 9, 12, 14, and 17), and physical 
victimization (items $2,5,8,10,15$, and 16). Response options for each subscale are on a six point Likert scale: $1=$ never, 2 = sometimes, $3=1$ or 2 times a month, $4=$ once a week, $5=$ several times a week, and $6=$ every day. In each of the six scales, a score of six for a particular form of bullying means that the participant has never bullied others or been bullied. On the other hand, scores higher than six in these subscales represent more frequent bullying perpetration or victimization.

In terms of the total scores, a score of 18 for either the bullying perpetration or victimization section indicates that the participant has never been bullied or has never bullied others. A higher score indicates more frequent bullying perpetration on the bully scale and more frequent victimization on the victim scale.

Reliability and Validity. The instrument was examined pre and posttest in a three week period among a sample of secondary school students in Australia and produced $r=0.81$ (Parada, 2000, 2006). The instrument (36-items) was found to be valid and reliable with Cronbach's alpha of 0.92, as reported by Parada (2000). In addition, the six subscales were found to have acceptable internal consistency and reliability with alpha coefficients ranging from .81 to $.89($ median $=.82)$ for the bully subscales (physical, verbal, social) with alpha coefficients ranging from .81 to .89 (median $=.82)$ for the victim subscales (physical, verbal, social; Finger et al., 2008). Similarly, the two 18-item scales were reliable with an acceptable alpha coefficient of .93 for the bully scale and .94 for the victim scale (Finger et al., 2008). All six subscales were found to have acceptable stability over time when tested using three time constructs: beginning, middle, and end of the school year.

Researchers measured adolescents' experiences with cyberbullying by asking four questions adapted from the Internet Experience Questionnaire (Raskauskas \& Stoltz, 2007). This 
questionnaire was used to examine internet experiences of U.S. adolescents age 13 to 18 . The four questions were asked of the participants who were identified as perpetrators or victims of cyberbullying. The first question asked if the individual had been cyberbullied or had cyberbullied someone in the past year, with response option of "yes" or "no". If the answer to the first question was "yes", participants were asked to answer second question regarding what technology the individual was cyberbullied or had cyberbullied someone else. Participants selected their responses from the following response options: creating a website, pictures on-line without permission, text messaging, by email, on MySpace, on Facebook, Twitter, Instagram, or Snapshot). The third question asked how many times the individual had cyberbullied someone or had been cyberbullied. Participants selected from the following options: (a) 1 or 2 times, (b) 3 to 5 times, or more than 5 times. For the victims, they were asked if they knew the cyberbully, with response option of either "yes" or "no".

To measure the context of bullying, the researcher asked the participants where bullying occurred and they were asked to select from the options provided: classroom, hallway, gym, bathroom, cafeteria, school bus, etc. In addition, adolescents were asked why they bullied others or why they thought they were bullied. Response options included "because of the clothes they wear," "their country of origin," "their religion," etc. In addition, the researcher asked the participants if they informed an adult about the bullying incidence and if so, who that adult was. Response options included: teacher, school staff, parents, sibling, etc. If they reported informing an adult, they were asked whether or not that adult did something to stop the bullying.

Perceived Stress Scale (PSS-10). The PSS-10 was used to measure individuals' perception of stress. According to Cohen, Kamarck and Mermelstein (1983), the PSS-10 is designed to measure individuals' appraisals of situations as stressful and to show how 
unpredictable, uncontrollable, and overloaded respondents consider their lives to be in stressful situations. The PSS-10 is easy to understand and was used in community samples who had at least a middle school education. The scale was translated into 25 languages. The original PSS included 14-items (PSS-14) and was developed by Cohen, Karmarck, and Mermelstein (1983). Later, a shorter version was developed (PSS-10), which was used in this study.

Scoring. Participants were asked to respond to each question on a five-point Likert scale ranging from $0=$ never to 4 = very often, indicating how often they felt or thought a certain way within the previous month. Scores ranged from 0 to 40 with higher scores indicating greater perceived stress (Cohen \& Williamson, 1988).

Validity and Reliability. The original scale's (14-item) psychometric properties were examined in three samples. The two samples included college students and one community sample with at least middle school education (Cohen et al., 1983). Coefficient alpha reliability was .84 , .85 , and .86 in the three samples. Test-retest reliability was tested for two intervals ( 2 days and 6 weeks). The correlation was .85 in the college sample after two days and .55 in the community sample after six weeks. The PSS-10's psychometric properties were examined by Roberti, Harrington and Storch (2006) in a sample of undergraduate students in three public universities. The Cronbach's alpha reliability coefficients for the PSS-10 total score (10 items) was .89. Lee (2012) reviewed studies on PSS-10 psychometric properties and found that Cronbach's alpha of the PSS-10 was greater than .70 in twelve different studies. The test-retest reliability of the PSS10 was assessed in four studies and met the criterion of greater than .70 in all of the four studies, and the interval between the first and second administrations of the PSS for assessment of the testretest reliability ranged from two days to six weeks (Lee, 2012). This study utilized the short form of PSS (PSS-10) as the psychometric properties of the PSS-10 are superior to those of the PSS-14 
(Lee, 2012). The scale requires five to ten minutes to be completed. The PSS is validated in adults and high school adolescents; however, it was not validated among adolescents younger than sixteen years old. Although the scale was not tested in younger adolescents, this study utilized the scale among adolescents age 12 to 16 because it was easy to understand, used simple questions, and was the only reliable and valid measurement for perceived stress. Internal consistency and reliability of the PSS was calculated for the study sample.

Children's Somatization Inventory (CSI-24). The CSI-24 is an updated and shortened version of CSI-35 (Walker, Beck, Garber, \& Lambert, 2009). This scale is designed to assess the severity of non-specific somatic symptoms commonly reported by children who experience high levels of stress related to abuse, trauma, or maltreatment. The CSI includes symptoms from the revised third edition of the Diagnostic and Statistical Manual of Mental Disorders criteria for somatization disorder (DSM-III-R) and from the somatization factor of the Hopkins Symptom Checklist (Derogatis, Lipman, Rickels, Uhlenhuth \& Covi, 1974). Examples of such symptoms are headaches, feeling low in energy, and faintness or dizziness. Two versions are available: parent and child reports. This study used the child report form in which adolescents were asked to rate the extent to which they had experienced each of the 24 symptoms during the last two weeks on five-point Likert scale. The CSI-24 was tested among clinical and community samples (Lavigne, Saps \& Bryant, 2012; Walker et al., 2009) and found to be a reliable and valid tool.

Scoring. Answers to this scale range from $0=$ not at all, $1=\mathrm{a}$ little; $2=$ some, $3=\mathrm{a}$ lot, and $4=\mathrm{a}$ whole lot. Total scores are calculated by adding the scores across all items ranging from 0 to 96, with higher scores indicating a greater intensity of somatic complaints.

Validity and reliability. CSI-24 was found to be a valid and reliable tool in previous studies conducted nationally and internationally in which Cronbach's alpha was as high as 0.92. (Kadığ lu, 
Şişman \& Ergün, 2012; Lavigne et al., 2012). In one study, CSI-24 was examined in a sample of 876 children between the ages of 8 and 18 and showed good psychometrics properties with Cronbach's alpha of .88 and was correlated at .99 with the original CSI (CSI-35; Walker et al., 2009). In another study, CSI-24 was applied to a community sample of 233 children ages eight to fifteen years. Cronbach's alpha was .92 (Lavigne et al., 2012). Test-retest reliability over two weeks was .72 (Kadığlu et al., 2012).

Kessler Psychological Distress Scale (K10). The K10 consists of ten items measuring the level of anxiety and depression symptoms experienced by an individual over the past four weeks. This scale is used by the National Center for Health Statistics in the U.S. as part of their National Health Interview Survey. In addition, it was used in national surveys conducted in Australia and Canada. Moreover, the K10 was included in the National Comorbidity Survey Replication (NCS-R) as well as in all of the national surveys in the World Health Organization's World Mental Health (WMH) Initiative (Kessler et al., 2003).

Scoring. The scale includes ten with response option on a five-point Likert scale $(1=$ none of the time, $2=$ a little of the time, $3=$ some of the time, $4=$ most of the time, $5=$ all of the time). Scores can range from 10 to 50. Higher scores indicate increased levels of psychological distress. Previous cut-off points were as follows: a score under 20 indicated no distress; a score of 20-24 indicated mild distress; a score of 25-29 indicated moderate distress; and a score of 30 and over indicated severe distress (Andrews \& Slade, 2001). The cut-off scores determined when the K10 was used in the National Survey of Mental Health and Well-Being conducted in 1997 for the general population of Australia (Andrews \& Slade, 2001; Kessler, Andrews, Colpe, 2002; Kessler et al., 2003). There was a strong association between high scores in the K10 and a current world health Composite International Diagnostic Interview and DSM-IV diagnosis of several 
psychological disorders (e.g., anxiety, affect disorder, and substance disorder). In addition, when compared to the General Health Questionnaire scores as well as the Short Form Survey (SF-12) scores, there was a significantly high correlation (Andrews \& Slade, 2001).

Validity and reliability. K10 was tested in several empirical studies and found to be a valid and reliable screening tool for adolescents as well as for adults. The scale was found to be very precise in differentiating cases from non-cases of severe mental illness (90th-99th percentile range; Kessler et al., 2002). It was administered by the World Health Organization to 30 countries and translated into 35 languages (Kessler et al., 2003). Although the scale originally tested feelings of distress in the past 30 days, this time frame can be increased to include the previous 12 months (Kessler et al., 2003). The K10 was found to be a valid tool for diagnosing multiple psychological diseases according to the DSM-IV criteria, such as depression and anxiety (Fassaert et al., 2009). The K10 had a high sensitivity (0.94) and specificity (0.99) in identifying people who met the CIDI criteria for any current anxiety and affective disorder (Andrews \& Slade, 2001). The scale has shown a good reliability in several studies with internal consistency in Cronbach's alpha of 0.90 and higher (e.g., Kessler, et al., 2003; Thomas, Chan, Scott, Connor, Kelly \& Williams, 2015). However, no data are available on the scale test-retest reliability over time.

\section{Data Collection Procedures}

Both the community center and the mosque were contacted, and letters of support and approval to conduct the study were obtained from both sites after they agreed to allow the use of their facilities for recruitment. After the Institutional Review Board approval was obtained, the researcher contacted the recruitment sites and scheduled the dates to make contact with the adolescents at the two locations. Adolescents arrived with their families to use the services offered by both sites, such as Arabic language classes and school supplies. Potential participants were 
identified by the staff members of the community center and the mosque. If they met the inclusion criteria, the researcher would approached the adolescents and their parents to explain the study and obtain their approval to participate. Once an adolescent and his or her parent agreed to participate in the study, the researcher provided them with the survey packets. The survey packets included copies of each of the instruments and demographic questionnaire. The researcher was available to answer any questions the participants and their parents might have as well as to read and explain the survey items if needed. Participants were asked not to provide any identifying information on the survey and to fill out the survey independently. After the participants were assured of confidentiality, they completed the survey in a quiet room available at each site. The researcher explained to participants and their parents that their participation was voluntary, and they could withdraw from the study at any time. Participants who completed the survey received a $\$ 10$ gift card as an appreciation for their time and effort.

Informed consent and asset documents were completed at the site, and no study materials were sent home. Flyers with the researcher's contact information were distributed at each recruitment site for the participants and their parents, inviting them to call the researcher and inquire about the study or to schedule a meeting on their next visit if they decided to participate in the study. The data collection was completed over a five-month period from June to October of 2016. Data collection continued until 155 surveys were completed. Of the 155 surveys, one was unusable due to missing pages, and four were excluded because adolescents were either younger or older than the age range required for the study. The remaining 150 surveys were used in the current study. 


\section{Data Analysis}

Data were coded and entered into a computer file for the analyses using the latest version of International Business Machines (IBM)-SPSS 22. The data were checked for accuracy by the researcher who verified that the instruments had been entered in the same order and that the input was accurate. The data analyses included four sections. The first section included descriptive statistics to measure the means, standard deviations, and frequencies for the sample. In addition, data were analyzed for symmetry, skewness, kurtosis, and outliers. Second, internal consistency reliability of the instruments for this sample was examined using Cronbach's alpha. Third, Person $r$ correlation coefficient was used to examine the relationships among the study variables: being a bully, being a victim, perceived stress, and physical and psychological health. Furthermore, all hypotheses were tested at the 0.05 level of significance. Inferential statistical analyses were used in the fourth section to test the hypotheses and address the research aims as follows:

1. To address research aim 1, the frequency and numbers of adolescents in each group were calculated. The percentages of bullies and victims were compared to previous national research findings (e.g., Nansel et al., 2001).

$\mathrm{H}_{1}$ : This sample of Arab American adolescents is expected to have a higher prevalence of bullying compared to the national U.S. adolescent samples.

$\mathrm{H}_{2}$ : Arab American adolescents in this sample are more likely to be involved as victims than bullies.

2. To address research aim 2 , correlation tests were conducted. The study variables included were: being a bully or victim and perceived stress.

$\mathrm{H}_{3}$ : Bullying involvement will be positively associated with levels of perceived stress. 
$\mathrm{H}_{4}$ : Adolescents who identify themselves as victims are more likely to perceive higher stress relative to bullies.

3. To address research aim 3, correlation tests were conducted. The study variables included were: being a bully, being a victim, physical health, and psychological health

$\mathrm{H}_{5}$ : More bullying involvement will be associated with higher level of physical complaints and psychological distress.

4. To address research aim 4, multiple regression analysis was conducted. The study variables included were: being a bully and being a victim and were considered as the independent variables, physical and psychological health were considered as dependent variables, and perceived stress was the mediator.

$\mathrm{H}_{6:}$ Perceived stress mediates the relationship between adolescents' bullying involvement and their physical and psychological health.

Past studies have shown that adolescents' experiences in bullying have a significant effect on their physical and psychological health. Thus, it is very important for nursing and other health professionals to understand this effect among a marginalized population, such as Arab American adolescents. Although studies have considered the effect of bullying on adolescents' stress levels, the role of adolescents' perceived stress from bullying (i.e., how they perceived bullying) has not been adequately addressed in the current literature. To fill this research gap, the present study examined the role of perceived stress as a mediator in the association between bullying involvement and health among a sample of Arab American adolescents living in the U.S. 


\section{CHAPTER 4 "RESULTS"}

The purpose of the study was to examine Arab American adolescents' experiences in bullying and perceived stress, the effect of bullying on their physical and psychological health, and the perceived stress as a potential mediating effect of bullying on physical/psychological health. This chapter describes the results of the statistical analyses and is divided into three sections. First, the demographic characteristics of the study sample are described. Second, the results of inferential statistics in regard to bullying involvement, perceived stress, and physical and psychological health among Arab American adolescents are addressed. Third, the statistical analyses of perceived stress as a mediating factor on the relationship of bullying and physical/psychological health are examined.

\section{Descriptive Statistics of the sample}

A total of 150 Arab American adolescents age 12 to 16 participated in the study. Participants were seeking services provided by mosques and community centers located in Southeastern Michigan. All participants provided their demographic information, including age, gender, country-of-origin, the length of time lived in the United States, religion, and school grade. The Participants' responses are summarized in Tables 3 and 4.

Table 3

Frequencies and Percentages of Demographic Variables

\begin{tabular}{llll}
\hline Demographic Variables & & Frequency & Percent \\
\hline Gender & Male & 105 & 70.0 \\
& Female & 45 & 30.0 \\
How you describe & White & 0 & 0 \\
yourself & Middle Eastern & 150 & 100 \\
& African American & 0 & 0 \\
& Multiracial & 0 & 0 \\
& Others & 0 & 0
\end{tabular}




$\begin{array}{llll}\text { School level } & \text { Elementary } & 2 & 1.3 \\ & \text { Middle } & 73 & 48.7 \\ & \text { High } & 75 & 50.0 \\ \text { Religion } & \text { Muslim } & 143 & 95.3 \\ & \text { Christian } & 7 & 4.7 \\ \text { How long you lived in } & \text { Less than 1 year } & 8 & 5.3 \\ \text { the U.S } & \text { 1 to 2 years } & 12 & 8.0 \\ & \text { 3 to 4 years } & 8 & 5.3 \\ & \text { 5 to 10 years } & 30 & 20 \\ & \text { All my life } & 92 & 61.3 \\ \text { Country of origin } & \text { Yemen } & 68 & 45.3 \\ & \text { Lebanon } & 32 & 21.3 \\ & \text { Iraq } & 12 & 8.0 \\ & \text { Syria } & 6 & 4.0 \\ & \text { Jordan } & 9 & 6.0 \\ & \text { Palestine } & 18 & 12.0 \\ & \text { Others } & 5 & 3.3 \\ & & & \\ \text { Taking any medications } & \text { Yes } & 21 & 14.0 \\ & \text { No } & 129 & 86.0 \\ & & & \\ & & & \end{array}$

Table 4

Continuous Demographic Variables, Age and Grade

\begin{tabular}{lrrrrr}
\hline & N & Minimum & Maximum & Mean & $\begin{array}{c}\text { Std. } \\
\text { Deviation }\end{array}$ \\
\hline Age & 150 & 12 & 16 & 13.72 & 1.443 \\
Grade & 150 & 5 & 12 & 8.72 & 1.631 \\
& & & & & \\
\hline
\end{tabular}

The participants' ages ranged from 12 to $16(M=13.72, S D=1.443)$. Their grade level ranged from 5 to $12(M=8.72, S D=1.631)$. The majority of the participants were males $(70.0 \%$, $n=105)$. Half of the participants were in high school $(50.0 \%, n=75)$, and the other half were mostly in middle school $(48.7 \%, n=73)$. All of the participants described themselves as Middle Eastern $(100 \%, n=150)$ and were mainly from Yemen $(45.3 \%, n=68)$, Lebanon $(21.3 \%, n=32)$, and Palestine $(12.0 \%, n=18)$. Approximately $61 \%$ lived in the U.S. their entire life, $20 \%$ lived in 
the U.S. five to ten years, and approximately $20 \%$ lived in the U.S. for less than five years. The majority identified as Muslims $(95.3 \%, n=143)$. None of the participants reported taking any medications at the time of the study $(86 \%, n=129)$.

\section{Descriptive Statistics for Bullying Involvement}

Classrooms and hallways were the most common places where bullying occured (44\% and $42 \%$ respectively), followed by the gym (32.7\%), and the cafeteria $(25.3 \%)$. When Bullies asked why they did bully someone, the most reported reason was because the victim was overweight or obese (21\%). Bullies also reported bullying others because of clothing (15\%), country-of-origin $(6 \%)$, religion $(4 \%)$, and being an immigrant $(10 \%)$. Victims were also asked why they were bullied. Country-of-origin was the most common reported reason among victims (18.7\%), followed by being overweight or obese (18\%), religion $(17.3 \%)$, clothing $(16.7 \%)$, and being an immigrant (8.7\%; see Table 3).

More than half of the adolescents bullied reported their bullying incident to adults $(52.7 \%)$, who were mostly teachers $(24.7 \%)$, followed by parents $(18 \%)$ and school staff $1(5.3 \%)$. Thirtyeight percent of the adolescents reported that the adult they notified took actions to stop the bullying. Talking to the bully was the most common action taken by the notified adult (17.3\%), followed by suspending the bully $(8.0 \%)$, and reporting the bully to the school office $(6.7 \%$; see

Table 5).

Table 5

Descriptive Statistics of Bullying Involvement

\begin{tabular}{llll}
\hline Variables & & Frequency & Percent \\
\hline Where bullying & Classroom & 66 & 44.0 \\
occurred & Hallway & 63 & 42.0 \\
& Gym & 49 & 32.7 \\
& Bathroom & 25 & 16.7 \\
Cafeteria & 38 & 25.3 \\
& School Bus & 15 & 10.0 \\
& Playground & 24 & 16.0
\end{tabular}




\begin{tabular}{|c|c|c|c|}
\hline & $\begin{array}{l}\text { Way to school } \\
\text { Others }\end{array}$ & $\begin{array}{l}9 \\
17\end{array}$ & $\begin{array}{l}6.0 \\
11.3\end{array}$ \\
\hline $\begin{array}{l}\text { Why you bullied } \\
\text { someone }\end{array}$ & $\begin{array}{l}\text { Clothing } \\
\text { Fat } \\
\text { Thin } \\
\text { Health problems } \\
\text { Poor } \\
\text { Immigrant } \\
\text { Country of origin } \\
\text { Religion } \\
\text { Other reasons }\end{array}$ & $\begin{array}{l}23 \\
32 \\
4 \\
7 \\
5 \\
15 \\
9 \\
6 \\
6\end{array}$ & $\begin{array}{l}15.3 \\
21.3 \\
2.7 \\
4.7 \\
3.3 \\
10.0 \\
6.0 \\
4.0 \\
4.0\end{array}$ \\
\hline $\begin{array}{l}\text { Why someone bullied } \\
\text { you }\end{array}$ & $\begin{array}{l}\text { Clothing } \\
\text { Fat } \\
\text { Thin } \\
\text { Health problems } \\
\text { Poor } \\
\text { Immigrant } \\
\text { Country of origin } \\
\text { Religion } \\
\text { Other reasons }\end{array}$ & $\begin{array}{l}25 \\
27 \\
20 \\
9 \\
120 \\
13 \\
28 \\
26 \\
6\end{array}$ & $\begin{array}{l}16.7 \\
18.0 \\
13.3 \\
6.0 \\
6.7 \\
8.7 \\
18.7 \\
17.3 \\
4.0\end{array}$ \\
\hline $\begin{array}{l}\text { Did you tell an adult } \\
\text { about the bullying }\end{array}$ & $\begin{array}{l}\text { Yes } \\
\text { No }\end{array}$ & $\begin{array}{l}79 \\
71\end{array}$ & $\begin{array}{l}52.7 \\
47.3\end{array}$ \\
\hline Who was that adult? & $\begin{array}{l}\text { Parent } \\
\text { Teacher } \\
\text { School staff } \\
\text { Sibling } \\
\text { Friend }\end{array}$ & $\begin{array}{l}27 \\
37 \\
23 \\
2 \\
20\end{array}$ & $\begin{array}{l}18.0 \\
24.7 \\
15.3 \\
1.3 \\
13.3\end{array}$ \\
\hline $\begin{array}{l}\text { Did the adult stop the } \\
\text { bullying? }\end{array}$ & $\begin{array}{l}\text { Yes } \\
\text { No }\end{array}$ & $\begin{array}{l}57 \\
93\end{array}$ & $\begin{array}{l}38.0 \\
62.0\end{array}$ \\
\hline What did the adult do? & $\begin{array}{l}\text { Reported the bully to the } \\
\text { office } \\
\text { Talked to the bully } \\
\text { Suspended the bully } \\
\text { Talked to the bully's } \\
\text { parents } \\
\text { Stopped the bullying } \\
\text { Others } \\
\text { Not applicable }\end{array}$ & $\begin{array}{l}10 \\
26 \\
12 \\
3 \\
5 \\
3 \\
91\end{array}$ & $\begin{array}{l}6.7 \\
17.3 \\
8.0 \\
2.0 \\
3.4 \\
2.0 \\
60.7\end{array}$ \\
\hline
\end{tabular}




\section{Cyberbullying}

Among our sample, $34 \%(n=51)$ reported being cyberbullied in the past year. Twinty one percent $(n=31)$ were cyberbullied one or two times, $9 \%(n=13)$ were cyberbullied fewer than five times, and $5 \%(n=7)$ were cyber bullied more than five times. Text messages $(11 \%, n=17)$ and Instagram $(11 \%, n=16)$ were reported as the most common technology used for cyberbullying, followed by Facebook $(7 \%, n=10)$ and Snapshot $(6 \%, n=9)$. About 18\% knew the person who cyberbullied them $(n=27)$. When adolescents were asked if they cyberbullied someone in the past year, approximately $27 \%(n=40)$ answered yes. Nineteen percent $(n=29)$ bullied someone one or two times, $7 \%(n=10)$ cyberbullied someone fewer than five times, and only one adolescent (1\%) reported cyberbullying someone more than five times. Text messages $(10 \%, n=15)$, Instagram $(9 \%, n=14)$, Snapshot $(6 \%, n=9)$, and Facebook (approximately 5\%, $n=7$ ) were the most frequent forms of technology used to cyberbully someone in the past year (see Table 6).

Table 6

Descriptive Statistics for Cyberbullying

\begin{tabular}{llll}
\hline Variables & & Frequency & Percent \\
\hline $\begin{array}{l}\text { Have you been } \\
\text { cyberbullied in the } \\
\text { past year? }\end{array}$ & Yes & 51 & 34.0 \\
& & 99 & 66.0 \\
How many times has & 1 or 2 times & & \\
someone cyberbullied & 3 to 5 times & 31 & 20.7 \\
you? & More than 5 times & 13 & 8.7 \\
& & 7 & 4.7 \\
What technology was & Text message & 17 & 11.3 \\
used? & Email & 6 & 4.0 \\
& Facebook & 10 & 6.7 \\
& Instagram & 16 & 10.7 \\
& Twitter & 5 & 3.3 \\
& Myspace & 2 & 1.3 \\
& Snapshot & 9 & 6.0
\end{tabular}




\begin{tabular}{llll} 
& Created website & 0 & 0.0 \\
& Blogs & 0 & 0.0 \\
& Chat & 5 & 3.3 \\
& others & 8 & 5.3 \\
Did you know who & Yes & & \\
cyberbullied you? & No & 27 & 18.0 \\
In the past year have & Yes & 123 & 82.0 \\
you cyberbullied & No & & \\
someone? & & 40 & 26.7 \\
& & 110 & 73.3 \\
How many times have & 1 or 2 times & & \\
you cyberbullied & 3 to 5 times & 29 & 19.3 \\
someone? & More than 5 times & 1 & 6.7 \\
& & & 0.7 \\
Using what & Text message & 15 & 10.0 \\
technology? & Email & 3 & 2.0 \\
& Facebook & 7 & 4.7 \\
& Instagram & 14 & 9.3 \\
& Twitter & 6 & 4.0 \\
& Myspace & 0 & 0.0 \\
& Snapshot & 9 & 6.0 \\
& Created website & 0 & 0 \\
& Blogs & 2 & 1.3 \\
& Chat & 5 & 3.3 \\
& others & 4 & 2.7 \\
\hline
\end{tabular}

\section{Scaled Variables}

The surveys were scored using the protocols provided by the scale developers to obtain descriptive information. The results of these analyses were summarized using descriptive statistics as presented in Table 7.

Adolescent Peer Relations Instrument (APRI). Divided into two scales with 18 items each, the APRI-Bully is the scale used to measure adolescents' involvement in bullying as bullies. The instrument scores can range from 18 to 108 , with higher scores indicating more frequent involvement in any form of bullying as a perpetrator. The range of actual scores was from 18 to 69 with a mean score of $24.95(\mathrm{SD}=9.77)$. The APRI-Bully included three subscales: verbal bully, 
social bully, and physical bully. The possible range of scores for each of the three subscales was 6 to 36 . For verbal bully subscale, the actual ranged from 6 to 26 , the mean score for the sample was $8.7(\mathrm{SD}=3.795)$. The actual range of the social bully scores on this subscale was from 6 to 22 . The social bully subscale had a mean score of $8.02(\mathrm{SD}=3.389)$. The range of actual scores on the physical bully subscale ranged from 6 to 22 , with a sample mean score of $8.23(\mathrm{SD}=3.524)$. The APRI-Victim was the scale used to measure adolescents' involvement in bullying as victims. Possible scores on this scale ranged from 18 to 108, with higher scores indicating more frequent involvement in any form of bullying as a victim. The range of actual scores was 18 to 65 and the mean score for the sample was $26.29(\mathrm{SD}=9.757)$. The APRI-Victim included three subscales: verbal victim, social victim, and physical victim. The range of possible scores on all three subscales was 6 to 36 . Verbal victim subscale actual scores ranged from 6 to 36, the mean score for the sample was $9.44(\mathrm{SD}=4.323)$. The social victim subscale actual range of scores was 6 to 22 , the mean score for the sample was $8.70(\mathrm{SD}=3.687)$. For the physical victim subscale, the actual range of scores was 6 to 23 and the mean score for the sample was $8.15(\mathrm{SD}=3.234)$.

Perceived Stress Scale (PSS). This scale was used to measure adolescent's perceived stress. The possible scores range was 0 to 40 , higher scores in this scale indicate more perceived stress. Actual range of scores was 0 to 31 and the mean for the sample was $14.67(\mathrm{SD}=7.953)$.

Children's Somatization Inventory (CSI-24). The scale was used to measure adolescents' physical health. The possible range of scores was 10 to 50 , higher score in this scale indicates a higher intensity of somatic complaints. The actual range of scores was 0 to 57 and the mean for the sample was $14.89(\mathrm{SD}=13.541)$.

Kessler Psychological Distress Scale. The scale was used to measure adolescents' psychological health. The possible range of scores was 0 to 96 where higher score indicates 
increased levels of psychological distress. The actual range of scores was 10 to 37 and the mean

for the sample was $17.07(\mathrm{SD}=6.651)$.

Reliability Testing for the Study Survey

All of the scales used in our study showed acceptable internal consistency and reliability.

The Adolescent Peer Relations Instrument (APRI) consists of two subscales (bully and victim) of 18 items each. The results of Cronbach's alpha was .92 for the bully subscale and .90 for the victim subscale. The Perceived Stress Scale (PSS-10) included ten items and was used in previous studies for students with at least a junior high school education. The study used the scale for adolescents age 12 to 16 in elementary, middle, and high schools. The reliability test results indicated Cronbach's alpha of .83 for the PSS in our sample, .92 for the Children's Somatization Inventory (CSI-24), and .88 for Kessler Psychological Distress Scale (K10).

Table 7

Descriptive Statistics of the Scaled Variables $(N=150)$

\begin{tabular}{|c|c|c|c|c|c|c|}
\hline \multirow[b]{2}{*}{ Scale } & \multicolumn{2}{|c|}{ Actual range } & \multirow[b]{2}{*}{ Mean } & \multirow[b]{2}{*}{ SD } & \multicolumn{2}{|c|}{ Possible Range } \\
\hline & $\begin{array}{l}\text { Minimu } \\
\mathrm{m}\end{array}$ & $\underset{\mathrm{m}}{\operatorname{Maximu}}$ & & & $\begin{array}{c}\text { Minimu } \\
\mathrm{m}\end{array}$ & $\begin{array}{c}\text { Maximu } \\
\mathrm{m}\end{array}$ \\
\hline APRI-Bully & & & & & & \\
\hline Total & 18 & 69 & 24.95 & 9.777 & 18 & 108 \\
\hline Verbal Bully & 6 & 26 & 8.70 & 3.795 & 6 & 36 \\
\hline Social Bully & 6 & 22 & 8.02 & 3.389 & 6 & 36 \\
\hline Physical Bully & 6 & 22 & 8.23 & 3.524 & 6 & 36 \\
\hline APRI-Victim & & & & & & \\
\hline Total & 18 & 65 & 26.29 & 9.757 & 18 & 108 \\
\hline Verbal Victim & 6 & 36 & 9.44 & 4.323 & 1 & 36 \\
\hline Social Victim & 6 & 22 & 8.70 & 3.687 & 1 & 36 \\
\hline Physical Victim & 6 & 23 & 8.15 & 3.234 & 1 & 36 \\
\hline $\begin{array}{l}\text { Perceived stress } \\
\text { scale (PSS) Total }\end{array}$ & 0 & 31 & 14.67 & 7.953 & 0 & 40 \\
\hline
\end{tabular}


Children's

Somatization

Inventory (CSI-24)

57

14.89

13.541

0

96

Total

Kessler

Psychological

10

$37 \quad 17.07$

6.651

10

50

Distress Scale (K10)

Total

\section{Research Hypotheses}

Seven hypotheses were tested in this study. Each hypothesis was tested using inferential statistics. The significance level was set at a p-value equal to or less than 0.05 .

Hypothesis One

This sample of Arab American adolescents is expected to have higher rates of bullying perpetration and victimization compared to national samples from the general youth population in the U.S.

The percentage of the students in our sample reporting that they had bullied someone else at school in the past year at least once was $77.3 \%$. On the other hand, the sample students reported that they had been bullied in school at least once in the past year was $80 \%$. The prevalence of both bullying perpetration and victimization of the study sample was higher than that of nationwide studies (e.g. CDC, 2015; Haynie et al., 2001; Nansel et al, 2001). Only 20\% of our sample reported no involvement in bullying. These findings support the hypothesis that Arab American adolescents were more involved in bullying, either as bullies or victims, compared to the general population (see Table 8). 
Table 8

Percentages of Bullying Subgroups

\begin{tabular}{lll}
\hline Category & Frequency & Percent \\
\hline Bullies & 116 & 77.3 \\
Victims & 120 & 80 \\
Uninvolved & 30 & 20 \\
\hline
\end{tabular}

In terms of cyberbullying (see Table 6$), 27 \%(n=40)$ of adolescents reported that they cyberbullied someone in the past year, relative to the national findings on cyberbullies $(10.9 \%)$ (Kowalski et al., 2012). In addition, 34\% $(n=51)$ of our sample reported being cyberbullied by someone during the past year, which is more than twice the national findings $(17.3 \%$; Kowalski et al., 2012).

Hypothesis Two

Arab American adolescents in this sample are more likely to be victims than bullies.

As indicated in Table 8, the percentage of Arab American adolescents involved in bullying, either as bullies or victims were $77.3 \%$ and $80 \%$ respectively. The results suggested that Arab American adolescents in the study sample were involved in bullying, as both bullies and victims in a similar frequency.

Hypothesis Three

Bullying will have a positive relationship with levels of perceived stress.

Pearson's correlation was used to examine the relationship between the scaled variables of bullying involvement as a bully (APRI-bully) or a victim (APRI-victim) and perceived stress. As Table 9 shows, the correlation between involvement of bullying as a bully (APRI-bully) and perceived stress was not significant $(\mathrm{r}=.08, \mathrm{p}=.306)$. In addition, no significant relationship was found between being involved as a bully in all forms of bullying and perceived stress. Table 9 
summarizes the findings of the correlation between bullying involvement as a bully using total scores, subscales, and perceived stress.

Table 9

Pearson's Correlation for APRI-Bully Total Score, Verbal Bully, Social Bully, Physical Bully and Perceived Stress $(N=150)$

\begin{tabular}{llllcc}
\hline & $\begin{array}{c}\text { APRI- } \\
\text { Bully } \\
\text { Total }\end{array}$ & Verbal & Social & Physic & Perceived \\
& & Bully & al & Stress \\
& Bcore & & & Bully & Total \\
& 1.00 & & & Score \\
\hline APRI-Bully Total Score & $0.91^{* *}$ & 1.00 & & \\
Verbal Bully & $0.91^{* *}$ & $0.70^{* *}$ & 1.00 & & \\
Social Bully & $0.93^{* *}$ & $0.76^{* *}$ & $0.80^{* *}$ & 1.00 & \\
Physical Bully & 0.08 & 0.09 & 0.10 & 0.03 & 1.00 \\
Perceived Stress Total & & & & \\
Score & & & & \\
\hline$* *$ Correlation is significant at the 0.01 level (2-tailed).
\end{tabular}

On the other hand, the correlation between involvement of bullying as a victim (APRIvictim) and perceived stress was positive and significant $(\mathrm{r}=.16, p=.045)$. When Pearson's correlation was used to examine the correlation between involvement of bullying as a victim subscales (verbal, social, and physical) and the perceived stress total score, the relationship was significant and positive only for the victims of social bullying $(\mathrm{r}=.20, p=.014)$. More frequent social bullying is correlated with higher scores on the perceived stress scale. However, being involved as a victim in verbal bullying and physical bullying was not significantly correlated with perceived stress total scores: $(\mathrm{r}=.13, p=.09)$ and $(\mathrm{r}=.08, p=.30)$ respectively. Table 10 summarizes the findings of the correlation of bullying involvement as a victim total scores and subscales. 
Table10

Pearson Correlation for APRI-Victim Total Score, Verbal Victim, Social Victim, Physical Victim and Perceived Stress $(N=150)$

\begin{tabular}{lrrrrr}
\hline & $\begin{array}{c}\text { APRI-victim } \\
\text { Total Score }\end{array}$ & $\begin{array}{c}\text { Verbal } \\
\text { Victim }\end{array}$ & $\begin{array}{c}\text { Social } \\
\text { Victim }\end{array}$ & $\begin{array}{c}\text { Physic } \\
\text { al } \\
\text { Victim }\end{array}$ & $\begin{array}{c}\text { Perceived } \\
\text { Stress Total } \\
\text { Score }\end{array}$ \\
\hline $\begin{array}{l}\text { APRI-victim } \\
\text { total scores } \\
\text { Verbal Victim }\end{array}$ & 1.00 & & & & \\
Social Victim & $.903^{* *}$ & 1.00 & & & \\
$\begin{array}{l}\text { Physical } \\
\text { Victim }\end{array}$ & $.889^{* *}$ & $.726^{* *}$ & 1.00 & & \\
$\begin{array}{l}\text { Perceived } \\
\text { Stress Total } \\
\text { Score }\end{array}$ & $.796^{* *}$ & $.561^{* *}$ & $.572^{* *}$ & 1.00 & \\
\hline
\end{tabular}

*. Correlation is significant at the 0.05 level (2-tailed).

**. Correlation is significant at the 0.01 level (2-tailed).

In terms of cyberbullying, being a bully or a victim of cyberbullying was not significantly related to perceived stress $(\mathrm{r}=.01, p=.920 ; \mathrm{r}=-.07, \mathrm{p}=.388$, respectively; see Table 11$)$.

Table 11

Pearson's Correlation for Cyberbullying and Perceived Stress

\begin{tabular}{lll}
$\begin{array}{l}\text { Perceived Stress } \\
\text { Total Score }\end{array}$ & $\begin{array}{l}\text { Have you ever been } \\
\text { cyberbullied by } \\
\text { someone }\end{array}$ & $\begin{array}{l}\text { Have you } \\
\text { cyberbullied } \\
\text { someone }\end{array}$ \\
\hline
\end{tabular}

Perceived Stress Total 1.00

Score

Have you ever been $\quad-.071 \quad 1.00$

cyberbullied by

someone

$\begin{array}{llll}\text { Have you cyberbullied } \quad .008 & .681^{* *} & 1.00\end{array}$

someone

*. Correlation is significant at the 0.05 level (2-tailed).

**. Correlation is significant at the 0.01 level (2-tailed). 


\section{Hypothesis Four}

Adolescents who are victims are more likely to perceive higher stress compared to bullies.

As illustrated in Table 9, there was no significant relationship between being involved as a bully and perceived stress. The correlation between involvement in bullying as a bully and perceived stress was not significant $(\mathrm{r}=.08, p=.306)$. On the other hand, the relationship between involvement in bullying as a victim and perceived stress was positive and significant $(\mathrm{r}=.16, p=$ .045 ; see Table 10).

Hypothesis Five

More bullying involvement is positively correlated with adolescents' physical complaints and psychological distress

To examine the relationship between bullying involvement and physical health, Pearson's correlation was first used to test the relationship between being involved in bullying as a bully and physical health (CSI-total score). Pearson's correlation was performed to test the relationship between being involved in bullying as a victim and physical health (CSI-total score).

The results of the Pearson's correlation test for adolescents' involvement as bullies and their physical complaints is presented in Table 11. The correlation was positive and significant ( $\mathrm{r}$ $=.560, \mathrm{p}=.000$ ) between bullying involvement as bullies (APRI-bully total score) and physical complaints (CSI-total score). The correlation was also positive and significant among the three bully subscales. Verbal bully $(\mathrm{r}=.435, p=.000)$, social bully $(\mathrm{r}=.549, p=.000)$, and physical bully $(\mathrm{r}=.558, p=.000)$. Adolescents' involvement in bullying in all forms as bullies was significantly associated with their physical complaints. More frequent bullying of others was positively and significantly associated with higher intensity of physical complaints (see Table 12). 
Table 12

Pearson's Correlation for APRI-Bully Total Score, Verbal bully, Social Bully, Physical Bully and Physical Health (CSI-Total Score) (N=150)

\begin{tabular}{llllll}
\hline & $\begin{array}{l}\text { APRI- } \\
\text { bully } \\
\text { Total } \\
\text { Score }\end{array}$ & $\begin{array}{l}\text { Verbal } \\
\text { Bully }\end{array}$ & $\begin{array}{l}\text { Social } \\
\text { Bully }\end{array}$ & $\begin{array}{l}\text { Physical } \\
\text { Bully }\end{array}$ & $\begin{array}{l}\text { CSI- } \\
\text { Total } \\
\text { Score }\end{array}$ \\
\hline $\begin{array}{l}\text { APRI-bully Total } \\
\text { Score }\end{array}$ & 1.00 & & & \\
Verbal Bully & $.904^{* *}$ & 1.00 & & & \\
Social Bully & $.906^{* *}$ & $.703^{* *}$ & 1.00 & & \\
Physical Bully & $.929^{* *}$ & $.756^{* *}$ & $.795^{* *}$ & 1.00 & \\
CSI-Total Score & $.560^{* *}$ & $.435^{* *}$ & $.549^{* *}$ & $.558^{* *}$ & 1.00 \\
\hline
\end{tabular}

*. Correlation is significant at the 0.05 level (2-tailed).

**. Correlation is significant at the 0.01 level (2-tailed).

The results of Pearson correlation tests for adolescents' involvement as victims and their physical health are presented in Table 10. The correlation was positive and significant $(\mathrm{r}=.47, \mathrm{p}$ $=.000$ ) between adolescents' involvement in bullying as victims and their physical complaints. The correlation was also positive and significant among the three victim subscales. Verbal victim $(\mathrm{r}=.31, \mathrm{p}=.000)$, social victim $(\mathrm{r}=.43, p=.000)$, and physical victim $(\mathrm{r}=.52, p=.000)$ Adolescents' involvement in bullying in all forms as victims was significantly and positively associated with their physical complaints. More frequent victimization was positively and significantly associated with higher intensity of physical complaints (see Table 13). 
Table 13

Pearson's Correlation for APRI-Victim Total Score, Verbal Victim, Social Victim, Physical Victim and Physical Health (CSI-Total Score) $(N=150)$

\begin{tabular}{lllcc}
\hline APRI- & Verbal & Social & Physical & CSI- \\
victim & Victim & Victim & Victim & Total \\
& & & & Score \\
& & & & \\
\hline
\end{tabular}

\begin{tabular}{|c|c|c|c|c|c|}
\hline APRI-victim & 1.00 & & & & \\
\hline $\begin{array}{l}\text { Verbal } \\
\text { Victim }\end{array}$ & $.903^{* *}$ & 1.00 & & & \\
\hline Social Victim & $.889^{* *}$ & $.726^{* *}$ & 1.00 & & \\
\hline $\begin{array}{l}\text { Physical } \\
\text { Victim }\end{array}$ & $.796^{* *}$ & $.561^{* *}$ & $.572^{* *}$ & 1.00 & \\
\hline $\begin{array}{l}\text { CSI-Total } \\
\text { Score }\end{array}$ & $.469^{* *}$ & $.309^{* *}$ & $.426^{* *}$ & $.516^{* *}$ & 1.00 \\
\hline
\end{tabular}

*. Correlation is significant at the 0.05 level (2-tailed).

**. Correlation is significant at the 0.01 level (2-tailed).

To examine the relationship between bullying involvement and psychological health, Pearson's correlation was first used to test the relationship between being involved in bullying as a bully and psychological health (K10-total score). Pearson's correlation was then performed to test the relationship between being involved in bullying as a victim and psychological health (K10total score).

The results of Pearson's correlation tests for adolescents' involvement as bullies and their psychological health are presented in Table 13 The correlation was positive and significant $(\mathrm{r}=$ $.37, p=.000$ ) between adolescent involvement in bullying as bullies and their psychological distress. The correlation was also positive and significant among the three bully subscales: verbal 
bully $(\mathrm{r}=.24, p=.004)$, social bully $(\mathrm{r}=.44, p=.000)$, and physical bully $(\mathrm{r}=.34, p=.000)$. Adolescents' involvement in bullying in all forms as bullies was significantly associated with their psychological distress. More frequent perpetration was positively and significantly associated with increased levels of psychological distress (see Table 14).

Table 14

Pearson's Correlation for APRI-Bully Total Score, Verbal Bully, Social Bully, Physical Bully and Psychological Health (K10-Total Score) $(N=150)$

\begin{tabular}{|c|c|c|c|c|c|}
\hline & $\begin{array}{l}\text { APRI-bully } \\
\text { Total Score }\end{array}$ & $\begin{array}{l}\text { Verbal } \\
\text { Bully }\end{array}$ & $\begin{array}{l}\text { Social } \\
\text { Bully }\end{array}$ & $\begin{array}{c}\text { Physical } \\
\text { Bully }\end{array}$ & K10 Total \\
\hline $\begin{array}{l}\text { APRI-bully } \\
\text { Total Score }\end{array}$ & 1.00 & & & & \\
\hline Verbal Bully & $.904^{* *}$ & 1.00 & & & \\
\hline Social Bully & $.906^{* *}$ & $.703^{* *}$ & 1.00 & & \\
\hline Physical Bully & $.929^{* *}$ & $.756^{* *}$ & $.795^{* *}$ & 1.00 & \\
\hline $\begin{array}{l}\text { K10 Total } \\
\text { Score }\end{array}$ & $.366^{* *}$ & $.236^{* *}$ & $.437^{* *}$ & $.339^{* *}$ & 1.00 \\
\hline
\end{tabular}

The results of Pearson's correlation tests for adolescents' involvement as victims and their psychological health are presented in Table 15. The correlation was positive and significant $(\mathrm{r}=.39, p=.000)$ between adolescents' involvement in bullying as victims and their psychological distress. The correlation was also positive and significant among the three victim subscales: verbal victim $(\mathrm{r}=.25, p=.002)$, social victim $(\mathrm{r}=.41, p=.000)$, and physical victim $(\mathrm{r}$ $=.37, p=.000)$. Adolescents' involvement in bullying in all forms as victims was significantly and positively associated with their psychological distress. More frequent victimization was 
positively and significantly associated with increased levels of psychological distress (see Table $15)$.

Table 15

Pearson's Correlation for APRI-Victim Total Score, Verbal Victim, Social Victim, Physical Victim and Psychological Health (K10-Total Score) $(N=150)$

\begin{tabular}{|c|c|c|c|c|c|}
\hline & $\begin{array}{l}\text { APRI- } \\
\text { Victim } \\
\text { Total } \\
\text { Score }\end{array}$ & $\begin{array}{l}\text { Verbal } \\
\text { Victim }\end{array}$ & $\begin{array}{l}\text { Social } \\
\text { Victim }\end{array}$ & $\begin{array}{l}\text { Physical } \\
\text { Victim }\end{array}$ & $\begin{array}{l}\text { K10 Total } \\
\text { Score }\end{array}$ \\
\hline $\begin{array}{l}\text { APRI- } \\
\text { Victim } \\
\text { Total score }\end{array}$ & 1.00 & & & & \\
\hline $\begin{array}{l}\text { Verbal } \\
\text { Victim }\end{array}$ & $.903^{* *}$ & 1.00 & . & & \\
\hline $\begin{array}{l}\text { Social } \\
\text { Victim }\end{array}$ & $.889^{* *}$ & $.726^{* *}$ & 1.00 & & \\
\hline $\begin{array}{l}\text { Physical } \\
\text { Victim }\end{array}$ & $.796^{* *}$ & $.561^{* *}$ & $.572^{* *}$ & 1.00 & \\
\hline $\begin{array}{l}\text { K10 Total } \\
\text { Score }\end{array}$ & $.389^{* *}$ & $.250^{* *}$ & $.413^{* *}$ & $.368^{* *}$ & 1.00 \\
\hline
\end{tabular}

Regarding cyberbullying, the results of the Pearson's correlation test for adolescents' involvement as victims or bullies in cyberbullying and their physical and psychological health are presented in Table 16. The correlation was positive and significant between adolescents' involvement in cyberbullying as victims and their physical complaints, as well as their psychological distress $(\mathrm{r}=.31, p=.000 ; \mathrm{r}=.33, p=.000$ respectively). Adolescents' involvement in cyberbullying as bullies was significantly and positively associated with their physical complaints and psychological distress $(\mathrm{r}=.405, p=.000 ; \mathrm{r}=.28, p=.001$, respectively). More cyberbullying involvement was positively and significantly associated with more somatic complaints and psychological distress (see Table 16). 
Table 16

Pearson's Correlation for Cyberbullying, Physical Health and Physiological Health

\begin{tabular}{cccc}
$\begin{array}{c}\text { Have you ever been } \\
\text { cyberbullied by } \\
\text { someone }\end{array}$ & $\begin{array}{c}\text { Have you } \\
\text { cyberbullie } \\
\text { d someone }\end{array}$ & CSITOT & K10TOT \\
\hline
\end{tabular}

\begin{tabular}{|c|c|c|c|c|}
\hline $\begin{array}{l}\text { Have you ever been } \\
\text { cyberbullied by } \\
\text { someone }\end{array}$ & 1.00 & & & \\
\hline $\begin{array}{l}\text { Have you } \\
\text { cyberbullied } \\
\text { someone }\end{array}$ & $.681^{* *}$ & 1.00 & & \\
\hline CSI-total score & $.311^{* *}$ & $.395^{* *}$ & 1.00 & \\
\hline K10-total score & $.328^{* *}$ & $.280^{* *}$ & $.550^{* *}$ & 1.00 \\
\hline
\end{tabular}

*. Correlation is significant at the 0.05 level (2-tailed).

$* *$. Correlation is significant at the 0.01 level (2-tailed).

Hypothesis Six

The relationship between adolescents' bullying involvement and their physical and psychological health is mediated by their perceived stress.

To examine if perceived stress mediates the relationship between bullying involvement and health outcomes, figure 6 , a mediation analysis was performed to identify if perceived stress mediates the relationship between:

1- Bullying involvement as a bully and physical complaints

2- Bullying involvement as a bully and psychological distress

3- Bullying involvement as a victim and physical complaints

4- Bullying involvement as a victim and psychological distress 


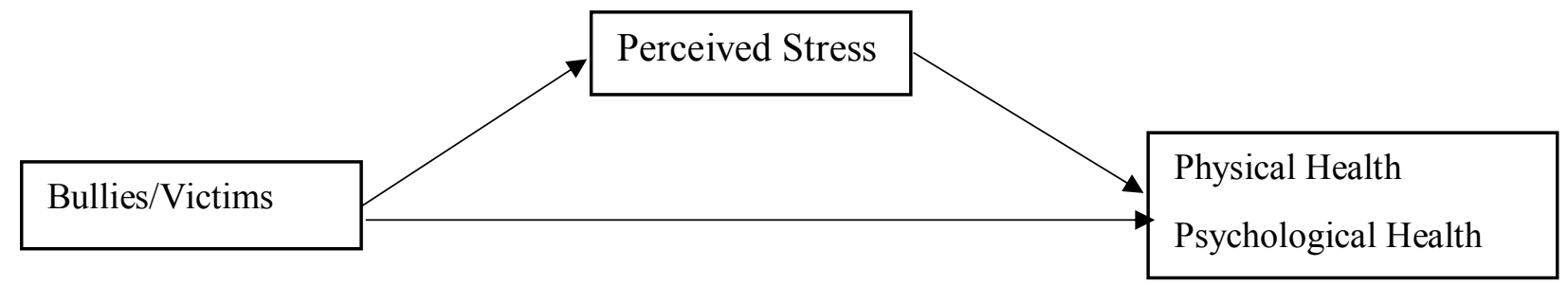

Figure 6. Variables and relationships examined through mediation analysis

Four steps were used to determine if the relationship between bullying involvement as a bully and physical complaints was mediated by adolescents' perceived stress. The following is a description of each of the four steps:

1- Determine if the relationship between bullying involvement as a bully (independent variable) and the physical health (dependent variable) is statistically significant. If a significant relationship exists between the two variables, Step 2 can be completed.

2- Determine if the relationship between bullying involvement as a bully (independent variable) and perceived stress (mediator variable) is statistically significant. If a significant relationship exists between the two variables, Step 3 can be completed.

3- Determine if the relationship between perceived stress (mediator variable) and physical health (dependent variable) is statistically significant. If a statistically significant relationship is found, then Step 4 can be completed.

4- Holding perceived stress (mediator variable) constant, determine if the relationship between bullying involvement as a bully (independent variable) and physical health (dependent variable) is not significant (zero). If the result is not significant, then the mediator variable is mediating the relationship between bullying involvement as a bully (independent variable) and physical health (dependent variable). If the amount of variable explained in Step 1 is reduced in Step 4 but remains statistically significant, then the 
mediator variable may be partially mediating the relationship between the independent and dependent variable.

On Step 1 of the mediation analysis, a statistically significant relationship was found between being a bully and physical complaints $\left(\mathrm{R}^{2}=.13, p=.000\right)$. The relationship between being a bully and perceived stress (mediator) was not significant $\left(\mathrm{R}^{2}=.01, p=.306\right)$. Consequently, the mediation relationship was not evident in the statistics. As a result, Steps 3 and 4 were not completed.

Four steps were used to determine if the relationship between bullying involvement as a bully and psychological distress was mediated by adolescents' perceived stress. A description of each of the four steps follows:

1- Determine if the relationship between bullying involvement as a bully (independent variable) and psychological distress (dependent variable) is statistically significant. If a significant relationship exists between the two variables, Step 2 can be completed.

2- Determine if the relationship between bullying/involvement as a bully (independent variable) and perceived stress (mediator variable) is statistically significant. If a significant relationship exists between the two variables, Step 3 can be completed.

3- Determine if the relationship between perceived stress (mediator) and psychological distress (dependent variable) is statistically significant. If a statistically significant relationship is found, then Step 4 can be completed.

4- Holding perceived stress (mediator) constant, determine if the relationship between bullying involvement as a bully (independent variable) and psychological distress (dependent variable) is not significant (zero). If the result is not significant, then the mediator variable is mediating the relationship between the bullying involvement as a bully 
(independent variable) and psychological distress (dependent variable). If the amount of variable explained in Step 1 is reduced in Step 4 but remains statistically significant, then the mediator variable may be partially mediating the relationship between the independent and dependent variable.

For step 1 of the mediation analysis, a statistically significant relationship was found between being a bully and psychological health $\left(\mathrm{R}^{2}=.13, p=.000\right)$. However, the relationship between being a bully and perceived stress (mediator) was not significant $\left(\mathrm{R}^{2}\right.$ $=.01, p=.306)$. Consequently, the mediation relationship was not supported and evident in the statistics. As a result, Steps 3 and 4 were not completed.

Four steps were used to determine if the relationship between bullying involvement as a victim and physical complaints was mediated by adolescents' perceived stress. An explanation of the four steps follows:

1- Determine if the relationship between bullying involvement as a victim (independent variable) and physical complaints (independent variable) is statistically significant. If a significant relationship exists between the two variables, Step 2 can be completed.

2- Determine if the relationship between bullying involvement as a victim (independent variable) and perceived stress (mediator) is statistically significant. If a significant relationship exists between the two variables, Step 3 can be completed.

3- Determine if the relationship between perceived stress (mediator) and physical complaints (dependent variable) is statistically significant, if a statistically significant relationship is found, then Step 4 can be completed.

4- Holding perceived stress (mediator) constant, determine if the relationship between the independent variable (bullying involvement as a victim) and the dependent variable 
(physical complaints) is not significant (zero). If the result is not significant, then perceived stress (mediator) is mediating the relationship between bullying involvement as a victim (independent variable) and physical complaints (dependent variable). If the amount of variable explained in Step 1 is reduced in Step 4 but remains statistically significant, then the mediator may be partially mediating the relationship between the independent and dependent variable.

On Step 1 of the mediation analysis, a statistically significant relationship was found between being a victim and physical complaints $\left(\mathrm{R}^{2}=.22, p=.000\right)$. In Step 2, the relationship between being a victim and perceived stress (mediator) was significant $\left(\mathrm{R}^{2}=.03, p=.045\right)$. On Step 3, the relationship between perceived stress (mediator) and physical complaints (dependent variable) was significant $\left(\mathrm{R}^{2}=.08, p=.000\right)$. After holding perceived stress (mediator) constant, the relationship between being a victim and physical complaints was statistically significant $\left(\mathrm{R}^{2}=\right.$ $.26, p=.000$ ). The amount of explained variance in this relationship increased from $22 \%$ in Step 1 to $26 \%$ in Step 4 . The relationship between being a victim and physical complaints remained statistically significant when perceived stress (mediator) was included in the analysis. The partial $t$ tests indicated a decrease in the $t$ score value for being a victim (independent variable) from 6.453 to 6.046 when perceived stress was included as a mediator. This indicates that perceived stress partially mediates the relationship between being a victim and physical complaints (see Figure 7). 


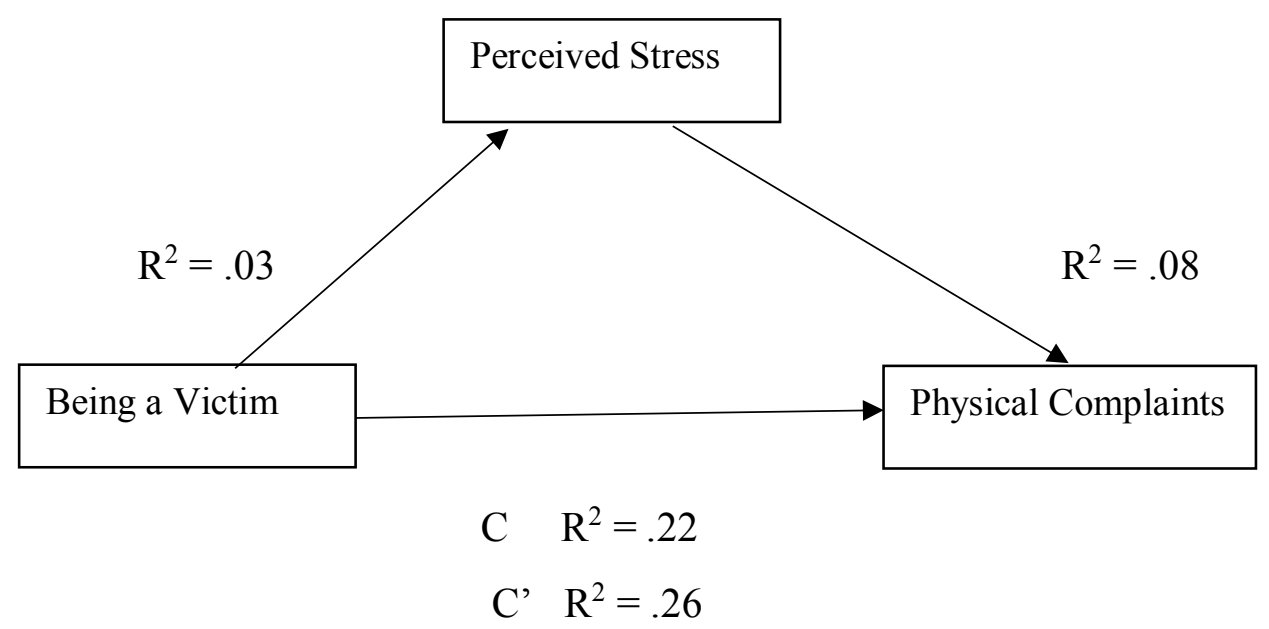

Figure 7. Mediation Model - Being a Victim and Physical Complaints as Mediated by Perceived Stress

Four steps were used to determine if the relationship between bullying involvement as a victim and psychological distress was mediated by adolescents' perceived stress. A description of each of the four steps follows:

1- Determine if the relationship between bullying involvement as a victim (independent variable) and psychological distress (dependent variable) is statistically significant. If a significant relationship exists between the two variables, Step 2 can be completed.

2- Determine if the relationship between bullying involvement as a victim (independent variable) and perceived stress (mediator) is statistically significant. If a significant relationship exists between the two variables, Step 3 can be completed.

3- Determine if the relationship between the perceived stress (mediator) and psychological distress (dependent variable) is statistically significant. If a statistically significant relationship is found, then Step 4 can be completed.

4- Holding perceived stress (mediator) constant, determine if the relationship between the bullying involvement as a victim (independent variable) and psychological distress 
(dependent variable) is not significant (zero). If the result is not significant, then the mediator variable is mediating the relationship between bullying involvement as a victim (independent variable) and psychological distress (dependent variable). If the amount of variable explained in Step 1 is reduced in Step 4 but remains statistically significant, then the mediator variable may be partially mediating the relationship between the independent and dependent variable.

For step 1 of the mediation analysis, a statistically significant relationship was found between being a victim and psychological distress $\left(\mathrm{R}^{2}=.15, p=.000\right)$. In step 2 , the relationship between being a victim and perceived stress (mediator) was significant $\left(\mathrm{R}^{2}=\right.$ $.03, p=.045$ ). In Step 3, the relationship between perceived stress (mediator) and psychological distress (dependent variable) was significant $\left(\mathrm{R}^{2}=.05, p=.007\right)$. After holding perceived stress (mediator) constant, the relationship between being a victim and psychological distress was statistically significant $\left(\mathrm{R}^{2}=.18, p=.000\right)$. The amount of explained variance in this relationship increased from $15 \%$ in Step 1 to $18 \%$ in Step 4 . The relationship between being a victim and psychological distress remained statistically significant when perceived stress (mediator) was included in the analysis. The partial t tests indicated a decrease in the $t$ score value for being a victim (independent variable) from 5.130 to 4.775 when perceived stress was included as a mediator. This indicates that perceived stress partially mediates the relationship between being a victim and psychological health (see Figure 8). 


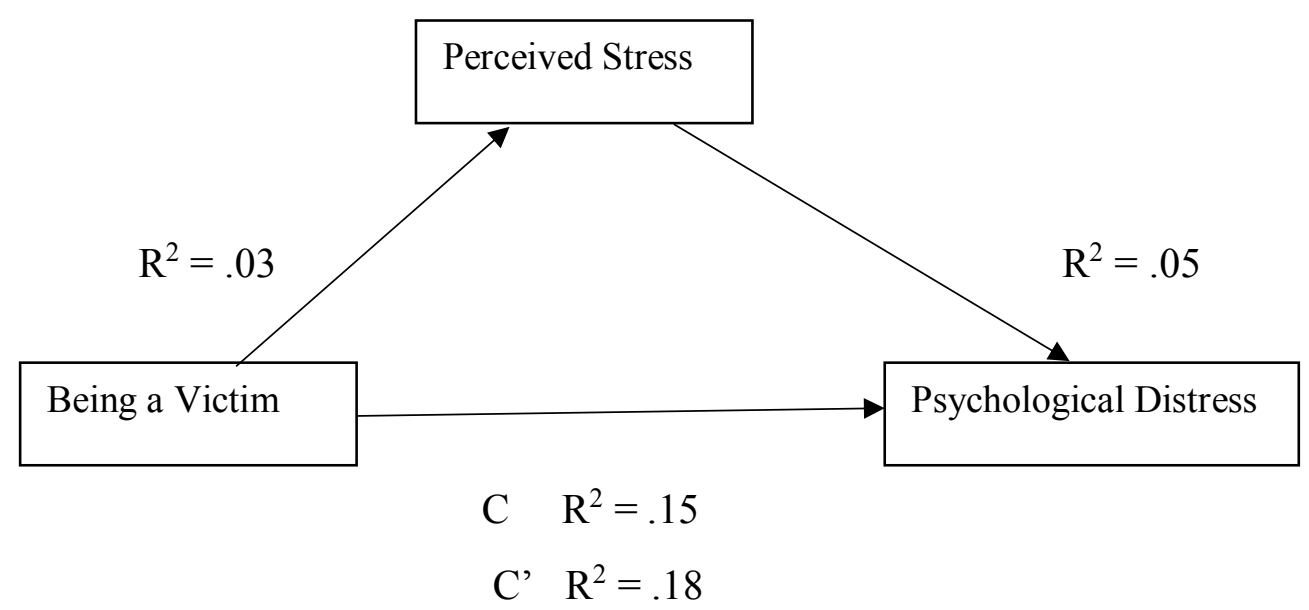

Figure 8. Mediation Model - Being a Victim and Psychological Distress as Mediated by Perceived Stress

\section{Gender Differences}

Male adolescents $(\mathrm{M}=26.72, \mathrm{SD}=.10 .829)$ reported significantly more frequent involvement in bullying as bullies than females $(\mathrm{M}=20.82, \mathrm{SD}=4.648 ; \mathrm{t}=4.65, p<0.000)$. In fact, males were significantly more involved as bullies than females in verbal bullying $(\mathrm{t}=3.896$, $p=.000)$, social bullying $(\mathrm{t}=2.730, p=.007)$, and physical bullying $(\mathrm{t}=6.078, p=.000)$. Males $(\mathrm{M}=26.60, \mathrm{SD}=9.354)$ and females $(\mathrm{M}=25.56, \mathrm{SD}=10.714)$ did not differ significantly on victimization $(\mathrm{t}=.599, p=.550)$. When forms of victimization were compared between males and females, only physical victimization was significantly different between the two groups $(\mathrm{t}=3.382$, $p=.001)$. In sum, males were more involved in physical victimization that females (see Table 17).

Table 17

Gender Differences in Bullying Experiences

\begin{tabular}{llrrrrrc}
\hline & Gender & $\mathrm{N}$ & Mean & $\begin{array}{c}\text { Std. } \\
\text { Deviation }\end{array}$ & $\begin{array}{c}\text { Std. Error } \\
\text { Mean }\end{array}$ & $\begin{array}{c}\mathrm{t} \\
\text { value }\end{array}$ & P value \\
\hline APRI-bully & Male & 105 & 26.72 & 10.829 & 1.057 & 4.670 & $<$ \\
Total Score & Female & 45 & 20.82 & 4.648 & .693 & & $0.0001^{* *}$ \\
& & & & & & & \\
Verbal Bully & Male & 105 & 9.30 & 4.208 & .411 & 3.896 & $.000^{* *}$ \\
& Female & 45 & 7.31 & 2.021 & .301 & &
\end{tabular}




\begin{tabular}{|c|c|c|c|c|c|c|c|}
\hline Social Bully & $\begin{array}{l}\text { Male } \\
\text { Female }\end{array}$ & $\begin{array}{r}105 \\
45\end{array}$ & $\begin{array}{l}8.42 \\
7.09\end{array}$ & $\begin{array}{l}3.731 \\
2.172\end{array}$ & $\begin{array}{l}.364 \\
.324\end{array}$ & 2.730 & $.007 * *$ \\
\hline Physical & Male & 105 & 9.01 & 3.879 & .379 & 6.078 & $.000 * *$ \\
\hline Bully & Female & 45 & 6.42 & 1.305 & .195 & & \\
\hline APRI-victim & Male & 105 & 26.60 & 9.354 & .913 & .599 & .550 \\
\hline total score & Female & 45 & 25.56 & 10.714 & 1.597 & & \\
\hline Verbal & Male & 105 & 9.35 & 3.549 & .346 & -.314 & .754 \\
\hline victim & Female & 45 & 9.64 & 5.785 & .862 & & \\
\hline Social & Male & 105 & 8.64 & 3.323 & .324 & -.279 & \\
\hline Victim & Female & 45 & 8.84 & 4.462 & .665 & & .781 \\
\hline Physical & Male & 105 & 8.61 & 3.548 & .346 & 3.382 & $.001 * *$ \\
\hline Victim & Female & 45 & 7.07 & 1.993 & .297 & & \\
\hline
\end{tabular}

*. Correlation is significant at the 0.05 level (2-tailed).

**. Correlation is significant at the 0.01 level (2-tailed).

Perceived stress was examined among Arab American adolescent males and females (see Table 14). Females $(\mathrm{M}=16.76, \mathrm{SD}=7.693)$ perceived significantly more stress than males $(\mathrm{M}=$ 13.77, $\mathrm{SD}=.775 ; \mathrm{t}=-2.131, p=.035)$. However, males and females did not differ significantly in terms of physical complaints $(\mathrm{t}=-.080, p=.936)$ and psychological distress $(\mathrm{t}=-.446, p=.656$; see Table 18).

Table 18 Physical Complaints and Psychological Distress among Males and Females

\begin{tabular}{|c|c|c|c|c|c|c|c|}
\hline & Gender & $\mathrm{N}$ & Mean & $\begin{array}{c}\text { Std. } \\
\text { Deviation }\end{array}$ & $\begin{array}{l}\text { Std. } \\
\text { Error } \\
\text { Mean }\end{array}$ & $\mathrm{t}$ value & $\mathrm{P}$ value \\
\hline $\begin{array}{l}\text { Perceived } \\
\text { stress- } \\
\text { total score }\end{array}$ & $\begin{array}{c}\text { Male } \\
\text { Female }\end{array}$ & $\begin{array}{r}105 \\
45\end{array}$ & $\begin{array}{l}13.77 \\
16.76\end{array}$ & $\begin{array}{l}7.929 \\
7.693\end{array}$ & $\begin{array}{r}.774 \\
1.147\end{array}$ & -2.131 & $.035 *$ \\
\hline $\begin{array}{l}\text { CSI-total } \\
\text { score }\end{array}$ & $\begin{array}{l}\text { Male } \\
\text { Female }\end{array}$ & $\begin{array}{r}105 \\
45\end{array}$ & $\begin{array}{l}14.83 \\
15.02\end{array}$ & $\begin{array}{l}13.848 \\
12.948\end{array}$ & $\begin{array}{l}1.351 \\
1.930\end{array}$ & -.080 & .936 \\
\hline & Male & 105 & 16.91 & 6.541 & .638 & -.446 & .656 \\
\hline
\end{tabular}




$\begin{array}{llrrrrrr}\begin{array}{l}\text { K10-total } \\ \text { score }\end{array} & \text { Female } & 45 & 17.44 & 6.959 & 1.037 & \\ \text { TOTBPSS } & \text { Male } & 105 & 381.08 & 282.870 & 27.605 & -1.096 & .275 \\ & & 45 & 438.04 & 311.578 & 46.447 & & \\ & \text { Female } & & & & & & \\ & \end{array}$

*. Correlation is significant at the 0.05 level (2-tailed).

**. Correlation is significant at the 0.01 level (2-tailed).

\section{Summary}

The results of the statistical analyses used to describe the sample and test the hypotheses

have been presented in this chapter. A discussion of the findings, implications for nursing, and recommendations for further research are presented in chapter 5. 


\section{CHAPTER 5 "DISCUSSION, IMPLICATIONS, AND RECOMMENDATIONS"}

In this study, 150 Arab American adolescents age 12 to 16 were included. The majority of the study participants were from Yemen (45\%), followed by Lebanon (21\%), and Palestine (12\%). The study sample is representative of the Arab American population residing in the Detroit metropolitan area. A previous survey (Baker, et al., 2004) indicated that Arab Americans in the Detroit area are predominately from Lebanon/Syria (37 \%), followed by Iraq (35\%), Palestine/Jordan (12\%), and Yemen (9\%). However, the data collection in this study was conducted in an area that is considered home to large numbers of Yemeni and Lebanese immigrants (Abraham, 1983; Baker et al., 2004; Hassoun, 2005). The majority of the study sample were Muslim with U.S. citizenship, which reflects the larger Arab American community in southeast Michigan (Hassoun, 2005; Nydell, 2012).

\section{Bullying among Arab American Adolescents}

Bullying prevalence in our sample is much higher than other national data. The percentage of students reporting that they had bullied someone else at least once at school in the past year was $77.3 \%$. This percentage is almost six times higher than studies that looked at students of multiple races within the same age range. For example, Nansel and colleagues (2001) used a national representative sample of students in grades six to ten who attended public, Catholic, and other private schools. Bullies represented $10.6 \%$ of their sample. Haynie and colleagues (2001) found that $24.1 \%$ of those surveyed reported bullying others in the past year. Compared to the previous two studies, this study sample reported significantly higher perpetration prevalence (77\%).

The percentage of victimization in this study was also 7 times higher than the national level. The sample students reported that they had been bullied by someone else (victimized) in school at least once in the past year was $80 \%$., in stark contrast to a study where $8.5 \%$ of the 
students nationwide reported being peer victimized (Nansel et al., 2001). Other national studies also reported a relatively lower prevalence of victimization 44.6\% (Haynie, et al., 2001) and 20\% (CDC, 2015).

Compared to other minorities, Arab American adolescents in the current sample had higher prevalence of bullying perpetration and victimization than African American, Hispanic, and Native American populations as reported in previous studies (Carlyle \& Steinman, 2007; Fitzpatrick et al., 2007; Livingstone \& Smith, 2014; Peskin, Tortolero, \& Markham, 2006; Wang et al., 2009). Yousef, Shaher, and Bellamy (2015) found that Arab American middle and high school students reported the highest prevalence of bullying victimization while in school compared to White, African American, and Hispanic American students

According to the adolescents in our sample, classrooms and hallways were the most common places where bullying occurred. Previous research reported that classroom and sites within the school environments (e.g., cafeteria, playground, and hallways) were the most common settings for bullying (Beaty \& Alexeyev, 2008). While bullying can happen anywhere in school, the majority of bullying occurs in places with little adult supervision, such as playgrounds, hallways, and route to and from school (Peterson \& Skiba, 2001, Seals \& Young, 2003). In this study, when adolescents were asked why they bullied others, the most common response was the physical appearance of the victim, particularly their weight (e.g., being overweight) and attire. However, victims reported country-of-origin and religion in addition to being overweight as the main reasons for victimization. Similar causes of bullying were reported in previous studies. For example, Nansel and colleagues (2001) examined a national representative sample of U.S. youth in grades six to ten. Religion, race, weight, and their appearance and speech reported as common reasons for bullying. In 2007, Frisén, Jonsson and Persson conducted a study to describe 
adolescents' perceptions and experiences of bullying. Participants were asked, "Why do you think adolescents are bullied?" Their answers were: (1) victims' appearance (thin, fat, and ugly); (2) victims' behavior (behaves strangely, speaks with a different dialect, shy, insecure); (3) characteristics of bullies (think they are cool, want to feel superior, want to show that they have power); and (4) social background (different culture, religion, economic situation). Based on the previous findings, bullying can occur due to multiple reasons. In general, adolescents seek to fit in with their peer groups and to feel a sense of belonging, which might be challenging for those who are physically, psychologically, or socially different from their peers (Steinberg, 2011).

A previous study reported that Arab American adolescents were bullied mainly because of their Arabic descent and/or perceived or actual Islamic affiliation (Albdour et al., 2016). Arabic culture and Islamic faith prescribes that a woman must be conservative in her attire by wearing long, loose, and non-revealing dresses to cover body parts, and a scarf to cover her head. Consequently, such attire can reinforce bullying of female Arab Americans by their mainstream peer groups. In addition, speaking in Arabic or having a common Arabic name (e.g., Mohammad) can also reinforce bullying. Names and clothing can visibly distinguish Arab American adolescents from their mainstream peers (Albdour et al., 2016), putting them at risk of bullying victimization and harassment.

Previous research findings also indicated that adolescents had little faith in adults' ability to address and stop bullying; as a result, bullied adolescents tended to avoid telling adults about their bullying experiences (Mishna, 2004). Similar findings were reported by Arab American adolescents in a previous qualitative study (Albdour et al., 2016), were Arab American adolescents did not report their bullying experiences to their teachers or school staff, and they did not find the school system to be a source of support. However, in this study sample, approximately $53 \%$ of 
those surveyed reported telling adults (mainly teachers and parents) about bullying situations, and $57 \%$ answered "yes" when asked if the adult did something to stop bullying. More research is needed to investigate the discrepancy in quantitative and qualitative findings related to Arab American adolescents' trust of the school system and teachers and

According to the National Youth Risk Behavior Survey (YRBS), 16\% of adolescents in grades 9 to 12 were cyberbullied within the 30 days preceding the survey. In a national sample of students in grades 6-10, Wang and colleagues (2009) reported that 8.3\% had electronically bullied someone at least once in the last two months, and 10\% reported being a victim of cyberbullying. Slightly higher prevalence was reported by Patchin and Hinduja (2006) who found that almost $11 \%$ of the adolescents reported bullying others online, while more than $29 \%$ reported being the victim of cyberbullying. This study sample reported higher prevalence of cyberbullying perpetration and victimization; 34\% of Arab Americans reported that they were cyberbullied in the past year, and $27 \%$ reported bullying others electronically. Future research needs to consider the overlap between traditional bullying and cyberbullying among Arab American adolescents. Victims of traditional bullying are more likely to be victims of cyberbullying, and traditional bullies are more likely to be cyberbullies (Raskauskas \& Stoltz, 2007). Text messaging and Instagram were the most common technologies used for cyberbullying in the present sample, which was consistent with previous studies. Recent meta-analysis (Kowalski, Giumetti, Schroeder \& Lattanner, 2014) reported that text messaging was used most frequently for cyberbullying among adolescents. As technology continues to grow into more sophisticated programs and trends, cyberbullying might be affected by these new developments. For instance, Instagram is relatively new compared to text messaging, so more research is needed to explore the influence of new technologies and forms of communication on adolescents' cyberbullying experiences. Eighteen 
percent of adolescents did not know who cyberbullied them. The fact that cyberbullying is anonymous, can reach a large audience, and remains online for a long time may intensify the negative effects on adolescents' health and their school performance (Kowalski et al., 2014; Sticca \& Perren, 2013; Tokunaga, 2010).

As we hypothesized, Arab American adolescents reported higher prevalence of perpetration and victimization compared to the adolescents in the general U.S. population, as well as other minority groups. It is important to look at the context of bullying and victimization. First, there are several factors that influence discrimination and negative views of Arab Americans. Recent terrorist actions conducted by extremists (e.g., September, 11, 2001 attack) has contributed to negative stereotypes of Arab American population (Cainkar, 2002; Ibish, 2003). The media has substantially influenced the perception of Arab Americans in general and Arab American adolescents in particular. Movies, television, radio, and advertisements continue to depict Arab Americans in extremely negative light, such as being terroristic, anti-Western, aggressive, and misogynistic. The media presents almost nothing of a positive nature about Arab Americans (Alsultany, 2013; Cainkar, 2002, 2006; Suleiman, 1999). Arab Americans are all perceived as Muslims stemming from one culture, which is a big misconception. Arab Americans include Christians and Jews and come from very diverse geographical and cultural backgrounds (Naber, 2000; Nydell, 2012). Unfortunately, all of these factors result in negative views of Arab Americans in general and lead to more discrimination and hate crimes against this population, in addition to increase the risk for Arab American students bullying (Abdelkarim, 2003; Alsultany, 2013; Ibish, 2003; Singh, 2002; Wingfield, 2006).

Arab American adolescents reported a significant increase in physical violence, death threats, ridicule, and many forms of harassment after 9/11 from other students, as well as teachers 
and staff(Abdelkarim, 2003; Ibish, 2003; Wingfield, 2006). Actually, Arab American adolescents and Muslim adolescents in particular, consider the 9/11 attacks on the United States as an event that prompted discrimination directed against them. The increase in discrimination and prejudice is due in part to the intensity of ongoing media assaults (Aroian, 2012; Ahmad \&Szpara, 2003). Arab American adolescents can be significantly at higher risk of bullying due to such social factors.

Second, acculturation and acculturative stress can also be a factor that influences bullying involvement. Arab American adolescents, especially Muslims, experience cultural constraints and high levels of acculturative stress (Ahmed, Kia-Keating \& Tsai, 2011; Amer, 2005). Arab Americans who are Muslims and less acculturated to dominant society tend to experience more discrimination, because they hold their own cultural beliefs and do not adapt the western culture (Awad, 2010)

Only $20 \%$ of this study sample reported no bullying involvement. These findings support the study hypothesis that Arab American adolescents are more involved in bullying either as bullies or victims than adolescents in the general population. Interpretation of this data should take into consideration that this study sample was derived from a community that constitutes large numbers of Arab Americans who emigrated from the Middle East and other states. Social disadvantages, such as low parental education, low income, and poverty, in addition to living in an urban environment were found to be significantly related to the bullying involvement of minority adolescents (Barboza et al., 2009; Carlson, 2006; Fitzpatrick et al., 2007; Peskin et al., 2007). However, Arab American adolescents' bullying and the association with the previously mentioned factors were not fully investigated in previous research. It is crucial to take social disadvantages into consideration when examining the context in which Arab American adolescents' bullying incidents occur. The earliest waves of Arab Americans were predominantly 
uneducated; however, later waves of Arab American immigrants in the 1990s and 2000s included more educated individuals (Cainkar, 2006). Notwithstanding, Arab Americans experience higher poverty rates than the total U.S. population ( $17 \%$ versus $12 \%)$, and approximately $20 \%$ of families lived below the federal poverty line in the last decade (Cainkar, 2006; Hammad, Kysia, Rabah, Hassoun \& Connelly, 1999). Low income and high poverty rates in the Arab American community influenced the number of uninsured, making health services unaffordable for many in this population (Hammad et al., 1999). When compared to U.S.-born Whites, Arab Americans were more likely to be under-educated, unemployed, living in poverty, and lacking health insurance (Read, Amick \& Donato, 2005). Despite the fact that living in an urban environment may aggravate adolescents' bullying involvement (Goldweber, Waasdorp \& Bradshaw, 2013), this relationship had not examined among the Arab American population, who mainly reside in large metropolitan areas, such as Detroit, Los Angeles, New York, Chicago, Washington, D.C., and northeastern New Jersey (Arab American Institute Foundation 2014; U.S. Census Bureau, 2003). There is a critical need for more research investigation the social factors that are associated with bullying perpetration and victimization among Arab American adolescents in association with social factors.

This study sample consisted of middle and high school adolescents: 49\% and 50\% respectively. For this sample, the prevalence of bullying perpetration was $77 \%$ and victimization was as high as $80 \%$. The reports of bullying showed that the prevalence of bullying was lower in elementary and middle school (grades 6-8) than in high school (grades 9-12), with a peak at the school transition point (grade 9; Pepler et al., 2006). In addition, a number of researchers have found that the frequency of bullying increases from elementary to middle school years and decreases in high school years (Espelage \& Horne, 2008; Nansel et al., 2001). More research is 
needed to understand the pattern of bullying among Arab American adolescents, particularly those who are transitioning from middle to high school. This study sample experienced high level of bullying perpetration and victimization in both middle school and high school.

Male adolescents reported significantly more frequent involvement in bullying as bullies than females, including verbal bullying, social bullying, and physical bullying. With the exception of physical bullying, males and females did not differ significantly in bullying victimization. Similar patterns were found in previous studies (e.g. Nansel et al., 2001; Pepler et al., 2006). Several national studies reported similar findings in which boys in general were more likely than girls to engage in bullying (Espelage et al., 2000; Nansel et al., 2001; Pepler et al., 2006; Seals \&Young, 2003). Previous research findings also indicated that boys were commonly both victims and perpetrators of direct forms of bullying (e.g., physical bullying), while girls experienced indirect bullying (e.g., social rejection, relational aggression) more frequently (Crick \& Grotpeter, 1995; Hong \& Espelage, 2012b).

The study hypothesized that bullying involvement (either as bullies or victims) has a positive relationship with levels of perceived stress, was partially supported empirically. In the current study, we found that being a victim was positively associated with higher levels of perceived stress. However, being involved as a bully was not associated with perceived stress. Similar findings were reported by Combs (2012), who investigated perceived stress, anxiety, and depressive symptoms among bullies, victims, and bully/victims of African American adolescents age 11 to 15 . The author found that perceived stress was associated with bullying victimization but not to bullying perpetration. Previously, Arab American adolescents who were victims of bullying described high stress levels and anxiety, which compromised their ability to function. They reported feeling sad, angry, overwhelmed, helpless, and hurt when they were bullied 
(Albdour et al., 2016). Alfven and colleagues (2008) also found that school harassment (e.g., bullying victimization) was associated with perceived stress among Swedish adolescents, age 10 to 18 . It is possible that bullies were found to enjoy a high status among their peers; and they were perceived as cool, powerful, and popular by their peers and social groups (Rodkin, Farmer, Pearl \& Van Acker, 2006; Salmivalli, 2010). In addition, bullies were found to be psychologically stronger (e.g. display less anxiety and higher self-esteem) than victims and bully/victims and enjoyed higher social standing among their classmates (Juvonen et al., 2003; O’Moore \& Kirkham, 2001). In addition, bullies have low levels of empathy (sharing another person's emotional state; Gini, Albiero, Benelli \& Altoè, 2007; Jolliffe \& Farrington, 2006). As a result, bullies might display less empathy and less stress compared to the victims.

In terms of cyberbullying, being a bully or a victim was not significantly related to perceived stress. However both cyberbullying victims and bullies reported significant physical complaints and psychological distress. Previously, Campbell, Spears, Slee, Butler and Kift (2012) compared perceptions of the harshness and impact of bullying among traditional and cyberbullying victims. Their findings showed that students were victims of traditional bullying reported described their bullying experience as harsher, crueler, and had more impact on their lives than cyberbullied students. However, victims of cyberbullying reported significantly more social difficulties, and higher levels of anxiety and depression than did traditional victims. Our study findings suggest that cyberbullying has a significant effect on adolescent physical and psychological distress, although not as stressful as traditional victimization. These findings contradict the hypotheses of previous studies in which cyberbullying has a greater impact and more severe consequences for victims because it is instant, continuous, anonymous, and has a wider audience (Kowalski \& Limber, 2007; Sticca \& Perren, 2013; Wang, Nansel \& Iannotti, 2011). The 
contradiction in the literature regarding whether cyberbullying is more stressful and more destructive than to traditional bullying confirms that cyberbullying may not be uniformly more harmful than other types of bullying. Inconsistency in the findings may be explained by other factors such as the context and severity of the bullying, which influence the adolescents' bullying experience rather than its method of delivery (Bauman \& Newman, 2013).

Consistent with previous studies, significant association between bullying experiences either as bullies or victims and reporting wide range of somatic complaints (e.g. abdominal pain, nausea, vomiting, weakness, muscles and joints pain) was found in this study (Due et al., 2005; Fekkes, Pijpers \& Verloove-Vanhorick, 2004; Gini \& Pozzoli, 2009; Vanderbilt, D., \& Augustyn, M. (2010). In this study bullies and victims of all forms of bullying (physical, verbal, and social) experienced such symptoms, which is consistent with other studies. Gini and Pozzoli, (2009) conducted a meta-analysis to examine the association between bullying and somatic complaints and found that victims, bullies, and bully/victims had a significantly higher risk for psychosomatic problems compared with uninvolved youth. A longitudinal study (Biebl, DiLalla, Davis, Lynch \& Shinn, 2011) also found that chronic victimization had the most significant negative effect on adolescents' physical health. Although previous research suggested that victims and bully/victims are at higher risk and show more significant physical complaints (Gini, 2008; Gini \& Pozzoli, 2009), this study showed significant physical complaints for both bullies and victims. Future research needs to examine physical complaints experienced by Arab American bully/victim groups.

It is important for nurses, pediatricians and other health care professionals and school staff to be aware of such symptoms and to investigate the association of these complaints with bullying and stress. Both bullying perpetration and victimization were significantly associated with more 
frequent visits to the school nurse for somatic complaints, including illnesses and injuries, which is similar to other study findings (e.g., Vernberg, Nelson, Fonagy \& Twemlow, 2011). Fekkes and colleagues (2004) suggested that when such complaints are detected, pediatricians, general practitioners, and school nurses need to work together to take appropriate actions to stop bullying and to refer adolescents to appropriate specialists (e.g. psychologist) for counseling in both bullies and victims. Careful assessments and serious efforts are required to address bullying which is a step towards preventing negative psychosocial and health outcomes, including poor school performance, serious physical injuries, and psychological problems. Screening adolescents for bullying can be completed as part of their school examination or during their routine visits to health care providers. Adolescents can be asked directly if they have been involved in bullying at school (see Lamb, Pepler \& Craig, 2009). Furthermore, health care providers should consider bullying when examining Arab American adolescents since this group is at an elevated risk for bullying. A multiple contextual approach should be considered to more effectively reduce bullying. School interventions that include health care providers, school staff, and parents have been proven to be effective in deterring bullying (Ttofi \& Farrington, 2011; Vreeman \& Carroll, 2007). However, such interventions had not been reported by Arab American adolescents in this sample.

Bullying of adolescents, either as bullies or victims, are significantly and positively associated with psychological distress. As hypothesized, more frequent bullying perpetration and victimization were associated with more psychological distress (e.g., feeling tired, hopeless, nervous, and worthless). Recent studies reported that both bullying perpetration and victimization were found to be associated with psychological distress in late adolescence (McVie, 2014) and which can continue to adulthood (Birkett, Newcomb \& Mustanski, 2015). Moreover, bullying was not only found to be associated with psychological distress but also with more destructive forms 
of psychological illness, including depression, suicide (Schneider, O'Donnell, Stueve, \& Coulter, 2012), and poor school performance (Totura, Karver, \& Gesten, 2014). Several previous studies focused on the psychological distress of victims and bully/victims since they experienced more psychological distress and negative outcomes compared to bullies (Cassidy, 2009; Dao et al., 2006; Hawker \& Boulton, 2000; Schneider, O'Donnell, Stueve \& Coulter, 2012). These studies suggested that bullies have better psychological health (lack of psychological distress) compared to victims and bully/victims (Cassidy, 2009; Juvonen, Graham \& Schuster, 2003). Contrary to these studies, adolescents in this study sample who were bullies or victims in all forms (verbal, physical, and social) were psychologically distressed. The contrast between our results and the findings in the literature regarding bullies and psychological distress might be explained by the findings of Herrero, Estévez, and Musitu (2006). Their study found that the link between adolescents' bullying involvement as bullies or victims and their psychological distress was influenced and mediated by their relationships with their parents and teachers. For bullies, their psychological distress was mediated by their relations with their parents and teachers because bullies were not rejected, had high social status, and were inclined to be integrated into their peer ecologies (Rodkin \& Hodges, 2003).

Psychological distress was found to be influenced by adolescents' coping strategies. For example, ineffective bullying coping strategies (e.g., avoidance) were associated with more psychological distress (Grennan \& Woodhams, 2007). A problem-solving style in which adolescents' were helpless, had less control, lacked confidence, and were more likely to avoid problems instead of approaching them was found to be related to more psychological distress as a result of bullying. In Albdour and colleagues' (2016) pilot study, the researchers found that Arab Americans did not cope effectively with bullying victimization. Future researchers needs to 
develop an effective prevention and intervention program that enhances Arab American adolescents' coping strategies, as well as problem-solving style. It is important for researchers and practitioners to consider that many Arab American children are taught to look within the family for solutions rather than developing their own coping strategies (Haboush, 2007). Future research should also examine the Arab American bully/victim group since they might experience greater psychological distress than bullies or victims.

This study hypothesized that the relationship between adolescents' bullying involvement and their physical and psychological health is mediated by their perceived stress. However, this hypothesis was only partially supported by the data and perceived stress partially mediated the relationship between being involved as a victim and physical/psychological health. There is a lack of research on the role of perceived stress in the link between bullying and physical/ psychological health; however, this study was consistent with the findings from Maidaniuc-Chirilă and Gherasim's (2014) study. The authors investigated the mediating role of perceived stress in the association with bullying and depressive symptoms. They found that although the mediator was not statistically significant, the indirect relationship between bullying victimization and depressive symptoms could be better explained through perceived stress. Future research needs to further investigate the mediating role of perceived stress and adolescent psychological health, especially since perceived stress was shown to explain the associations with adolescents' involvement in bullying and psychological health (Combs, 2011; Maidaniuc-Chirilă \& Gherasim 2014; Yarcheski \& Mahon, 2000). In terms of physical health, perceived stress was found to partially mediate the relationship between bullying victimization and physical complaints. This finding is consistent with Alfven, Östberg, and Hjern's (2008) study which found that perceived stress had a positive 
association with bullying victimizations and symptoms of pain (e.g., headache and abdominal pain).

On the other hand, perceived stress did not mediate the association between bullying perpetration and physical/psychological health. This study findings is contrary to MaidaniucChirilă and Gherasim's (2014) finding that perceived stress mediated the link between aggressive behavior and depressive symptoms. It is plausible that bullies in this study sample did not experience stress in the first place, so the mediating role of perceived stress was not evident. Future research needs to further investigate the role of perceived stress in explicating the link between bullying perpetration and health relationships, especially given that high stress levels are significantly related to anger control problems, emotional distress, and negative self-perception (Hampel \& Petermann, 2006).

\section{Recommendations for Future Research}

To date, this study provides a necessary first step in examining the prevalence of bullying among Arab American adolescents; more quantitative and qualitative studies are needed to better understand bullying among this marginalized population. This study focused on bullies and victims and their perceived stress and physical/psychological health. Future research needs to consider examining the bully/victim group in relation to previous variables (e.g., perceived stress, physical and psychological symptoms) since this group may show different patterns of bullying. Arab American adolescents' bullying involvement need to be further examined in relation to discrimination and acculturation, as well as social disadvantages since these contextual factors may significantly influence their bullying involvement. There is a crucial need to conduct more research to understand why this population involved in bullying at higher levels, even higher than the general U.S. adolescent population and other minority adolescent populations. The first step 
might be to create a clearer definition of what constitutes Arab American and distinguished this group from Whites. This would help to clarify Arab American adolescents' bullying experiences and provide more accurate findings compared to other ethnic groups. The effect of bullying experiences on Arab American adolescents' physical complaints and psychological distress was evident in this study. The relationship between bullying involvement, psychological disorders (e.g. depression, anxiety, and suicidal thoughts and behavior), and physical illness needs to be further investigated among the Arab American adolescent population. Victims, in particular, are greatly affected by bullying and perceived significant stress levels. Additionally, studies using longitudinal research design are needed to understand the causal relationship between bullying involvement and health outcomes and whether the role of perceived stress can explain this relationship. Arab American adolescents come from different cultural backgrounds and family dynamics, so it is critical to examine Arab American adolescents' perceptions of bullying and experiences in bullying victimization. Sawyer, Bradshaw, and O'Brennan (2008) found that these concepts (e.g. bullying \& victimization) might be different among adolescents from different cultures and ethnic minorities. In summary, research related to Arab American adolescents' bullying involvement, associated risks and protective factors, and effects on their health and stress levels is necessary to enhance our understanding and contribute significantly to the literature on bullying.

\section{Implications for Practice and Policy}

Findings of this study contribute to practice and policy by first addressing the gap in the literature related to Arab American adolescents' bullying involvement and its effects on their health and stress levels. This study findings reveal similarities and differences between bullying involvement of Arab American adolescents, other racial/ethnic minorities, and the U.S general 
population, which may help future research to develop culturally tailored intervention and prevention strategies. Both bullies and victims reported physical symptoms and psychological distress. Thus, it is imperative that health care providers screen for physical symptoms, further investigate bullying involvement, provide necessary treatments to prevent further deterioration, and provide referrals to appropriate resources when needed.

It is important for health care providers, school staff, teachers, psychologists, and social workers to understand the cultural influence on Arab American adolescents' bullying involvement. Hammad and colleages (1999) and Haboush (2007) highlighted some cultural tips with regards to Arab American adolescents. In the Arab American culture, adolescents are encouraged to resolve their problems within the family instead of developing their own problem-solving skills. Parents and extended family members are involved in the decision-making process. Children are encouraged to live in the parents' home until marriage, and little pressure exists for the child to seek his/her own social independence. Disciplinary practices tends to be punitive rather than reward oriented. Expressions of feelings are highly discouraged, especially among males, and eye contact is avoided, especially among females. Short or revealing clothing is considered contrary to modest behavior expected of both men and women. Considering that family is the center of Arab American culture, it is essential that practitioners working with Arab American adolescents to involve their families when using prevention and intervention programs.

Given the complexity of bullying and victimization and its association with multiple factors, prevention and intervention efforts need to include not only the individual, peer group, family, and school, but also the community (Espelage \& Swearer, 2003). School officials need to consider working with community centers, churches and mosques, recreation centers, libraries, and youth programs to develop a community wide effort to reduce bullying. Increasing the 
awareness of Arab American culture and reducing stereotyping is an important key to creating an atmosphere of acceptance in the schools and communities that include Arab American adolescents and their families.

Schools also need to adopt policies that support diversity, acceptance of one another, and awareness of different cultures within the student body. School policies should seriously take into consideration that Arab American adolescents frequently experience discrimination and bullying by their classmates, peers, and teachers. Although current law mandates that school districts have a bullying prevention program or policy in place, such programs are only effective when discrimination is seriously considered and how discriminatory practices can evoke bullying behavior among students. This is a necessary first step towards ensuring a positive school climate for all students.

\section{Strengths and Limitations}

The strengths of this study are: 1) examining traditional and cyberbullying among a diverse sample of Arab American adolescents; 2) examining the prevalence of bullying types (physical, verbal, relational); 3) examining contexts related to their bullying experiences (e.g., where and why bullying occurred); 4) using the Perceived Stress Scale (PSS) to examine perceived stress among Arab American adolescents, age 12 to 16 (unlike previous studies, which utilized this scale among middle school sample only); and 5) support for the Neuman Systems Model (NSM; The results of the present study have validated the concept of interactive variables, intrapersonal stressors, and the need for secondary and tertiary prevention strategies for Arab American bullies and victims.) The NSM takes into account the complexity of bullying involvement and associated factors (e.g., individual, familial, community, and culture). Future research should consider the utility of this model to guide prevention and intervention programs since the NSM can untangle a 
complex phenomenon, such as bullying. The NSM can guide interventions that considers primary, secondary and tertiary strategies to decrease stressors and promote rehabilitation and well-being. Although this study presents important findings, some limitations also need to be considered. First, the use of non-random sampling from only two sites in southeast Michigan might limit the generalizability of the study findings to Arab American adolescents living in other parts of the U.S. The site is predominantly Arab American, and the findings may not be similar to other parts of the U.S. where Arab Americans are a minority group. However, it is also important to note that the recruitment among Arab American adolescents is challenging and researchers are often confronted with barriers, such as lack of trust to disclose sensitive information and language barriers (Timraz, Alhasanat, Albdour, Lewin, Giurgescu \& Kavanaugh, 2017).

This study also did not include comparable groups (e.g. Whites or other racial and ethnic minorities) and used previous research findings for comparison; however, it is important that future research consider using a comparable group for more reliable findings. In addition, bully/victim subgroup was not considered and need to be addressed in future research. Another limitation of this study was respondent bias from the use of self-report instruments. Bullying involvement were obtained from adolescents' self-reports and not validated by other means, such as peer or teacher nominations or observations. Additionally, the cross-sectional research design reflected temporal inferences. Longitudinal research design is needed to examine causal relationships among the study variables.

\section{Conclusions}

There are several missing pieces to the puzzle in terms of bullying among Arab American adolescents. When examining the current literature regarding bullying involvement and adolescents' health and stress, a pilot study was needed to begin the exploration of differences 
pertaining to Arab American adolescents and the role of perceived stress in the link between bullying and health. The current study findings can inform nurse researchers and health professionals working with Arab American adolescents to further explore these areas and take into consideration the Arab American culture when providing treatment to this vulnerable, yet overlooked population. 


\section{APPENDIX A}

INSTRUMENTS

\section{Demographic Questionnaire}

\section{Initials}

Date

What is your Gender?

- Male

○ Female

Are you Middle Eastern?

- Yes, Country of Origin

- No, Country of Origin

How long you lived in the U.S?

- Less than 1 year

- 1 to 2 years

○ 3 to 4 years

○ 5 to 10 years

○ All your life

Please check how you describe yourself:

○ White : if yes check one : Middle Eastern Hispanic Non-Hispanic

- Black/African American

- Multiracial

- Others

Please circle your age:

$\begin{array}{llllllllllll}8 & 9 & 10 & 11 & 12 & 13 & 14 & 15 & 16 & 17 & 18 & 19\end{array}$

Please circle your grade:

$\begin{array}{llllllll}5 & 6 & 7 & 8 & 9 & 10 & 11 & 12\end{array}$

What level is your school?

- Elementary school

- Middle school

○ High school

What is you religion?

○ Muslim

- Christian

o Others 
Do you receive any medications?

○ Yes, What for-------------------

○ No 


\section{Adolescent Peer Relations Instrument (APRI)}

\section{$A P R I-B T_{\odot} 2003$}

\section{SECTION A}

Since you have been at this school THIS YEAR how often HAVE YOU done any of the following things to a STUDENT (or students) at this school. CIRCLE THE NUMBER THAT IS CLOSEST TO YOUR ANSWER.

In the past year at this school I...

1 Teased them by saying things to them

2 Pushed or shoved a student

3 Made rude remarks at a student

4 Got my friends to turn against a student

5 Made jokes about a student

6 Crashed into a student on purpose as they walked by

7 Picked on a student by swearing at them

Told my friends things about a student to get them into trouble

9 Got into a physical fight with a student because I didn't like them

10 Said things about their looks they didn't like

11 Got other students to start a rumour about a student

12 I slapped or punched a student

13 Got other students to ignore a student

14 Made fun of a student by calling them names

15 Threw something at a student to hit them

Threatened to physically hurt or harm a student

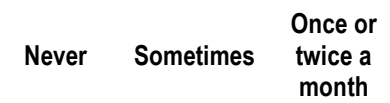

Once a
week

Several times a Everyday

$\begin{array}{llll}3 & 4 & 5 & 6\end{array}$

1

1

2

3

4

5

6

$\begin{array}{llllll}1 & 2 & 3 & 4 & 5 & 6\end{array}$

$\begin{array}{llllll}1 & 2 & 3 & 4 & 5 & 6\end{array}$

12

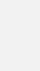

1

1

2

3

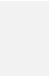

1

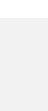


17 Left them out of activities or games on purpose

18 Kept a student away from me by giving them mean looks

$\begin{array}{llllll}1 & 2 & 3 & 4 & 5 & 6 \\ 1 & 2 & 3 & 4 & 5 & 6\end{array}$

\section{SECTION B}

Please indicate how often a student (or students) at this school has done the following things TO YOU since you have been at this school this year. CIRCLE THE NUMBER THAT IS CLOSEST TO YOUR ANSWER

In the past year at this school...

1 I was teased by students saying things to me

2 I was pushed or shoved

3 A student wouldn't be friends with me because other people didn't like me

4 A student made rude remarks at me

5 I was hit or kicked hard

$6 \quad$ A student ignored me when they were with their friends

7 Jokes were made up about me

8 Students crashed into me on purpose as they walked by

9 A student got their friends to turn against me

10 My property was damaged on purpose

11 Things were said about my looks I didn't like

12 I wasn't invited to a student's place because other people didn't like me

13 I was ridiculed by students saying things to me

14 A student got students to start a rumour about me

15 Something was thrown at me to hit me

16 I was threatened to be physically hurt or harmed

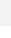
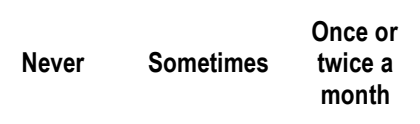

Once a
week $\begin{array}{cc}\text { Several } & \text { Every- } \\ \text { times a } & \text { day } \\ \text { week } & \end{array}$

3

4

5

6

1

1

2

3

4

5

6

1

1

2

$\begin{array}{llll}3 & 4 & 5 & 6\end{array}$


17 I was left out of activities, games on purpose

18 I was called names I didn't like
1

1

2

2
3

3

3

$4 \quad 5$

4
6

6 


\section{Additional Bullying Questions}

Where did bullying happen?

- Class room

○ Hallway

○ Gym

○ Bathroom

- Cafeteria

- School bus

- Playground

- Way to school

O Others

Why did you bully someone? (Select all that apply):

○ Clothing

○ Fat

o Thin

○ Health problems

○ Poor

Immigrant

○ Country-of-origin

$\circ$ Religion

Why did someone bully you? (Select all that apply):

○ Clothing

o Fat

o Thin

○ Health problems

○ Poor

- Immigrant

○ Country-of-origin

○ Religion

Did you tell an adult about your bullying situation?

○ Yes

○ No

If yes, who was that adult?

o Parent

- Teacher

- School staff (e.g. principal)

○ Sibling

$\circ$ Friend 
Did the adult do something to stop the bullying?
○ Yes
o No

If yes, what the adult did to stop bullying?

During the past year, have you ever been cyberbullied by someone (i.e., someone bullied you using technology or social media)?
○ Yes
○ No

If yes, how many times?
- 1 or 2 times
- 3 to 5 times
- More than 5 times

You were cyber bullied using what technology? (Select all that apply)
- Text message
- Emails
- Facebook
- Instagram
- Twitter
- Myspace
- Snapshot
- Created website
○ Blogs
○ Chat
o Other

Did you know who cyberbullied you?
○ Yes
o No

During the past year, have you cyberbullied someone?
- Yes
○ No

If yes, how many times have you cyberbullied someone?
- 1 or 2 times
- 3 to 5 times
○ More than 5 times 
What technology did you use to cyberbully someone? (Select all that apply)

- Text message

- Emails

- Facebook

- Instagram

- Twitter

- Myspace

- Snapshot

- Created website

- Blogs

○ Chat

○ Other 


\section{Perceived Stress Scale (PSS-10)}

The questions in this scale ask you about your feelings and thoughts during the last month. In each case, you will be asked to indicate by circling how often you felt or thought a certain way.

0 = Never 1 = Almost Never 2 = Sometimes $3=$ Fairly Often $4=$ Very Often

1. In the last month, how often have you been upset

because of something that happened unexpectedly?......................

2. In the last month, how often have you felt that you were unable

to control the important things in your life?.........................................

3. In the last month, how often have you felt nervous and "stressed"? ..........

4. In the last month, how often have you felt confident about your ability

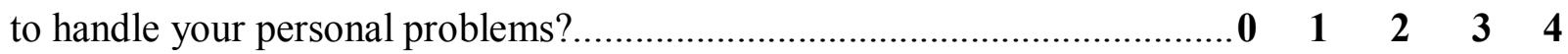

5. In the last month, how often have you felt that things

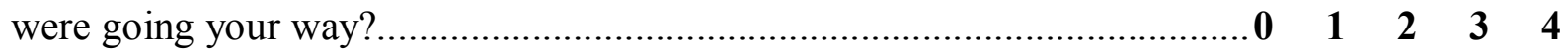

6. In the last month, how often have you found that you could not cope

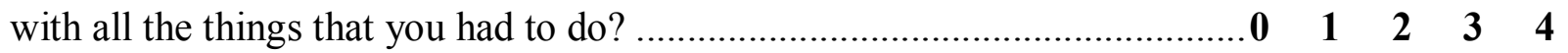

7. In the last month, how often have you been able

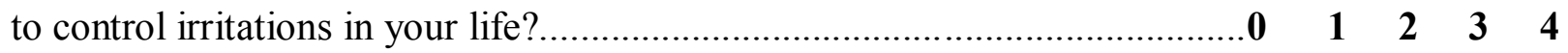

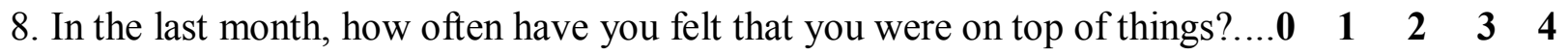

9. In the last month, how often have you been angered

because of things that were outside of your control?

$\begin{array}{lllll}0 & 1 & 2 & 3 & 4\end{array}$

10. In the last month, how often have you felt difficulties

were piling up so high that you could not overcome them? $\begin{array}{llll}0 & 1 & 2 & 3\end{array}$ 


\section{Children's Somatization Inventory CSI-24 (Child Report) \\ Your Symptoms}

Below is a list of symptoms that children and teenagers sometimes have. Circle a number telling how much you were bothered by each symptom during the past two weeks.

In the last 2 weeks, how much were you bothered by each symptom?

\begin{tabular}{|c|c|c|c|c|c|}
\hline & $\begin{array}{l}\text { Not at } \\
\text { all }\end{array}$ & $\begin{array}{c}\text { A } \\
\text { little }\end{array}$ & Some & $\begin{array}{l}\text { A } \\
\text { lot }\end{array}$ & $\begin{array}{c}\text { A whole } \\
\text { lot }\end{array}$ \\
\hline 1. Headaches & 0 & 1 & 2 & 3 & 4 \\
\hline 2. Faintness or dizziness (feeling faint or dizzy) & 0 & 1 & 2 & 3 & 4 \\
\hline 3. Pain in your heart or chest & 0 & 1 & 2 & 3 & 4 \\
\hline 4. Feeling low in energy or slowed down & 0 & 1 & 2 & 3 & 4 \\
\hline 5. Pains in your lower back & 0 & 1 & 2 & 3 & 4 \\
\hline 6. Sore muscles & 0 & 1 & 2 & 3 & 4 \\
\hline $\begin{array}{l}\text { 7. Trouble getting your breath (when you're } \\
\text { not exercising) }\end{array}$ & 0 & 1 & 2 & 3 & 4 \\
\hline $\begin{array}{l}\text { 8. Hot or cold spells (suddenly feeling hot } \\
\text { or cold for no reason) }\end{array}$ & 0 & 1 & 2 & 3 & 4 \\
\hline 9. Numbness or tingling in parts of your body & 0 & 1 & 2 & 3 & 4 \\
\hline 10. Weakness (feeling weak) in parts of your body & 0 & 1 & 2 & 3 & 4 \\
\hline $\begin{array}{l}\text { 11. Heavy feelings in your arms or legs (when } \\
\text { they feel too heavy to move) }\end{array}$ & 0 & 1 & 2 & 3 & 4 \\
\hline $\begin{array}{l}\text { 12. Nausea or upset stomach (feeling like you } \\
\text { might throw up, or having an upset stomach) }\end{array}$ & 0 & 1 & 2 & 3 & 4 \\
\hline $\begin{array}{l}\text { 13. Constipation (when it's hard to have a B.M. } \\
\text { or go poop) }\end{array}$ & 0 & 1 & 2 & 3 & 4 \\
\hline
\end{tabular}


14. Loose (runny) BM's or diarrhea

15. Pain in your stomach or abdomen (stomach aches)

16. Your heart beating too fast (even when you're not exercising)

17. Difficulty swallowing

18. Losing your voice

19. Blurred vision (when things look blurry, even with glasses on)

20. Vomiting (or throwing up)

21. Feeling bloated or gassy

22. Food making you sick

23. Pain in your knees, elbows or other joints

24. Pain in your arms or legs
0

0

1

1

2

3

4

4

0

1

2

3

4

0

0

0

12

3

4

4

4

$\begin{array}{llllll}0 & 1 & 2 & 3 & 4\end{array}$

$\begin{array}{llllll}0 & 1 & 2 & 3 & 4\end{array}$

$\begin{array}{lllll}0 & 1 & 2 & 3 & 4\end{array}$

$\begin{array}{lllll}0 & 1 & 2 & 3 & 4\end{array}$

$\begin{array}{lllll}0 & 1 & 2 & 3 & 4\end{array}$




\section{Kessler Psychological Distress Scale (K10)}

These questions concern how you have been feeling over the past 30 days. Tick a box below each question that best represents how you have been.

\begin{tabular}{|l|l|l|l|}
\hline 1. During the last $\mathbf{3 0}$ days, about how often did you feel tired out for no good reason? \\
\begin{tabular}{|l|l|l|l|} 
1. None of the time & $\begin{array}{l}\text { 2. A little of the } \\
\text { time }\end{array}$ & $\begin{array}{l}\text { 3. Some of the } \\
\text { time }\end{array}$ & All of the \\
\hline
\end{tabular}
\end{tabular}

\begin{tabular}{|l|l|l|l|}
\hline 2. During the last $\mathbf{3 0}$ days, about how often did you feel nervous? \\
\hline & $\begin{array}{l}\text { 2. A little of the } \\
\text { 1. None of the time }\end{array}$ & $\begin{array}{l}\text { 3. Some of the } \\
\text { time }\end{array}$ & $\begin{array}{l}\text { 5. All of the } \\
\text { 4. Most of the time time }\end{array}$ \\
\hline
\end{tabular}

\begin{tabular}{|c|c|c|c|}
\hline \multicolumn{4}{|c|}{$\begin{array}{l}\text { 3. During the last } 30 \text { days, about how often did you feel so nervous that nothing could calm } \\
\text { you down? }\end{array}$} \\
\hline None of the time & $\begin{array}{l}\text { 2. A little of the } \\
\text { time }\end{array}$ & $\begin{array}{l}\text { 3. Some of the } \\
\text { time }\end{array}$ & \begin{tabular}{l|l} 
4. Most of the time & 5. Olime \\
4time
\end{tabular} \\
\hline
\end{tabular}

\begin{tabular}{|c|c|c|c|}
\hline \multicolumn{4}{|c|}{ 4. During the last 30 days, about how often did you feel hopeless? } \\
\hline 1. None of the time & $\begin{array}{l}\text { 2. A little of the } \\
\text { time }\end{array}$ & $\begin{array}{l}\text { 3. Some of the } \\
\text { time }\end{array}$ & \begin{tabular}{l|l} 
4. Most of the time & All of the \\
time
\end{tabular} \\
\hline
\end{tabular}

\begin{tabular}{|c|c|c|c|}
\hline \multicolumn{4}{|c|}{ 5. During the last 30 days, about how often did you feel restless or fidgety? } \\
\hline 1. None of the time & $\begin{array}{l}\text { 2. A little of the } \\
\text { time }\end{array}$ & $\begin{array}{l}\text { 3. Some of the } \\
\text { time }\end{array}$ & 4. Most of the time 5 time \\
\hline
\end{tabular}

\begin{tabular}{|c|c|c|c|}
\hline \multicolumn{4}{|c|}{ 6. During the last 30 days, about how offen did you feel so restless you could not sit still? } \\
\hline 1. None of the time & $\begin{array}{l}\text { 2. A little of the } \\
\text { time }\end{array}$ & $\begin{array}{l}\text { 3. Some of the } \\
\text { time }\end{array}$ & 4. Most of the time 5 . All of the \\
\hline
\end{tabular}

\begin{tabular}{|l|l|l|l|}
\hline 7. During the last 30 days, about how often did you feel depressed? \\
\begin{tabular}{|l|l|l|l|l|l} 
1. None of the time & $\begin{array}{l}\text { 2. A little of the } \\
\text { time }\end{array}$ & $\begin{array}{l}\text { 3. Some of the } \\
\text { time }\end{array}$ & All of the \\
4. Most of the time & time \\
\hline
\end{tabular}
\end{tabular}

\begin{tabular}{|c|c|c|c|}
\hline \multicolumn{4}{|c|}{ 8. During the last 30 days, about how often did you feel that everything was an effort? } \\
\hline 1. None of the time & $\begin{array}{l}\text { 2. A little of the } \\
\text { time }\end{array}$ & $\begin{array}{l}\text { 3. Some of the } \\
\text { time }\end{array}$ & 4. Most of the time $\begin{array}{l}\text { 5. All of the } \\
\text { time }\end{array}$ \\
\hline
\end{tabular}

\begin{tabular}{|c|c|c|c|}
\hline \multicolumn{4}{|c|}{ 9. During the last 30 days, about how offen did you feel so sad that nothing could cheer you up? } \\
\hline 1. None of the time & $\begin{array}{l}\text { 2. A little of the } \\
\text { time }\end{array}$ & $\begin{array}{l}\text { 3. Some of the } \\
\text { time }\end{array}$ & \begin{tabular}{l|l} 
4. Most of the time & All of the \\
4ime
\end{tabular} \\
\hline
\end{tabular}

10. During the last 30 days, about how often did you feel worthless?

\begin{tabular}{|l|l|l|l|}
\hline 1. None of the time & $\begin{array}{l}\text { 2. A little of the } \\
\text { time }\end{array}$ & $\begin{array}{l}\text { 3. Some of the } \\
\text { time }\end{array}$ & $\begin{array}{l}\text { 5. All of the } \\
\text { 4. Most of the time }\end{array}$ \\
\hline
\end{tabular}




\section{APPENDIX B}

\section{HUMMAN INVESTIGATION COMMITTEE APPROVAL}

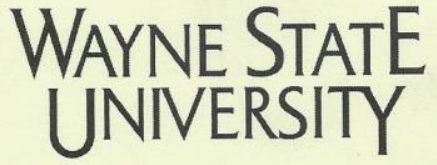

\section{NOTICE OF EXPEDITED APPROVAL}

To: $\quad$ Maha Albdour

Adult Health/Administration

5557 Cass Ave., Cohn Bldg., Ro

From: Or. Deborah Ellis or designee

(h.) 2.2

Chairperson, Behavioral Institutional Review Board (B3)

Date: May 26, 2016

RE: IRB \#

046716B3E

Protocol Title: $\quad$ Arab American Adolescents Bullying Experience and Effects on their Health and Perceived Stress

Funding Source: Sponsor: Sigma Theta Tau International, Incorporated

Protocol \#: $\quad 1604014865$

Expiration Date: $\quad$ May 25, 2017

Risk Level / Category: 45 CFR 46.404 - Research not involving greater than minimal risk

The above-referenced protocol and items listed below (if applicable) were APPROVED following Expedited Review Category (\#7 $)^{\star}$ by the Chairperson/designee for the Wayne State University Institutional Review Board (B3) for the period of $05 / 26 / 2016$ through $05 / 25 / 2017$. This approval does not replace any departmental or other approvals that may be required.

- Revised Protocol Summary Form (revision received in the IRB office 05/24/16)

- Research Protocol - Dissertation (received in the IRB office 04/18/16)

- Medical records are not being accessed therefore HIPAA does not apply

- Documentation of Adolescent Assent Form Ages 13 - 17 (revision dated 05/24/16)

- Parental Permission / Research Informed Consent (revision dated 05/24/2016)

- Study Flyer

- Data Collection Tools (6): i) Demographic Questionnaire, ii) APRI-BT, iii) Additional Bullying Questions, iv) Perceived Stress Scale, v) CSI-24 (Child Report) and vi) K10 Test

- Federal regulations require that all research be reviewed at least annually. You may receive a "Continuation Renewal Reminder" approximately two months prior to the expiration date; however, it is the Principal Investigator's responsibility to obtain review and continued approval before the two months prior to the expiration date; however, it is the papproval is unapproved research and can never be reported or published as research expiration

data.

- All changes or amendments to the above-referenced protocol require review and approval by the IRB BEFORE implementation.

- Adverse Reactions/Unexpected Events (AR/UE) must be submitted on the appropriate form within the timeframe specified in the IRB Administration Office Policy (http://www.irb.wayne.edu//policies-human-research.php).

NOTE:

1. Upon notification of an impending regulatory site visit, hold notification, and/or external audit the IRB Administration Office must be contacted immediately.

2. Forms should be downloaded from the IRB website at each use.

*Based on the Expedited Review List, revised November 1998

Notify the IRB of any changes to the funding status of the above-referenced protocol. 


\section{REFERENCES}

Abdelkarim, R. Z. (2003). Arab and Muslim Americans: Collateral damage in the wars on terrorism, Iraq. The Washington Report on Middle East Affairs, 22(4), 55.

Abraham, S. (1983). Detroit's Arab-American Community: A Survey of Diversity and Commonality. In Arabs in the New World: Studies on Arab American Communities, edited by S. Abraham and Nabeel Abraham, 84-86. Detroit: Center for Urban Studies, Wayne State University.

Ahmed, S. R., Kia-Keating, M., \& Tsai, K. H. (2011). A structural model of racial discrimination, acculturative stress, and cultural resources among Arab American adolescents. American journal of community psychology, 48(3-4), 181-192.

Ahmad, I. \& Szpara, M. (2003). Muslim children in urban America: The New York city schools experience. Journal of Muslim Minority Affairs, 23 (2): 295-301

Albdour, M., Lewin, L., Kavanaugh, K., Hong, J. S., \& Wilson, F. (2016). Arab American adolescents' perceived stress and bullying experiences: a qualitative study. Western Journal of Nursing Research. doi: 10.1177/0193945916678214

Albdour, M. \& Krouse, H. J. (2014), Bullying and victimization among African American adolescents: A literature review. Journal of Child and Adolescent Psychiatric Nursing, 27(2), 68-82. doi: 10.1111/jcap.12066. 
Alikasifoglu, M., Erginoz, E., Ercan, O., Uysal, O., Kaymak, D.A., \& Ilter, O. (2004). Violent behavior among Turkish high school students and correlates of physical fighting. European Journal of Public Health, 14(2), 173-177

Alfven, G., Östberg, V., \& Hjern, A. (2008). Stressor, perceived stress and recurrent pain in Swedish schoolchildren. Journal of Psychosomatic Research, 65(4), 381-387. doi:10.1016/j.jpsychores.2008.07.004

Allison, S., Roeger, L., \& Reinfeld-Kirkman, N. (2009). Does school bullying affect adult health? Population survey of health-related quality of life and past victimization. Australian and New Zealand journal of psychiatry, 43(12), 1163-1170

Alsultany, E. (2013). Arabs and Muslims in the media after 9/11: Representational strategies for a" postrace" era. American Quarterly, 65(1), 161-169.

American Nurses Association (ANA). (2016). What is Nursing. Retrieved from http://www.nursingworld.org/EspeciallyForYou/What-is-Nursing

Amer, M. M. (2005). Arab American mental health in the post September 11 era: Acculturation, stress, and coping (Doctoral dissertation, University of Toledo).

Andrews, G., Slade, T (2001). Interpreting scores on the Kessler Psychological Distress Scale (k10). Australian and New Zealand Journal of Public Health, 25, 494-497. 
Arab American Institute Foundation (2014). Arab Americans demographics. Retrieved on December 1, 2016 from http://www.nursingworld.org/EspeciallyForYou/What-isNursing

Aroian, K. J. (2012). Discrimination against Muslim American adolescents. The Journal of School Nursing, 28(3), 206-213.

Awad, G.H. (2010).The impact of acculturation and religious identification on perceived discrimination for Arab/Middle Eastern Americans. Cultural Diversity and Ethnic Minority Psychology, 16(1), 59-67.

Baker, W., Howell, S., Jamal, A., Lin, A., Shryock, A., Stockton, R., \& Tessler, M. (2004) The Detroit Arab American study: Preliminary findings and technical documentation. University of Michigan. Retrieved on November 25, 2016 from http://www.umich.edu/news/index.html?Releases/2004/Ju104/r072904

Barboza, G. E., Schiamberg, L. B., Oehmke, J., Korzeniewski, S. J., Post, L. A., \& Heraux, C. G. (2009). Individual characteristics and the multiple contexts of adolescent bullying: An ecological perspective. Journal of Youth and Adolescence, 38(1), 101-121.

Bauman, S., \& Newman, M. L. (2013). Testing assumptions about cyberbullying: Perceived distress associated with acts of conventional and cyber bullying. Psychology of Violence, 3(1), 27. 
Bauman, S., \& Summers, J. J. (2009). Peer victimization and depressive symptoms in Mexican American middle school students: Including acculturation as a variable of interest. Hispanic Journal of Behavioral Sciences, 31 (4), 515-535.

Beale, A. V. (2001). Bully busters: Using drama to empower students to take a stand against bullying behavior. Professional School Counseling, 4 (4), 300-306.

Beaty, L. A., \& Alexeyev, E. B. (2008). Adolescence: The problem of school bullies: What the research tells us. Youth Studies Australia, 27(3), 59-60.

Berry, J. W. (2001). A psychology of immigration. Journal of social issues, 57(3), 615-631.

Blank, J. J., Clark, L., Longman, A. J., \& Atwood, J. R. (1989). Perceived home care needs of cancer patients and their caregivers. Cancer Nursing,12(2), 78-84.

Bond, L., Carlin, J. B., Thomas, L., Rubin, K., \& Patton, G. (2001). Does bullying cause emotional problems? A prospective study of young teenagers. British Medical Journal, 323(7311), 480-484. doi:10.1136/bmj.323.7311.480

Biebl, S. J., DiLalla, L. F., Davis, E. K., Lynch, K. A., \& Shinn, S. O. (2011). Longitudinal associations among peer victimization and physical and mental health problems. Journal of Pediatric Psychology, 36(8), 868-877.

Birkett, M., Newcomb, M. E., \& Mustanski, B. (2015). Does it get better? A longitudinal analysis of psychological distress and victimization in lesbian, gay, bisexual, transgender, and questioning youth. Journal of Adolescent Health, 56(3), 280-285. 
Björling, E. A. (2009). The momentary relationship between stress and headaches in adolescent girls. Headache: The Journal of Head and Face Pain, 49(8), 1186-1197. doi:10.1111/j.1526-4610.2009.01406.x.

Bradshaw, C. P., Waasdorp, T. E., Goldweber, A., \& Johnson, S. L. (2013). Bullies, gangs, drugs, and school: Understanding the overlap and the role of ethnicity and urbanicity. Journal of youth and adolescence, 42(2), 220-234.

Carlson, K. T. (2006). Poverty and youth violence exposure: Experiences in rural communities. Children \& Schools, 28(2), 87-96.

Carlyle, K., \& Steinman, K.J. (2007).Demographic differences in the prevalence, co-occurrence, and correlates of adolescent bullying at school. Journal of School Health, 77(9), 623-629.

Carney, J. V., Hazler, R. J., Oh, I., Hibel, L. C., \& Granger, D. A. (2010). The relations between bullying exposures in middle childhood, anxiety, and adrenocortical activity. Journal of School Violence, 9(2), 194-211

Cassidy, T. (2009). Bullying and victimization in school children: The role of social identity, problem-solving style, and family and school context. Social Psychology of Education, 12(1), 63-76

Cassidy, T., \& Taylor, L. (2005). Coping and psychological distress as a function of the bully victim dichotomy in older children. Social Psychology of Education, 8(3), 249-262. 
Centers for Disease Control and Prevention (CDC) (2012). Understanding bullying: Fact sheet.

Retrieved on November 3, 2016 from

https://www.cdc.gov/violenceprevention/pdf/bullying factsheet.pdf

Centers for Disease Control and Prevention (CDC) (2014). Featured Topic: Bullying Research.

Retrieved on November 15, 2016 from

https://www.cdc.gov/violenceprevention/youthviolence/bullyingresearch/index.html

Centers for Disease Control and Prevention (2015). Youth risk behavior surveillance—United

States. MMWR, Surveillance Summaries 2016; 65(SS9). Retrieved on December 3, 2016

from https://www.cdc.gov/healthyyouth/data/yrbs/pdf/2015/ss6506 updated.pdf

Cohen, S., Kamarck, T., \& Mermelstein, R. (1983). A global measure of perceived stress.

Journal of Health and Social Behavior, 24(4), 385-396.

Cohen, S. \& Williamson, G.M (1988). Perceived stress in a probability sample of the United States. In: Spacapan S, Oskamp S, eds. Social psychology of health. Beverly Hills, CA: Sage.

Combs, T. D. (2012). Perceived stress, anxiety and depressive symptoms associated with African-American youth who are bullies, victims, or Bully/Victims (Order No. 3508750). Available from ProQuest Dissertations \& Theses A\&I. (1018421616). Retrieved from http://search.proquest.com.proxy.lib.wayne.edu/docview/1018421616?accountid=14925 
Compas, B. E., Connor-Smith, J. K., Saltzman, H., Thomsen, A. H., \& Wadsworth, M. E. (2001). Coping with stress during childhood and adolescence: Problems, progress, and potential in theory and research. Psychological bulletin, 127(1), 87.

Campbell, M., Spears, B., Slee, P., Butler, D., \& Kift, S. (2012). Victims' perceptions of traditional and cyberbullying, and the psychosocial correlates of their victimization. Emotional and Behavioral Difficulties, 17(3-4), 389-401

Craig, W., Harel-Fisch, Y., Fogel-Grinvald, H., Dostaler, S., Hetland, J., Simons-Morton, B. Molcho, M., Gaspar de Mato, M., Overpeck, M., Due, P. \& Pickett, W. (2009). A crossnational profile of bullying and victimization among adolescents in 40 countries. International Journal of Public Health, 54 (Supplement 2), 216-224. doi: 10.1007/s00038-009-5413-9.

Cainkar, L. (2002) No longer invisible: Arab and Muslim exclusion after September 11, Middle East Report, 224. Retrieved on December 15, 2016 from www.merip.org/mer/mer224/224_cainkar.html

Cainkar, L. (2006). The Social Construction of Difference and the Arab American Experience. Journal of American Ethnic History, 25(2/3), 243-278. Retrieved on December 17, 2016 from http://www.jstor.org.proxy.lib.wayne.edu/stable/27501698

Carter, J. M. (2011). Examining the relationship among physical and psychological health, parent and peer attachment, and cyberbullying in adolescents in urban and suburban 
environments (Doctoral dissertation). Retrieved on December 16, 2016 from Wayne State University Data base $\underline{\text { http://digitalcommons.wayne.edu/cgi/viewcontent.cgi?article }=1367 \& \text { context=0a_disserta }}$ tions

Cazzell, M. (2008). Linking theory, evidence, and practice in assessment of adolescent inhalant use. Journal of Addictions Nursing, 19(1), 17-25.

Crick, N. R., \& Grotpeter, J. K. (1995). Relational aggression, gender, and social-psychological adjustment. Child development, 710-722.

Dao, T. K., Kerbs, J. J., Rollin, S. A., Potts, I., Gutierrez, R., Choi, K., ... \& Prevatt, F. (2006). The association between bullying dynamics and psychological distress. Journal of Adolescent Health, 39(2), 277-282.

Delfabbro, P., Winefield, T., Trainor, S., Dollard, M., Anderson, S., Metzer, J., \& Hammarstrom, A. (2006). Peer and teacher bullying/victimization of south Australian secondary school students: Prevalence and psychosocial profiles. British Journal of Educational Psychology, 76(1), 71-90.

DeLongis, A., Coyne, J. C., Dakof, G., Folkman, S., \& Lazarus, R. S. (1982). Relationship of daily hassles, uplifts, and major life events to health status. Health psychology, 1(2), 119. 
Derogatis, L. R., Lipman, R. S., Rickels, K., Uhlenhuth, E. H., \& Covi, L. (1974). The Hopkins Symptom Checklist (HSCL): A self-report symptom inventory. Behavioral science, $19(1), 1-15$.

Disha, I., Cavendish, J. C., \& King, R. D. (2011). Historical events and spaces of hate: Hate crimes against Arabs and Muslims in post-9/11 America. Social problems, 58(1), 21-46

Due, P., Holstein, B. E., Lynch, J., Diderichsen, F., Gabhain, S. N., Scheidt, P., \& Currie, C. (2005). Bullying and symptoms among school-aged children: international comparative cross sectional study in 28 countries. The European Journal of Public Health, 15(2), 128132.

El-Sayed, A.M. \& Galea, S. (2009).The health of Arab-Americans living in the United States: A systematic review of the literature. BMC Public Health, 9 (272). Open access retrieved from http://www.biomedcentral.com.proxy.lib.wayne.edu/content/pdf/1471-2458-9272.pdf.

Lee, E. H. (2012). Review of the psychometric evidence of the perceived stress scale. Asian Nursing Research, 6(4), 121-127.

Espelage, D. L., Bosworth, K., \& Simon, T. R. (2000). Examining the social context of bullying behaviors in early adolescence. Journal of Counseling \& Development, 78(3), 326-333. 
Espelage, D., \& Horne, A. (2008). School violence and bullying prevention: From research based explanations to empirically based solutions. Handbook of counseling psychology, 588-606.

Espelage, D. L., \& Swearer, S. M. (2003). Research on school bullying and victimization: What have we learned and where do we go from here?. School Psychology Review, 32(3), 365384.

Farrington, D. P., \& Ttofi, M. M. (2011). Bullying as a predictor of offending, violence and later life outcomes. Criminal Behaviour and Mental Health, 21(2), 90-98.

Fassaert, T., De Wit, M. A. S., Tuinebreijer, W. C., Wouters, H., Verhoeff, A. P., Beekman, A. T. F., \& Dekker, J. (2009). Psychometric properties of an interviewer-administered version of the Kessler Psychological Distress scale (K10) among Dutch, Moroccan and Turkish respondents. International Journal of Methods in Psychiatric Research, 18(3), $159-168$.

Faul, F., Erdfelder, E., Buchner, A., \& Lang, A. G. (2009). Statistical power analyses using G* Power 3.1: Tests for correlation and regression analyses. Behavior Research Methods, 41(4), 1149-1160.

Fekkes, M., Pijpers, F. I., Fredriks, A. M., Vogels, T., \& Verloove-Vanhorick, S. P. (2006). Do bullied children get ill, or do ill children get bullied? A prospective cohort study on the 
relationship between bullying and health-related symptoms. Pediatrics, 117(5), 15681574.

Fekkes, M., Pijpers, F. I., \& Verloove-Vanhorick, S. P. (2004). Bullying behavior and associations with psychosomatic complaints and depression in victims. The Journal of pediatrics, 144(1), 17-22.

Finger, L.R., Yeung, A.S., Craven, R.G., Parada, R.H. \& Newey, K. (2008). Adolescent peer relations instrument: Assessment of its reliability and construct validity when used with upper primary students, presented at Australian Association for Research in Education Annual Conference, Brisbane, 2008. Sydney: Australian Association for Research in Education

Fitzpatrick, K. M. (1997). Aggression and environmental risk among low-income AfricanAmerican youth. Journal of Adolescent Health, 21, 172-178.

Fitzpatrick, K.M., Dulin, A.J., \&Piko, B.F. (2007). Not just pushing and shoving: School bullying among African American adolescents. The Journal of School Health, 77(1), 1622.

Folkman, S., Lazarus, R. S., Dunkel-Schetter, C., DeLongis, A., \& Gruen, R. J. (1986). Dynamics of a stressful encounter: cognitive appraisal, coping, and encounter outcomes. Journal of personality and social psychology, 50(5), 992. 
Frisen, A., Jonsson, A.K., Persson, C. (2007). Adolescents' perception of bullying: Who is the victim? Who is the bully? What can be done to stop bullying? Adolescence, 42 (168), $749-761$

Gini, G. (2008). Associations between bullying behavior, psychosomatic complaints, emotional and behavioral problems. Journal of pediatrics and child health, 44(9), 492-497.

Gini, G., Albiero, P., Benelli, B., \& Altoè, G. (2007). Does empathy predict adolescents' bullying and defending behavior?. Aggressive behavior, 33(5), 467-476.

Gini, G., \& Espelage, D. L. (2014). Peer victimization, cyberbullying, and suicide risk in children and adolescents. JAMA: Journal of The American Medical Association, 312(5), 545-546. doi:10.1001/jama.2014.3212

Gini, G., \& Pozzoli, T. (2009). Association between bullying and psychosomatic problems: A meta-analysis. Pediatrics, 123(3), 1059-1065.

Gini, G., Pozzoli, T., Lenzi, M., \& Vieno, A. (2014). Bullying victimization at school and headache: A meta-analysis of observational studies. Headache: The Journal of Head and Face Pain, 54(6), 976-986. doi:10.1111/head.12344

Gladstone, G. L., Parker, G. B., \& Malhi, G. S. (2006). Do bullied children become anxious and depressed adults?: A cross-sectional investigation of the correlates of bullying and anxious depression. Journal of Nervous and Mental Disease, 194(3), 201-208.

doi:10.1097/01.nmd.0000202491.99719.c3 
Glew, G. M., Fan, M. Y., Katon, W., Rivara, F. P., \& Kernic, M. A. (2005). Bullying, psychosocial adjustment, and academic performance in elementary school. Archives of pediatrics \& adolescent medicine, 159(11), 1026-1031.

Gobina, L., Zaborskis, A., Pudule, L., Kalnins, L., \& Villerusa, A. (2008). Bullying and subjective health among adolescents at schools in Latvia and Lithuania. International Journal of Public Health, 53(5), 272-276.

Goldweber, A., Waasdorp, T.E., \& Bradshaw, C.B. (2013). Examining Associations between Race, Urbanicity, and patterns of bullying involvement. Journal of Youth and Adolescence, 42 (2), 206-219 doi 10.1007/s10964-012-9843.

Grant, K. E., Compas, B. E., Stuhlmacher, A. F., Thurm, A. E., McMahon, S. D., \& Halpert, J. A. (2003). Stressors and child and adolescent psychopathology: moving from markers to mechanisms of risk. Psychological bulletin, 129(3), 447.

Grant, K. E., Compas, B. E., Thurm, A. E., McMahon, S. D., \& Gipson, P. Y. (2004). Stressors and child and adolescent psychopathology: Measurement issues and prospective effects. Journal of Clinical Child and Adolescent Psychology, 33(2), 412-425.

Grennan, S., \& Woodhams, J. (2007). The impact of bullying and coping strategies on the psychological distress of young offenders. Psychology, Crime \& Law, 13(5), 487-504. 
Haboush, K.L. (2007). Working with Arab American families: Culturally competent practice for school psychologists. Psychology in the Schools, Vol. 44(2). Open Access Published online in Wiley Inter Science www.interscience.wiley.com.

Hamilton, L. D., Newman, M. L., Delville, C. L., \& Delville, Y. (2008). Physiological stress response of young adults exposed to bullying during adolescence. Physiology \& Behavior, 95(5), 617-624. doi:10.1016/j.physbeh.2008.09.001

Hammad, A., Kysia, R., Rabah, R., Hassoun, R., \& Connelly, M. (1999). Guide to Arab culture: Health care delivery to the Arab American community. Arab Community Center for Economic and Social Services, Dearborn, MI.

Hampel, P., \& Petermann, F. (2006). Perceived stress, coping, and adjustment in adolescents. Journal Of Adolescent Health, 38(4), 409-415.

doi:10.1016/j.jadohealth.2005.02.014

Hanish, L. D., \& Guerra, N. G. (2000). The roles of ethnicity and school context in predicting children's victimization by peers. American Journal of Community Psychology, 28 (2), $201-223$.

Hanson, M. J. S., \& Laffrey, S. C. (1999). Cross-cultural study of beliefs about smoking among teenaged females. Western Journal of Nursing Research, 21(5), 635-651. 
Harel-Fisch, Y., Walsh, S. D., Fogel-Grinvald, H., Amitai, G., Pickett, W., Molcho, M., ... \& Craig, W. (2011). Negative school perceptions and involvement in school bullying: A universal relationship across 40 countries. Journal of adolescence, 34(4), 639-652.

Hassoun RJ. Arab Americans in Michigan. Lansing: Michigan State University Press; 2005.

Hawker, D. S. J. and Boulton, M. J. (2000), Twenty years' research on peer victimization and psychosocial maladjustment: A meta-analytic review of cross-sectional studies. Journal of Child Psychology and Psychiatry, 4(4), 441-455. doi: 10.1111/14697610.00629

Haynie, D. L., Nansel, T., Eitel, P., Crump, A. D., Saylor, K., Yu, K., \& Simons-Morton, B. (2001). Bullies, victims, and bully/victims: Distinct groups of at-risk youth. The Journal of Early Adolescence, 21(1), 29-49.

Hemphill, S. A., Heerde, J. A., \& Gomo, R. (2014). A conceptual definition of school-based bullying for the Australian research and academic community. Canberra, Australia: Australian Research Alliance for Children and Youth

Herrero, J., Estévez, E., \& Musitu, G. (2006). The relationships of adolescent school-related deviant behavior and victimization with psychological distress: Testing a general model of the mediational role of parents and teachers across groups of gender and age. Journal of Adolescence, 29(5), 671-690 
Hertz, M. F., Donato, I., \& Wright, J. (2013). Bullying and suicide: A public health approach. Journal of Adolescent Health, 53(1, Suppl), S1-S3.

doi:10.1016/j.jadohealth.2013.05.002

Hinduja, S., \& Patchin, J. W. (2010). Bullying, cyberbullying, and suicide. Archives of suicide research, 14(3), 206-221.

Holler, B. \& Hurrelmann, K (1990). The role of parent and peer contacts for adolescents' state of health. In K. Hurrelmann \& F. Lösel (Eds.), Health hazards in adolescence (pp, 409432). Germany: Walter de Gruyte.

Hong, J. S., \& Espelage, D. L. (2012). A review of research on bullying and peer victimization in school: An ecological system analysis. Aggression and Violent Behavior, 17(4), 311-322.

Hong, J.S., Davis, J.P., Sterzing, P.R., Yoon, J., Choi, S., \& Smith, D.C. (2014). A conceptual framework for understanding the association between school bullying victimization and substance misuse. American Journal of Orthopsychiatry, 84(6), 696-710.

Hong, J. S., Kral, M. J., \& Sterzing, P. R. (2015). Pathways from bullying perpetration, victimization, and bully victimization to suicidality among school-aged youth: a review of the potential mediators and a call for further investigation. Trauma, Violence, \& Abuse, 16(4), 379-390. 
Hussein, M. H. (2012). The social and emotional skills of bullies, victims, and bully-victims of Egyptian primary school children. International Journal of psychology, 48(5), 910-21. doi: $10.1080 / 00207594$

Ibish, I. (2003). Report on hate crimes and discrimination against Arab Americans: The postSeptember 11 backlash, September 11, 2001-October 11, 2002. Washington, DC: American-Arab Anti-Discrimination Committee.

Idsoe, T., Dyregrov, A., \& Idsoe, E. C. (2012). Bullying and PTSD symptoms. Journal of abnormal child psychology, 40(6), 901-911.

Jolliffe, D., \& Farrington, D. P. (2006). Examining the relationship between low empathy and bullying. Aggressive behavior, 32(6), 540-550.

Juvonen, J., Graham, S., \& Schuster, M. A. (2003). Bullying among young adolescents: The strong, the weak, and the troubled. Pediatrics, 112(6), 1231-1237.

Kadıoğlu, H., Şişman, F. N., \& Ergün, A. (2012). Reliability and validity of the Turkish version of children's somatization inventory. Asian nursing research,6 (1), 9-12.

Kazarian, S.S. \& Ammar, J. (2013). School bullying in the Arab world: A Review. Arab Journal of Psychiatry, 24 (1), 37-45.

Kessler, R.C., Andrews, G., Colpe, .et al (2002). Short screening scales to monitor population prevalence and trends in non-specific psychological distress. Psychological Medicine, 32, 959-956. 
Kessler, R.C., Barker, P.R., Colpe, L.J., Epstein, J.F., Gfroerer, J.C., Hiripi, E., Howes, M.J, Normand, S-L.T., Manderscheid, R.W., Walters, E.E., Zaslavsky, A.M. (2003). Screening for serious mental illness in the general population Archives of General Psychiatry. 60(2), 184-189.

King, C. A., Horwitz, A., Berona, J., \& Jiang, Q. (2013). Acutely suicidal adolescents who engage in bullying behavior: 1-year trajectories. Journal of Adolescent Health, 53(1), S43-S50. doi:10.1016/j.jadohealth.2012.09.016

Klomek, A. B., Kleinman, M., Altschuler, E., Marrocco, F., Amakawa, L., \& Gould, M. S. (2013). Suicidal adolescents' experiences with bullying perpetration and victimization during high school as risk factors for later depression and suicidality. Journal of Adolescent Health, 53(1, Suppl), S37-S42. doi:10.1016/j.jadohealth.2012.12.008.

Klomek, A. B., Sourander, A., \& Gould, M. (2010). The association of suicide and bullying in childhood to young adulthood: A review of cross-sectional and longitudinal research findings. The Canadian Journal of Psychiatry, 55(5), 282-288

Knack, J. M., Jensen-Campbell, L. A., \& Baum, A. (2011). Worse than sticks and stones? Bullying is associated with altered HPA axis functioning and poorer health. Brain and Cognition, 77(2), 183-190. doi:10.1016/j.bandc.2011.06.011 
Konishi, C., \& Hymel, S. (2009). Bullying and stress in early adolescence: The role of coping and social support. The Journal Of Early Adolescence, 29(3), 333-356. doi: $10.1177 / 0272431608320126$

Kowalski, R. M., Giumetti, G. W., Schroeder, A. N., \& Lattanner, M. R. (2014). Bullying in the digital age: A critical review and meta-analysis of cyberbullying research among youth. Psychological bulletin, 140(4), 1073.

Kowalski, R. M., \& Limber, S. P. (2007). Electronic bullying among middle school students. Journal of adolescent health, 41(6), S22-S30.

Kowalski, R. M., \& Limber, S. P. (2013). Psychological, physical, and academic correlates of cyberbullying and traditional bullying. Journal of Adolescent Health, 53(1, Suppl), S13S20. doi:10.1016/j.jadohealth.2012.09.018

Kowalski, R. M., Morgan, C. A., \& Limber, S. P. (2012). Traditional bullying as a potential warning sign of cyberbullying. School Psychology International, 33(5), 505-519.

Kurokawa, M. (2010). Relationships between victimization and psychological stress, peer relationships, and enjoyment of school life: Traditional and cyber bullying. Japanese Journal Of Counseling Science, 43(3), 171-181.

La Greca, A. M., \& Harrison, H. M. (2005). Adolescent peer relations, friendships, and romantic relationships: Do they predict social anxiety and depression. Journal of Clinical Child and Adolescent Psychology, 34(1), 49-61. 
Lamb, J., Pepler, D. J., \& Craig, W. (2009). Approach to bullying and victimization. Canadian Family Physician, 55(4), 356-360.

Lavigne, J. V., Saps, M., \& Bryant, F. B. (2012). Reexamining the factor structure of somatization using the children's somatization inventory (CSI-24) in a community sample. Journal of pediatric psychology, 37(8), 914-924.

Lazarus, R. S., \& Folkman, S. (1984). Stress, appraisal, and coping. Springer publishing company.

Litwiller, B. J., \& Brausch, A. M. (2013). Cyber bullying and physical bullying in adolescent suicide: The role of violent behavior and substance use. Journal of Youth and Adolescence, 42(5), 675-684. doi:10.1007/s10964-013-9925-5

Livingstone, S., \& Smith, P. K. (2014). Annual research review: Harms experienced by child users of online and mobile technologies: The nature, prevalence and management of sexual and aggressive risks in the digital age. Journal of child psychology and psychiatry, 55(6), 635-654

Loescher, L. J., Clark, L., Atwood, J. R., Leigh, S., \& Lamb, G. (1989). The impact of the cancer experience on long-term survivors. Oncology Nursing Forum 17 (2), 223-229.

Love, E. (2009). Confronting Islamophobia in the United States: framing civil rights activism among Middle Eastern Americans. Patterns of Prejudice, 43(3-4), 401-425. 
Low, S., \& Espelage, D. (2013). Differentiating cyber bullying perpetration from non-physical bullying: Commonalities across race, individual, and family predictors. Psychology of Violence, 3(1), 39-52. doi: 10.1037/a0030308.

Luk, J. W., Wang, J., \& Simons-Morton, B. G. (2012). The co-occurrence of substance use and bullying behaviors among U.S. adolescents: Understanding demographic characteristics and social influences. Journal of Adolescence, 35(5), 1351-1360.

Lyon, B. L. (2000). Stress, coping, and health: A conceptual overview. In V. H. Rice (Ed.), Handbook of stress, coping, and health: Implications for nursing research, theory, and practice (pp. 3-23). Thousand Oaks, CA: Sage

Maidaniuc-Chirilă, T., \& Gherasim, L. R. (2014). School bullying and adolescents' depressive s ymptoms: The mediation role of perceived stress. Journal of Psychological and Educational Research (JPER), 22(2), 7-27.

Marsh, H. W., Nagengast, B., Morin, A. S., Parada, R. H., Craven, R. G., \& Hamilton, L. R. (2011). Construct validity of the multidimensional structure of bullying and victimization: An application of exploratory structural equation modeling. Journal Of Educational Psychology, 103(3), 701-732. doi:10.1037/a0024122

McGuckin, C., Lewis, C. A., \& Cummins, P. K. (2010). Experiences of school bullying, psychological well-being and stress in Northern Ireland: Data from the 2004 Young Life 
and Times Survey. The Irish Journal Of Psychology, 31(1-4), 53-61.

doi:10.1080/03033910.2010.10446322

McKenney, K. S., Pepler, D., Craig, W., \& Connolly, J. (2006). Peer victimization and psychosocial adjustment: The experiences of Canadian immigrant youth. Electronic Journal of Research in Educational Psychology, 9(4), 239-264.

McVie, S. (2014). The impact of bullying perpetration and victimization on later violence and psychological distress: a study of resilience among a Scottish youth cohort. Journal of School Violence, 13(1), 39-58.

Menesini, E., Modena, M., Tani, F. (2009). Bullying and Victimization in Adolescence: Concurrent and Stable Roles and Psychological Health Symptoms. The Journal Genetic Psychology, 170(2), 115-133.

Meltzer, H., Vostanis, P., Ford, T., Bebbington, P., \& Dennis, M. S. (2011). Victims of bullying in childhood and suicide attempts in adulthood. European Psychiatry, 26(8), 498-503.

Mesch, G.S. (2009). Parental mediation, online activities, and cyber-bullying. Cyber Psychology and Behavior, 12(4), 387-393.

Mishna, F. (2004). A qualitative study of bullying from multiple perspectives. Children \& Schools, 26(4), 234-247. 
Moore, S., \& Munro, M. (1990). The Neuman System Model applied to mental health nursing of older adults. Journal Of Advanced Nursing, 15(3), 293-299. doi:10.1111/j.13652648.1990.tb01816.x

Mouttapa, M., Valente, T., Gallaher, P., Rohrbach, L. A., \& Unger, J. B. (2004). Social network predictors of bullying and victimization. Adolescence, 39 (154), 315-335.

Muedini, F. (2009). Muslim American college youth: Attitudes and responses five years after 9/11. The Muslim World, 99(1), 39-59.

Mynard, H., Joseph, S., \& Alexander, J. (2000). Peer-victimization and posttraumatic stress in adolescents. Personality and Individual Differences, 29(5), 815-821.

Naber, N. (2000). Ambiguous insiders: An investigation of Arab American invisibility. Ethnic and Racial Studies, 23(1), 37-61.

Nansel, T.R., Overpeck, M., Pilla, R.S., Ruan, W.J., Simons-Morton, B. \& Scheidt, P. (2001). Bullying behaviors among U.S. youth: Prevalence and association with psychosocial adjustment Journal of the American Medical Association, 285 (16), 2094-2100

Nassar-McMillan, S.C., Ajrouch, K. J. \& Hakim-Larson, J. (2013). Biopsychosocial perspectives on Arab Americans: Culture, development, and health. New York, NY: Springer. Retrieved from http://www.eblib.com

Nassar-McMillan, S.C. \& Hakim-Larson, J. (2003). Counseling considerations among ArabAmericans. Journal of Counseling and Development, 81 (2), 150-160. 
Neuman, B. M. (1990). Health as a continuum based on the Neuman systems model. Nursing science quarterly, 3(3), 129-135.

Neuman, B. (1995). The Neuman Systems Model (3rd ed.). Norwalk, CT: Appleton \& Lange.

Neuman, B., \& Fawcett, J. (2002). The Neuman system model. (4th ed.). Upper Saddle River, NJ: Prentice Hall.

Neuman, B., \& Reed, K. S. (2007). A Neuman systems model perspective on nursing in 2050. Nursing science quarterly, 20(2), 111-112.

Newman, M. L., Holden, G. W \& Delville, Y. (2005). Isolation and the stress of being bullied. Journal of Adolescence, 28 (3), 343-357

Nydell, M.K. (2012). Understanding Arabs: A contemporary guide to Arab society (5th ed.). Boston, MA: Intercultural Press. Retrieved from http://www.eblib.com

Olsen L. (1988). Crossing the schoolhouse border: Immigrant children in California. Phi Delta Kappan, 70 (3), 211-218.

Olsen, L. (2000). Learning English and learning America: Immigrants in the center of a storm. Theory into Practice, 39 (4), 196-202.

Olweus, D. (1978). Aggression in the schools: Bullies and whipping boys. Washington, DC: Hemisphere Publishing Corp.

Olweus, D. (1993a). Bullying at school: What we know and what we can do. Oxford, UK, and Cambridge, MA, USA: Blackwell Publishers. 
Olweus, D. (1993b). Victimization by peers: Antecedents and long-term outcomes. Social withdrawal, inhibition, and shyness in childhood, 315, 341.

Olweus, D. (1996). Bully/Victim Problems at School: Facts and Effective Intervention. Reclaiming Children and Youth: Journal of Emotional and Behavioral Problems, 5(1), 15-22.

O’Moore, M., \& Kirkham, C. (2001). Self-esteem and its relationship to bullying behavior. Aggressive behavior, 27(4), 269-283.

Ouellet-Morin, I., Wong, C. Y., Danese, A., Pariante, C. M., Papadopoulos, A. S., Mill, J., \& Arseneault, L. (2013). Increased serotonin transporter gene (SERT) DNA methylation is associated with bullying victimization and blunted Cortisol response to stress in childhood: A longitudinal study of discordant monozygotic twins. Psychological Medicine, 43(9), 1813-1823.

Padela, A. I., \& Heisler, M. (2010). The association of perceived abuse and discrimination after September 11, 2001, with psychological distress, level of happiness, and health status among Arab Americans. American Journal of Public Health, 100(2), 284.

Parada, R. (2000). Adolescent Peer Relations Instrument: A theoretical and empirical basis for the measurement of participant roles in bullying and victimization of adolescence: An interim test manual and a research monograph: A test manual. Publication Unit, Self- 
concept Enhancement and Learning Facilitation (SELF) Research Centre, University of Western Sydney.

Parada, R. H. (2006). School bullying: psychosocial determinants and effective intervention. Unpublished doctoral dissertation, University of Western Sydney, Sydney.

Patchin, J. W., \& Hinduja, S. (2006). Bullies move beyond the schoolyard a preliminary look at cyberbullying. Youth violence and juvenile justice, 4(2), 148-169.

Pavlovskaya, M., \& Bier, J. (2012). Mapping census data for difference: towards the heterogeneous geographies of Arab American communities of the New York metropolitan area. Geoforum, 43(3), 483-496.

Peek, L. (2003). Reactions and response: Muslim student's experiences on New York City campuses post 9/11. Journal of Muslim Minority Affairs, 23(2): 273-85.

Peguero, A. A. (2009). Victimizing the children of immigrants: Latino and Asian American student victimization. Youth and Society, 41 (2), 186-208.

Pepler, D. J., Craig, W. M., Connolly, J. A., Yuile, A., McMaster, L., \& Jiang, D. (2006). A developmental perspective on bullying. Aggressive behavior, 32(4), 376-384.

Peskin, M. F., Tortolero, S. R., \& Markham, C. M. (2006). Bullying and victimization among Black and Hispanic adolescents. Adolescence, 4l(163), 467. 
Peskin, M. F., Tortolero, S. R., Markham, C. M., Addy, R. C., \& Baumler, E. R. (2007).

Bullying and victimization and internalizing symptoms among low-income Black and Hispanic students. Journal of Adolescent Health, 40(4), 372-375.

Peterson, R. L., \& Skiba, R. (2001). Creating school climates that prevent school violence. The Clearing House, 74(3), 155-163.

Pew Research Center (2007). Muslim Americans: Middle class and mostly mainstream. Washington, DC: Pew Research Center.

Pottie, K., Dahal, G., Georgiades, K., Premji, K., \& Hassan, G. (2014). Do first generation immigrant adolescents face higher rates of bullying, violence and suicidal behaviors than do third generation and native born?. Journal of Immigrant and Minority Health, 110.

Qin, D. B., Way, N., \& Rana, M. (2008). The "model minority" and their discontent: Examining peer discrimination and harassment of Chinese American immigrant youth. New Directions for Child and Adolescent Development, 2008 (121), 27-42.

Raskauskas, J., \& Stoltz, A. D. (2007). Involvement in traditional and electronic bullying among adolescents. Developmental psychology, 43(3), 564.

Read, J. N. G., Amick, B., \& Donato, K. M. (2005). Arab immigrants: a new case for ethnicity and health?. Social Science \& Medicine, 61(1), 77-82. 
Reed, K. S. (1993). Adapting the Neuman systems model for family nursing. Nursing science quarterly, 6(2), 93-97.

Reijntjes, A., Kamphuis, J. H., Prinzie, P., Boelen, P. A., Van der Schoot, M., \& Telch, M. J. (2011). Prospective linkages between peer victimization and externalizing problems in children: A meta-analysis. Aggressive behavior, 37(3), 215-222.

Reijntjes, A., Kamphuis, J. H., Prinzie, P., \& Telch, M. J. (2010). Peer victimization and internalizing problems in children: A meta-analysis of longitudinal studies. Child abuse \& neglect, 34(4), 244-252.

Rigby, K. (1998). The relationship between reported health and involvement in bully/victim problems among male and female secondary schoolchildren. Journal of Health Psychology, 3(4), 465-476. doi:10.1177/135910539800300402

Rigby, K. (2000). Effects of peer victimization in schools and perceived social support on adolescent well-being. Journal of Adolescence, 23(1), 57-68.

Rice, V. H. (2000). Handbook of stress, coping and health. London: International Educational and Professional Publisher.

Roberti, J. W., Harrington, L. N., \& Storch, E. A. (2006). Further psychometric support for the 10-Item Version of the Perceived Stress Scale. Journal of College Counseling, 9(2), 135147. 
Rodkin, P. C., \& Hodges, E. V. (2003). Bullies and victims in the peer ecology: Four questions for psychologists and school professionals. School Psychology Review, 32(3), 384-400.

Rodkin, P., Farmer, T., Pearl, R. \& Van Acker, R. (2006). They're cool: Social status and peer group supports for aggressive boys and girls. Social Development, 15 (2). 175-204

Rudolph, K. D., Troop-Gordon, W., \& Granger, D. A. (2011). Individual differences in biological stress responses moderate the contribution of early peer victimization to subsequent depressive symptoms. Psychopharmacology, 214(1), 209-219.

Salari, S. (2002). Invisible in Aging Research Arab Americans, Middle Eastern Immigrants, and Muslims in the United States. The Gerontologist, 42(5), 580-588.

Salmivalli, C. (2010). Bullying and the peer group: A review. Aggression and violent behavior, 15(2), 112-120.

Sansone, R. A., \& Sansone, L. A. (2008). Bully victims: psychological and somatic aftermaths. Psychiatry (Edgmont), 5(6), 62.

Seals, D., \&Young, J. (2003). Bullying and victimization: Prevalence and relationship to gender, grade level, ethnicity, self-esteem, and depression. Adolescence, 38 (152), 735-747.

Schneider, S. K., O'Donnell, L., Stueve, A., \& Coulter, R. W. (2012). Cyberbullying, school bullying, and psychological distress: A regional census of high school students. American Journal of Public Health, 102(1), 171-177

Schuster, M. A., Elliott, M. N., Kanouse, D. E., Wallander, J. L., Tortolero, S. R., Ratner, J. A., 
Banspach, S. W. (2012). Racial and ethnic health disparities among fifth-graders in three cities. New England Journal of Medicine, 367(8), 735-745.

Sawyer, A. L., Bradshaw, C. P., \& O'Brennan, L. M. (2008). Examining ethnic, gender, and developmental differences in the way children report being a victim of "bullying" on selfreport measures. Journal of Adolescent Health, 43(2), 106-114.

Sheikh, M. F. (2009). An exploratory study of the challenges of living in American as a Muslim adolescent attending public school (Doctoral dissertation, Rutgers University-Graduate School of Applied and Professional Psychology). Retrieved from https://rucore.libraries.rutgers.edu/rutgers-lib/26145/

Shetgiri, R., Lin, H., Avila, R. M., \& Flores, G. (2012). Parental characteristics associated with bullying perpetration in US children aged 10 to 17 years. American journal of public health, 102(12), 2280-2286.

Shin, J. Y., D’Antonio, E., Son, H., Kim, S., \& Park, Y. (2011). Bullying and discrimination experiences among Korean-American adolescents. Journal Of Adolescence, 34(5), 873883. doi:10.1016/j.adolescence.2011.01.004

Singh, A. (2002). "We are Not the Enemy": Hate Crimes Against Arabs, Muslims, and Those Perceived to be Arab Or Muslim After September 11 (Vol. 14, No. 6). Human Rights Watch. Retrieved on December 20, 2016 from https://books-googlecom.proxy.lib.wayne.edu/books?hl=en\&lr=\&id=nzFteIAWOFkC\&oi=fnd\&pg=PA3\&dq=).\%22 
+ We + are + Not + the + Enemy $\% 22:+$ Hate + Crimes + Against + Arabs,+ Muslims,+ and + Those $+\% 09$ Per

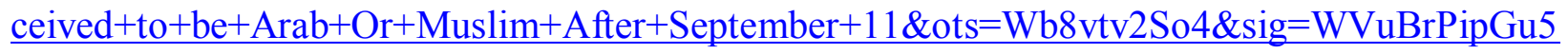

$\underline{\mathrm{X}}-$

CU5mMdtudWF2 $\mathrm{w} \# \mathrm{v}=$ onepage $\& \mathrm{q}=) . \% 22 \% 20 \mathrm{We} \% 20$ are $\% 20$ Not $\% 20$ the $\% 20$ Enemy $\% 22 \% 3 \mathrm{~A}$

\%20Hate\%20Crimes\%20Against $\% 20$ Arabs\%2C\%20Muslims\%2C\%20and $\% 20$ Those $\% 20 \% 09 \mathrm{P}$

erceived $\% 20$ to $\% 20 \mathrm{be} \% 20$ Arab $\% 20$ Or $\% 20$ Muslim $\% 20$ After $\% 20$ September $\% 2011 \& \mathrm{f}=$ false

Skalski, C. A., DiGerolamo, L., \& Gigliotti, E. (2006). Stressors in five client populations:

Neuman systems model-based literature review. Journal of advanced nursing, 56(1), 69-

78.

Sleet, D. A., \& Dane, J. K. (1985). Wellness factors among adolescents. Adolescence, 20 (80), 909-920

Smokowski, P. R., \& Kopasz, K. H. (2005).Bullying in school: An overview of types, effects, family characteristics, and intervention strategies. Children and Schools, 27, 101-109.

Somerville, L. H. (2013). The teenage brain sensitivity to social evaluation. Current directions in psychological science, 22(2), 121-127.

Sontag, L. M., \& Graber, J. A. (2010). Coping with perceived peer stress: Gender-specific and common pathways to symptoms of psychopathology. Developmental Psychology, 46(6), 1605-1620. doi:10.1037/a0020617 
Spriggs, A. L., Iannotti, R. J., Nansel, T. R., \& Haynie, D. L. (2007). Adolescent bullying involvement and perceived family, peer and school relations: Commonalities and differences across race/ethnicity. The Journal of Adolescent Health : Official Publication of the Society for Adolescent Medicine, 41(3), 283-293.

doi:10.1016/j.jadohealth.2007.04.009

Spurr, S., Bally, J., Ogenchuk, M., \& Walker, K. (2012). A framework for exploring adolescent wellness. Pediatric nursing, 38(6), 320.

Srabstein, J. \& Piazza, T. (2012). Is there a syndrome of bullying? International Journal of Adolescent Medicine and Health, 24(1), 91-96.

Stapinski, L. A., Araya, R., Heron, J., Montgomery, A. A., \& Stallard, P. (2015). Peer victimization during adolescence: Concurrent and prospective impact on symptoms of depression and anxiety. Anxiety, Stress \& Coping: An International Journal, 28(1), 105120. doi:10.1080/10615806.2014.962023

Stein, J. A., Dukes, R. L., Warren, J. I. (2007). Adolescent male bullies, victims, and bully victims: a comparison of psychosocial and behavioral characteristics. Journal of Pediatric Psychology. 32(3), 273-282

Steinberg, L. (2011). Adolescence (9th ed.). New York: McGraw-Hill.

Steinberg, L., \& Morris, A. S. (2001). Adolescent development. Journal of Cognitive Education and Psychology, 2(1), 55-87. 
Sticca, F., \& Perren, S. (2013). Is cyberbullying worse than traditional bullying? Examining the differential roles of medium, publicity, and anonymity for the perceived severity of bullying. Journal of Youth and Adolescence, 42(5), 739-750.

Suleiman, M. W. (1999). Islam, Muslims and Arabs in America: the other of the other of the other. Journal of Muslim Minority Affairs, 19(1), 33-47.

Thomas, H. J., Chan, G. C., Scott, J. G., Connor, J. P., Kelly, A. B., \& Williams, J. (2015). Association of different forms of bullying victimisation with adolescents' psychological distress and reduced emotional wellbeing. Australian and New Zealand Journal of Psychiatry. Advance online publication. doi:10.1177/0004867415600076

Timraz, S. M., Alhasanat, D. I., Albdour, M. M., Lewin, L., Giurgescu, C., \& Kavanaugh, K. (2017). Challenges and strategies for conducting sensitive research with an Arab American population. Applied Nursing Research, 33, 1-4.

Tokunaga, R. S. (2010). Following you home from school: A critical review and synthesis of research on cyberbullying victimization. Computers in human behavior, 26(3), 277-287.

Totura, C. M. W., Karver, M. S., \& Gesten, E. L. (2014). Psychological distress and student engagement as mediators of the relationship between peer victimization and achievement in middle school youth. Journal of youth and adolescence, 43(1), 40-52. 
Ttofi, M. M., \& Farrington, D. P. (2011). Effectiveness of school-based programs to reduce bullying: A systematic and meta-analytic review. Journal of Experimental Criminology, 7(1), 27-56.

Turner, M. G., Exum, M. L., Brame, R., \& Holt, T. J. (2013). Bullying victimization and adolescent mental health: General and typological effects across sex. Journal of Criminal Justice, 41(1), 53-59. doi:10.1016/j.jcrimjus.2012.12.005

United State Census Bureau of the Census (2003). The Arab Population: 2000. Retrieved on October 25, 2016 from http://www.census.gov/prod/2003pubs/c2kbr-23.pdf?cssp=SERP

United State Commission on Civil Rights. (2011). Peer-to-peer violence and bullying examining the federal response. (Pursuant to Public Law 103-419). Washington, DC: U.S. Commission on Civil Rights. Retrieved from http://www.usccr.gov/pubs/2011statutory.pdf on (May, 15, 2015).

Vaillancourt, T., Duku, E., Becker, S., Schmidt, L. A., Nicol, J., Muir, C., \& MacMillan, H. (2011). Peer victimization, depressive symptoms, and high salivary cortisol predict poorer memory in children. Brain and Cognition, 77(2), 191-199.

Vaillancourt, T., Duku, E., Decatanzaro, D., Macmillan, H., Muir, C., \& Schmidt, L. A. (2008). Variation in hypothalamic-pituitary-adrenal axis activity among bullied and non-bullied children. Aggressive Behavior, 34(3), 294-305. doi:10.1002/ab.20240 
Vanderbilt, D., \& Augustyn, M. (2010). The effects of bullying. Paediatrics and Child Health, 20(7), 315-320.

Velderman, M.K., Dorst, A.G., Wiefferink, C.H., Detmar, S.B. \&Paulussen, T. (2008). Quality of life of victims, bullies, and bully/victims among school-aged children in the Netherlands. Advances in School Mental Health Promotion, 1(4), 42-52.

Vernberg, E. M., Nelson, T. D., Fonagy, P., \& Twemlow, S. W. (2011). Victimization, aggression, and visits to the school nurse for somatic complaints, illnesses, and physical injuries. Pediatrics, 127(5), 842-848.

Vreeman, R. C., \& Carroll, A. E. (2007). A systematic review of school-based interventions to prevent bullying. Archives of Pediatrics \& Adolescent Medicine, 161(1), 78-88

Wang, J., Iannotti, R. J., \& Luk, J. W. (2010). Bullying victimization among underweight and overweight US youth: Differential associations for boys and girls. Journal of Adolescent Health, 47(1), 99-101.

Wang, J., Iannotti, R. J., \& Nansel, T. R. (2009). School bullying among adolescents in the United States: Physical, verbal, relational, and cyber. Journal of Adolescent Health, 45(4), 368-375.

Wang, J., Nansel, T. R., \& Iannotti, R. J. (2011). Cyber and traditional bullying: Differential association with depression. Journal of Adolescent Health, 48(4), 415-417.

doi:10.1016/j.jadohealth.2010.07.012 
Waasdorp, T. E., \& Bradshaw, C. P. (2015). The overlap between cyberbullying and traditional bullying. Journal of Adolescent Health, 56(5), 483-488.

doi:10.1016/j.jadohealth.2014.12.002

Walker, L. S., Beck, J. E., Garber, J., \& Lambert, W. (2009). Children's Somatization Inventory: psychometric properties of the revised form (CSI-24). Journal of pediatric psychology, 34(4), 430-440.

West, A., \& Salmon, G. (2000). Bullying and depression: A case report. International Journal of Psychiatry In Clinical Practice, 4(1), 73-75. doi:10.1080/13651500050518433

Wingfield, M. (2006). Arab Americans: Into the multicultural mainstream. Equity and Excellence in Education, 39(3), 253-266. doi:10.1080/10665680600788453.

Wolke, D., Woods, S., Bloomfield, L., \& Karstadt, L. (2001). Bullying involvement in primary school and common health problems. Archives of disease in childhood, 85(3), 197-201.

Wray-Lake, L., Syvertsen, A.K., \& Flanagan, C.A. (2008). Contested Citizenship and Social Exclusion: Adolescent Arab American Immigrants' Views of the Social Contract. Applied Development Science, 12(2), 84-92

Yarcheski, A., \& Mahon, N. E. (2000). A causal model of depression in early adolescents. Western Journal of Nursing Research, 22(8), 879-894. 
Yousef, M., Shaher, W., \& Bellamy, A. (2015). The Impact of Cyberbullying on the Self-Esteem and Academic Functioning of Arab American Middle and High School Students. Electronic Journal of Research in Educational Psychology, 13(3).

Yarcheski, T. J., Mahon, N. E., Yarcheski, A., \& Hanks, M. M. (2010). Perceived stress and wellness in early adolescents using the Neuman Systems Model. The Journal of School Nursing, 26(3), 230-237.

Zaal, M. (2012). Islamophobia in classrooms, media, and politics. Journal of Adolescent and Adult Literacy 55(6), 555-558.

Zhang, B., Yan, X., Zhao, F., \& Yuan, F. (2015). The relationship between perceived stress and adolescent depression: The roles of social support and gender. Social Indicators Research, 123(2), 501-518. 


\begin{abstract}
ARAB AMERICAN ADOLESCENTS' BULLYING EXPERIENCES AND EFFECTSON THEIR PERCEIVED STRESS AND HEALTH
\end{abstract}

by

\title{
MAHA MOHAMMAD ALBDOUR
}

May 2017

Advisor: Dr. Feleta Louise Wilson

Major: Nursing

Degree: Doctor of Philosophy

This study is intended to examine the bullying experience among Arab American adolescents and effects on their perceived stress and health. Adolescents who are vulnerable or marginalized might be at higher risk for bullying. Arab American adolescents have not been included in research studies examining bullying and described as the invisible population.

The Neuman System Model, which focuses on wellness of adolescents in relation to environmental stress, guided this study. Bullying is a tension producing stressor, operationally defined as repeated attacks or intimidation that cause fear, distress or harm and perceived power imbalance between bully and victim. Perceived stress is the adolescent's appraisal of the bullying situation as stressful, operationally defined as current levels of experienced stress. Health is the dynamic state of adjustment to stressors, operationally defined adolescents physical and psychological health.

Utilizing a community-based approach and cross- sectional, correlational descriptive design, a convenient sample of 150 Arab American adolescents ages12 to 16 were recruited from two community centers, located at southeastern Michigan. Adolescents completed a survey about their bullying experience, their stress levels and if they experience any physical or psychological 
symptoms in the last year. Measurements included are the Adolescents Peer Relation Instrument (APRI), the Perceived Stress Scale (PSS-10), the Children's Somatization Inventory (CSI-24) and Kessler Psychological Distress Scale (K10). Multiple regression and correlation statistics were used to examine the relationships between the study variables.

Results shows that adolescents who were victims of bullying experienced high stress levels, increased somatic complaints and psychological distress. In contrast, bullies did not reported high stress levels but indicated significant somatic complaints and psychological distress.

Bullying experience was associated with negative physical and psychological health outcomes as well as increased levels of stress among victims. Nurses and other primary health care providers can screen adolescents for physical symptoms and stress related to bullying. In addition providing culturally tailored prevention and intervention strategies may help to promote the overall health of adolescents who experience bullying by increasing their resistance to stress and developing supportive coping mechanisms. 


\section{AUTOBIOGRAPHICAL STATEMENT}

\section{MAHA MOHAMMAD ALBDOUR}

\section{Education}

2007

Bachelor of Science Nursing

University of Jordan, Amman, Jordan

2011 Masters of Science: Community Health Nursing

Wayne State University, Detroit, MI

2017 Doctor of Philosophy, Major: Nursing

Wayne State University, Detroit, MI

\section{Professional Experiences}

2007-2009 Jordan University Hospital Amman, Jordan Registered Nurse

2008-2009 University of Jordan, Amman, Jordan Clinical Instructor

2012- 2016 Wayne State University, Detroit, MI Graduate Teaching

Assistant

Fall 2016 Wayne State University, Detroit, MI Part Time Faculty

2014- Present Campus Health Center (outreach program) Registered Nurse

$$
\text { WSU, Detroit, MI }
$$

\section{Publications (* Data Based)}

*Albdour, M., Lewin, L., Kavanaugh, K., Hong, J., \& Wilson, F. (2016). Arab-American adolescents' perceived stress and bullying experience: A qualitative study. Western Journal of Nursing Research. doi10.1177/0193945916678214

Albdour, M. \& Krouse, H. (2014). Bullying and Victimization among African America Adolescents: A Literature Review. Journal of Child and Adolescent Psychiatric Nursing, $27(2), 68-82$.

Timraz, S. M., Alhasanat, D. I., Albdour, M. M., Lewin, L., Giurgescu, C., \& Kavanaugh, K. (2016). Challenges and strategies for conducting sensitive research with an Arab American population. Applied Nursing Research. 33, 1-4

*Cho, S., Rivers, Jr., T., Albdour, M., Patel, S.Y., Peguero, A., Hong, J.S., \& Misuraca, J.A. (In Review). Cyberbullying and cyber-victimization experienced by African American adolescents: Applying the Social-Ecological framework. Journal of School Violence. 